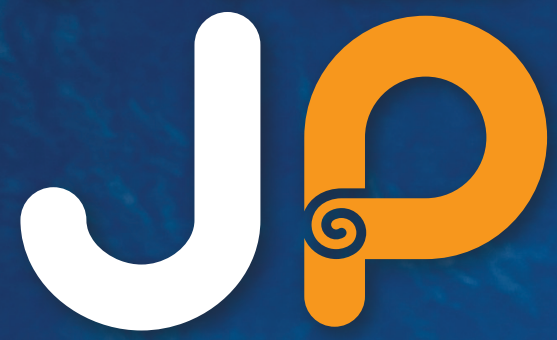

NEW ZEALAND JOURNAL OF PHYSIOTHERAPY

- Physiotherapy education investment in our future

- Levodopa on Gait in Parkinson's Disease

- Participating in a community circuit group

- Back pain questionnaire for adolescents

- International graduates seeing registration to practice in Australia

- Health Enhancement Programme for physiotherapy students

- Physiotherapy clinical education in Australia

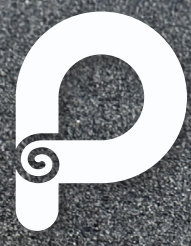

PHYSIOTHEPAPY NEW ZEAI AND Romin Aotearod

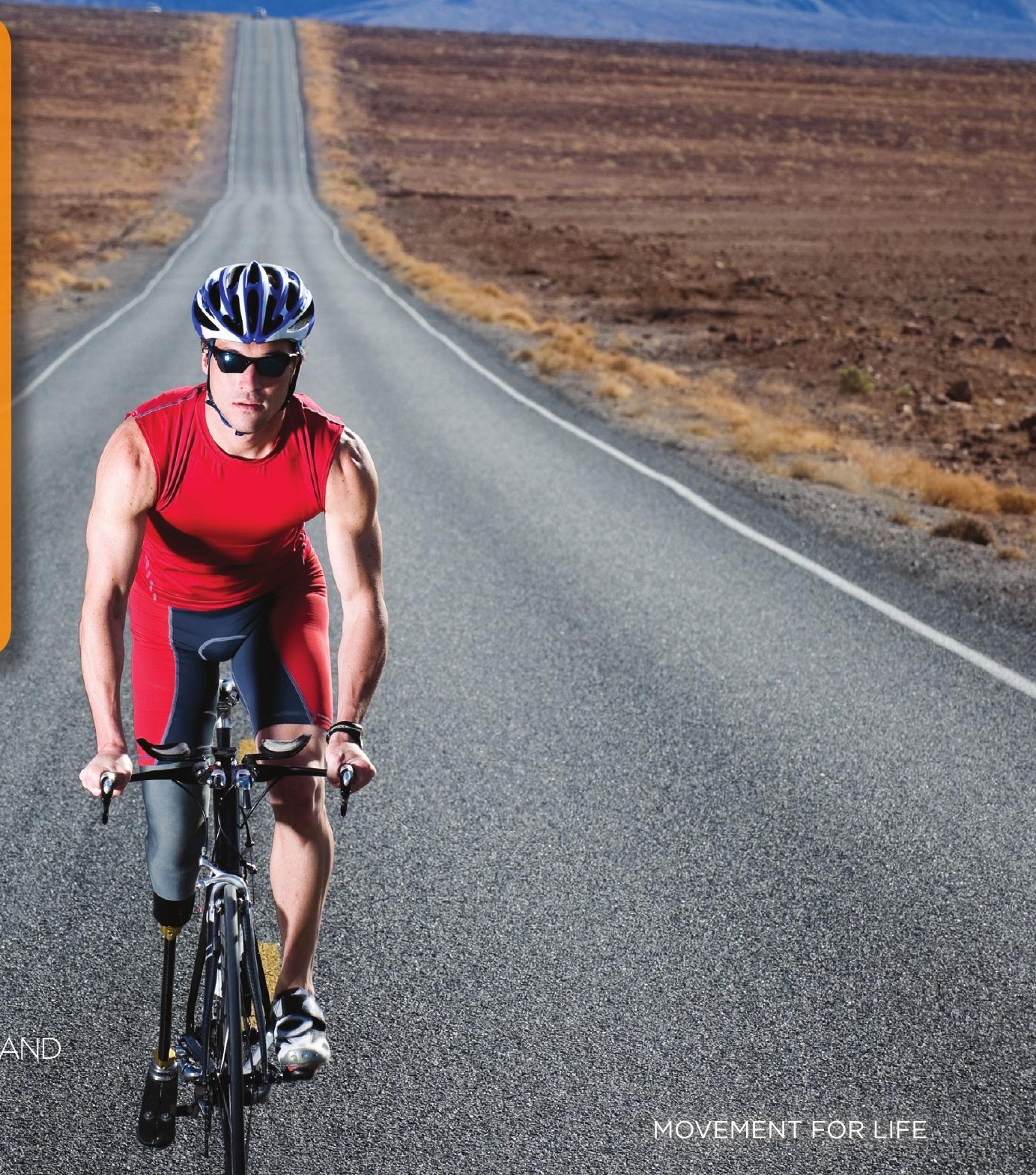





\section{OCTOBER 2017, VOLUME 45 \\ NUMBER 3: 101-172}

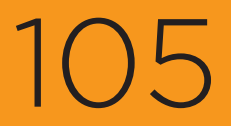

Guest Editorial

Physiotherapy education -

investment in our future.

Joan McMeeken

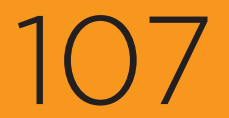

Literature Review

The effects of levodopa

on gait in Parkinson's

disease.

Emily Schaaf

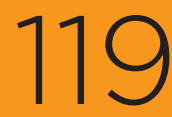

Research Report

What are the outcomes and views of people with mobility limitations after participating in a community circuit group? Verna Stavric, Suzie Mudge, Louise Robinson, Michala Mewa
126

Research Report

Validation of back

pain questionnaire in a population of New Zealand adolescents. Helen Macdonald, Gillian Johnson

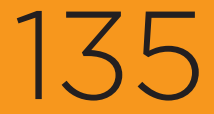

Research Report

The characteristics and experiences of international physiotherapy graduates seeking registration to practise in Australia. Jonathan Foo, Michael Storr, Stephen Maloney

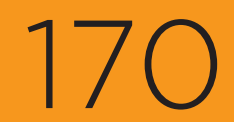

143

Research Report

A Health Enhancement

Programme for physiotherapy students: a mixed methods pilot study.

154 Research Report Physiotherapy clinical education in Australia: Development and validation of a survey instrument to profile clinical educator characteristics, experience and training requirements. Clint Newstead, Catherine Johnston, Gillian Nisbet, Lindy McAllister

\section{Clinically Applicable} Papers

Efficacy and safety of non-immersive virtual reality exercising in stroke rehabilitation (EVREST): a randomised, multicenter, single-blind, controlled trial.

Nina Barker

Alison Francis-Cracknell, Kristin Lo, Craig Hassed

New Zealand Journal of Physiotherapy

Official Journal of Physiotherapy New Zealand

ISSN 0303-7193

Copyright statement: New Zealand Journal of Physiotherapy. All rights reserved. Permission is given to copy, store and redistribute the material in this publication for non-commercial purposes, in any medium or format as long as appropriate credit is given to the source of the material. No derivatives from the original articles are permissible.
Physiotherapy New Zealand

PO Box 27 386, Wellington 6141

Level 6, 342 Lambton Quay, Wellington 6011

Phone: +64 48016500 | Fax: +64 48015571 | www.pnz.org.nz/journal

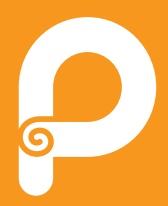




\section{NEW ZEALAND JOURNAL OF PHYSIOTHERAPY}

\author{
Honorary Editorial \\ Committee \\ Leigh Hale \\ PhD, MSc, BSc(Physio), \\ FNZCP \\ Centre for Health Activity \\ and Rehabilitation Research \\ School of Physiotherapy \\ University of Otago \\ New Zealand \\ Editor
}

Anna Mackey

$\mathrm{PhD}, \mathrm{MSc}$, BHSC

(Physiotherapy)

Dept of Paediatric

Orthopaedics

Starship Children's Hospital

Auckland District Health

Board, Auckland,

New Zealand

Associate Editor,

Book Reviews

\section{Stephanie Woodley}

PhD, MSc, BPhty

Dept of Anatomy

University of Otago

New Zealand

Associate Editor, Clinically

Applicable Papers

\section{Suzie Mudge}

PhD, MHSc, DipPhys

Centre for Person Centred

Research

Health and Rehabilitation

Research Institute

School of Clinical Sciences

Auckland University of

Technology

New Zealand

Associate Editor, Invited

Clinical Commentaries

\section{Sarah Mooney}

DHSC, MSC, BSC(Hons)

Counties Manukau Health

Department of Physiotherapy

School of Clinical Sciences

Auckland University of

Technology

New Zealand

\author{
Meredith Perry \\ PhD, MManipTh, BPhty \\ Centre for Health Activity \\ and Rehabilitation Research \\ School of Physiotherapy \\ University of Otago \\ New Zealand \\ Richard Ellis \\ PhD, PGDip, BPhty
}

Department of Physiotherapy

School of Clinical Sciences

Auckland University of

Technology

New Zealand

\section{Liz Binns}

MHSC (Neurological Physiotherapy), DipPhys

Department of Physiotherapy and Health and Rehabilitation

Research Institute

School of Clinical Sciences

Auckland University of

Technology, New Zealand

National Executive

Committee, Physiotherapy

New Zealand liaison

\section{Editorial Advisory Board}

Sandra Bassett PhD, MHSc (Hons), BA, DipPhty

Department of Physiotherapy

School of Clinical Sciences

Auckland University of

Technology

New Zealand

\section{David Baxter}

TD, DPhil, MBA, BSC (Hons)

Centre for Health Activity and Rehabilitation

School of Physiotherapy

University of Otago

New Zealand

\section{Jean Hay Smith} PhD, MSc, DipPhys

Women and Children's

Health, and Rehabilitation

Research and Teaching Unit

University of Otago

New Zealand
Mark Laslett

PhD, DipMT, DipMDT,

FNZCP, Musculoskeletal

Specialist Registered with

the Physiotherapy Board of

New Zealand

PhysioSouth@ Moorhouse

Medical Centre

New Zealand

Sue Lord

PhD, MSc, DipPT

Institute for Ageing and

Health

Newcastle University

United Kingdom

Peter McNair

PhD, MPhEd (Distinction),

DipPhysEd, DipPT

Department of Physiotherapy and Health and Rehabilitation

Research Institute

School of Clinical Sciences

Auckland University of

Technology

New Zealand

Margot Skinner

PhD, MPhEd, DipPhty,

FNZCP, MPNZ (HonLife)

Centre for Health Activity

and Rehabilitation Research

School of Physiotherapy

University of Otago

New Zealand

Peter O'Sullivan

PhD, PGradDipMTh,

DipPhysio FACP

School of Physiotherapy

Curtin University of

Technology

Australia

Barbara Singer

PhD, MSc,

GradDipNeuroSc,

DipPT

Centre for Musculoskeletal

Studies

University of Western

Australia

Australia
Stephan Milosavljevic

PhD, MPhty, BAppSc

School of Physical Therapy

University of Saskatchewan

Saskatoon

Canada

\section{Jennifer L Rowland}

$P h D, P T, M P H$

Adjunct Associate Professor Baylor College of Medicine,

Houston, Texas

\section{Physiotherapy}

New Zealand

Liz Binns

National President

Sandra Kirby

Chief Executive

\section{Nick Taylor}

Marketing and

Communications Manager,

Design and Distribution

Administration

\section{Stella Clark}

Copy Editor

Level 6

342 Lambton Quay

Wellington 6011

PO Box 27386

Marion Square

Wellington 6141

New Zealand

Phone: +64 48016500

Fax: +64 48015571

pnz@physiotherapy.org.nz www.pnz.org.nz/journal 


\section{Physiotherapy education - investment in our future}

New Zealand and Australian physiotherapists share a very proud history from their beginnings in the nineteenth century. Early in the twentieth century practitioners from our countries who offered remedial exercise, hands-on manipulation and massage, electrotherapy, radiology and hydrotherapy formed the Australasian Massage Association. It was the first such Australasian professional association, begun with the intent of ensuring high educational standards, ethical practice and registration of its practitioners. The first educational programme commenced in conjunction with the University of Melbourne in 1906. By 1907 a programme began with the University of Sydney, in 1908 with the University of Adelaide and in 1913 with the University of Otago. Over the ensuing century physiotherapy continued to develop as a clinical science with increasing demand for its well-educated practitioners. Maintaining and improving the standards of education and practice have been the avowed intention of physiotherapists, their accrediting bodies, education providers, the professional associations, leading practitioners and the legal regulating agencies.

In Australasia physiotherapists can be proud of the role they have played on the world stage. New Zealand and Australia, founding members of the World Confederation for Physical Therapy (WCPT) in 1951, offer all their physiotherapy education in universities, where programmes are led by professorial level internationally recognised academics with strong research. With long experience of leading and participating in the accreditation processes of the Australian Physiotherapy Counci for nearly all entry level physiotherapy programmes in Australia and further accreditation and review activities internationally, I argue that it is critical that physiotherapy education sustains the highest standards and Australasia continues to be a world leader (McMeeken, 1998, 2007, 2009, 2011, 2014; Rodger, Webb, Devitt, Gilbert, Wrightson, \& McMeeken, 2008). Our mission is to provide the best quality physiotherapy services to communities through our graduates and to advance knowledge in physiotherapy through ongoing research. As part of this mission senior Australasian physiotherapists support the WCPT by providing pro bono support to developing and accrediting physiotherapy entry level programmes throughout the Asia Western Pacific Region and beyond (Skinner, McMeeken, Stewart, Xerri de Caro, \& Sykes, 2016). Over the century that physiotherapists have been educated in New Zealand and Australia, the profession has demonstrated significant levels of adaptability and responsiveness as verified by their capacity to respond to, for example, the needs of service personnel in both World Wars, the devastating poliomyelitis epidemics from the early 1900 s to the 1950s and beyond, the increasing awareness of needs in women's health, and the expansion of practice in orthopaedic and emergency departments. Australasian physiotherapists are clear leaders in evidence-based practice, translating research into their clinical work.

Worldwide physiotherapy aspires to meet the WCPT's guideline for degree standard and university status (WCPT, 2017).

The Confederation recommends that education for entry level physical therapists be based on university or university level studies of a minimum of four years, independently validated and accredited as being at a standard that affords graduates full statutory and professional recognition. We worked hard to achieve all our education within universities which have understood our educational requirements. Our current international status reflects the fact that our physiotherapists are educated within university systems where such education is underpinned by research and advancement of knowledge. Furthermore, the biomedical sciences necessary for physiotherapy education continue to require access to the highest levels of human anatomy, physiology, pathology, biomechanics and exercise science. Physiotherapy specific laboratories for sophisticated movement analysis, cardiorespiratory function testing and women's and men's health assessment are also necessary to enable students to transition to graduation and further into advanced clinical specialisation and doctoral research.

Tertiary education for physiotherapists is regulated by accreditation bodies and for the profession through national registration and further examination for specialist practice. The Trans-Tasman Mutual Recognition Act (1997) provides for mutual recognition of qualifications between Australia and New Zealand. In August 2015, the separate Physiotherapy Boards of Australia and Aotearoa New Zealand announced that the National Physiotherapy Practice Thresholds would be shared (New Zealand Physiotherapy Board, 2015). These bi-national thresholds define the professional ethics, theoretical knowledge and clinical skills that are required of entry-level physiotherapists to be registered to practise. In Australia, physiotherapists are regulated by the Health Practitioner Regulation National Law Act. Physiotherapists must be registered with the Physiotherapy Board of Australia to practise (www. physiotherapyboard.gov. au/). In Aotearoa New Zealand, physiotherapists are regulated by the Health Practitioners Competence Assurance Act 2003 and to practise must be registered with the Physiotherapy Board of New Zealand (www. physioboard.org.nz/).

Accreditation of educational programmes is also a quality assurance process, which uses all aspects of review and assessment according to pre-defined standards. Accreditation of a physiotherapist professional entry level education programme gives a status to that programme demonstrating that it meets the international standard set by the WCPT.

Physiotherapists are specialists in the analysis and treatment of disorders of human movement in all body systems. As primary contact practitioners physiotherapists have the responsibility of clinical decision making regarding the health and well-being of patients who seek their expertise. This level of professional practice requires a rigorous training in the medical sciences combined with a fully integrated programme of clinical education. Universities contemplating mounting a suite of physiotherapy educational and research programmes need to undertake a comprehensive workforce analysis to provide evidence of need for such programmes. The latest available information for physiotherapists in Victoria Australia demonstrates that demand is primarily driven by population growth and population ageing, changes in medical and surgical practices and advances in fields such as ergonomics and 
occupational health and safety. Physiotherapists required are those with experience and not new graduates (Australian and New Zealand Standard Classification of Occupations (ANZSCO), 2016). The Strategic Workforce Services Workforce Assessment Report District Health Board Physiotherapy Workforce (Central Region's Technical Advisory Services Limited, 2017) report an increasing demand for physiotherapists, citing similar reasons to the 2016 ANZSCO report and state that whilst the number of graduates is increasing, the substantial issue is the inability to recruit and retain experienced physiotherapists.

My experience of more than two decades on the Australian Physiotherapy Council and in reviewing and accrediting international programmes indicates that new educational providers in physiotherapy require the support and facilities of the highest university level of pedagogical and administrative understanding, a strong human biomedical sciences faculty, suitable facilities and an active research culture that is already aligned with aspects of physiotherapy research. Students benefit from interactions with fellow students in congruent disciplines. Leadership should be at professorial level by a physiotherapist of international standing, with sufficient postgraduate qualified physiotherapists to lead each of the physiotherapy specialist areas. Furthermore unless there is comprehensive and reliable clinical education by experienced clinical educators, whose practice is evidence informed and who have strong collaborations with the universities, the anticipated programmes will fail.

From its beginning in December 1905, the Australasian Massage Association produced clear goals of registration, a university standard of training and examination and promotion of the interests of the profession (Australian Physiotherapy Association History Collections, 1905). Initially physiotherapists deferred to medical men to build on their previous experience in developing professions and to ensure the patronage from the medical faculties at the universities (The Advertiser, 1908). With increasing autonomy in clinical practice and advances in physiotherapy-specific knowledge both countries rescinded the medical referral ethic in the mid-1970s - the first countries in the world to do so. They promoted physiotherapy as a specialised branch of science. The successors of the Australasian Massage Association, the Australian Physiotherapy Association and Physiotherapy New Zealand, have continued to advocate for excellence in education, clinical practice and in service to communities.

In the early 1990s I brought together the leaders of all physiotherapy programmes in New Zealand and Australia, now the Council of Deans of Physiotherapy (CPDANZ). Membership of CPDANZ requires that all programmes represented have met accreditation standards of at least a 4-year Bachelor degree at a university with appropriate physiotherapy leadership. The number of programmes has increased in Australia since the early 1990's and the student intake in the New Zealand programmes has also increased. I reiterate that factors critical to accreditation have been the need to ensure professorial leadership, research capacity and facilities, faculty who have the requisite knowledge and skills and the breadth and depth of clinical placements necessary for graduates. 'CPDANZ members continue to be proud flagbearers of the high standards of physiotherapy education in Australasia and are working together to ensure these are retained and built upon to meet the future needs of the profession' (Professor Sandra Brauer, Head of Physiotherapy, The University of Queensland. Australia, President Council of Physiotherapy Deans Australia and New Zealand, personal communication, 2017).

Professor Joan McMeeken AM, PhD, MSc, BSc (Hons), Dip Physio, APAM (HonLife)

Professorial Fellow, The University of Melbourne.

doi: 10.15619/NZJP/45.3.01

\section{ADDRESS FOR CORRESPONDENCE}

Joan McMeeken, Faculty of Medicine, Dentistry and Health Sciences, 4th Floor, 766 Elizabeth Street, The University of Melbourne 3010, Australia. Telephone: +61 38344 5631, Email: j.mcmeeken@unimelb.edu.au

\section{REFERENCES}

Australian and New Zealand Standard Classification of Occupations (ANZSCO) 2525-11 Physiotherapist. Victoria, Australia. June 2016. Retrieved on 7th October 2017 from https://docs.employment.gov.au/ system/files/doc/other/2525-11 physiotherapistvic_0.pdf.

Australian Physiotherapy Association History Collections, University of Melbourne Archives APAH2012/16: Box 1. Newspaper cutting 1905 The Advertiser 30 December. 10.

Forster, A. L. (1969). Physiotherapy in Australia. Australian Journal of Physiotherapy, 15, 96-99.

McMeeken, J. M. (1998). Competition or cooperation. New Zealand Journal of Physiotherapy, 26,13-18.

McMeeken, J. M. (2007). Physiotherapy education in Australia. Physical Therapy Reviews, 12,83-91.

McMeeken, J. M. (2009). Australia's health workforce: implications of change. International Journal of Therapy and Rehabilitation, 16,472-73.

McMeeken, J. M. (2011). Accréditation des programmes d'enseignement des professions de santé en Australie: Accreditation in the Health Professions. Kinésithérapie, la revue 11: 38-45

McMeeken, J. M. (2014). Celebrating a shared past, planning a shared future: Physiotherapy in Australia and New Zealand. New Zealand Journal of Physiotherapy, 42,1-8.

Physiotherapy Board of New Zealand. (2015). Physiotherapy Practice Thresholds in Australia and Aotearoa New Zealand. Retrieved on $14^{\text {th }}$ January 2016 from https://www. physioboard.org.nz/physiotherapypractice-thresholds-australia-aotearoa-new-zealand.

Rodger, S., Webb G., Devitt L., Gilbert J., Wrightson P, \& McMeeken, J. (2008). Clinical education and practice placements in the allied health professions: an international perspective. Journal of Allied Health, 37(1),53-62.

Skinner, M., McMeeken, J., Stewart, A., Xerri de Caro, J., \& Sykes, C. (2016). Raising the standard of physiotherapy education worldwide: Wcpt'CPTs Accreditation Service. Physiotherapy, 102,e24.

Central Region's Technical Advisory Services Limited (Wellington). Strategic Workforce Services Workforce Assessment Report District Health Board Physiotherapy Workforce (April 2017)

The Advertiser (27 February 1908). Appointment of Fitzgerald. "Topics of the Day," 4.

Trans-Tasman Mutual Recognition Act. (1997). Retrieved on 7th October 2017 from http://www.legislation.govt.nz/act/public/1997/0060/49.0/ DLM410793.html.

World Confederation for Physical Therapy. WCPT guideline for standard process for accreditation/recognition of physical therapist professional entry level education programmes. Retrieved on $7^{\text {th }}$ October 2017 from http://www.wcpt.org/guidelines/entry-level-education. 


\section{The effects of levodopa on gait in Parkinson's disease}

Emily Cecilia Schaaf BSC (Hons) Physiotherapy, MPNZ

Physiotherapist, Assessment Treatment and Rehabilitation Unit, Pukekohe Hospital, Auckland.

\section{ABSTRACT}

This literature review aimed to explore the effects of levodopa on gait in Parkinson's disease. Understanding the degree of and fluctuations in spatiotemporal, kinematic and kinetic gait variables over the course of the levodopa cycle aids clinicians in determining the effectiveness of treatment. A literature search was carried out between August 2015 and October 2015. Databases were searched and abstracts were read for suitability. Appropriate articles were read in full and their reference lists were checked for further relevant titles. The evidence suggests during the 'off' phase of the levodopa cycle, the Parkinson's disease gait is considerably slower, shuffling and flexed compared to that of healthy age match controls. During the 'on' phase, spatiotemporal, kinematic and kinetic gait parameters appear to improve compared to the 'off' phase, although the improvements are still less than that of healthy matched controls. The effects of levodopa on Parkinson's disease gait are dependent on the stage of the medication cycle. Further research is needed to evaluate the effects of levodopa on gait in functionally relevant settings.

Schaaf, E.C. The effects of levodopa on gait in Parkinson's disease. New Zealand Journal of Physiotherapy 45(3): 107118. doi: 10.15619/NZJP/45.3.02

Key words: Parkinson's disease, Levodopa, Gait, Physiotherapy

\section{INTRODUCTION}

Parkinson's disease (PD) is a progressive neurodegenerative disorder affecting 1 in every 100 people over the age of 65 worldwide (Svehlik et al., 2009). Therefore it could be estimated that more than 6000 New Zealanders currently have PD (Statistics New Zealand, 2013). However the prevalence of PD in New Zealand is largely unknown due to the lack of data. This is surprising considering the increasing proportion of older adults in New Zealand and the fact that within three years of diagnosis, $85 \%$ of people with PD will develop gait problems leading to an increased risk of falls and decreased quality of life (Kelly, Eusterbrock, \& Shumway-Cook, 2012) putting an increasing strain on medical and physiotherapy services.

Gait may be initiated by voluntary (visuomotor), emotional (fight or flight reactions) and autonomic systems controlled by the brain, spinal cord and peripheral muscles (Takakusaki, Tomita, \& Yano, 2008). Gait deficiencies can be caused by changes in any of the above systems. The control of movement in relation to the basal ganglia is complex. The basal ganglia is made up of several nuclei at the base of the forebrain (Graybiel, 2000). The nuclei work together with the thalamus and motor cortex to allow us to make and control movement and prevent unwanted movement (Graybiel, 2000).

PD is caused by a loss of dopamine containing neurons in the substantia nigra, one of the nuclei of the basal ganglia (Soufa et al., 2005). The cause for the loss of dopamine is unclear. Data suggests ageing, genetics, viruses, free radicals and or environmental factors may have a role to play (Wirdefeldt, Adami, Cole, Trichopoulos, \& Mandel, 2011). A loss of dopamine neurons causes a reduction in the amount of dopamine travelling in the nigrostriatal pathway from the substania nigra to the striatum (Smith et al., 1998). This means the substantia nigra cannot prevent an excessive reduction in movement (Smith et al., 1998). A 60-70\% loss of dopamine concentration (Rodriguez-Oroz et al., 2009) in the striatum results in the characteristic motor signs of PD namely hypokinesia, bradykinesia, rigidity and tremor (Kimmeskamp \& Hennig, 2001).

The characteristic Parkinsonian gait pattern has several hypokinetic features including reduced stride length, velocity and step height resulting in short shuffling steps, associated with a flexed posture and poor arm swing (Peppe, Chiavalon, Pasqualetti, Crovato, \& Caltagirone, 2007). Bradykinesia is also evident in Parkinsonian gait (Rodriguez-Oroz et al., 2009; Soufa et al., 2005).

With age, gait can become slower with a reduced stride length and flat footed heel strike. This together with a reduced arm swing and stooped posture gives the presentation of a Parkinsonian gait pattern (Friedman, 2012). This may be due to a small natural loss of dopamine with age (Ostrosky, Van Swearingen, Burdett, \& Gee, 1994), but may also be due to neuromuscular and vestibular changes that occur during the ageing process (Friedman, 2012).

There are, however, some characteristic differences between an ageing gait and a Parkinsonian gait, which may only be observed through clinical gait analysis and analysis of spatiotemporal, kinematic and kinetic data. Gait analysis is a functionally relevant objective outcome measure and it can provide a better understanding of gait patterns and identify impairments which may help to facilitate a clinician's rehabilitation programme (MacKay-Lyons, 1998). Observational gait analysis may be the initial stage in constructing a patient's gait pattern. Other methods include 2D and 3D motion analysis and pressure sensitive insoles.

Despite advances in surgical treatments, including bilateral subthalamic nucleus deep brain stimulation and stem cell therapy (Fox et al., 2011); and pharmacological therapies, including Rivastigmine (Henderson et al., 2016) and 
Methlyphenidate (Espay, Dwivedi \& Payne, 2011) for PD suffers with gait disorders, there is no cure and treatments are aimed at managing the symptoms.

PD causes a progressive deterioration in motor performance, function, independence and cognition. Increasingly doctors are referring people with PD for physiotherapy assessment to evaluate the motor response to PD medication. The most common and effective pharmacological management of PD is the administration of levodopa, a precursor to dopamine (Contin \& Martinelli, 2010). By monitoring a person's motor performance in response to levodopa, physiotherapists can measure the level of disability and modify their treatments, thus maximising function. In the clinical setting, motor performance can be measured by functional tasks including walking.

Therefore knowledge of the effects of levodopa on gait is important for physiotherapists

The aim of this review was to investigate the effects of levodopa on gait in PD, which could aid the assessment process and treatment planning for physiotherapists.

\section{METHOD}

A literature search was conducted between August - October 2015, using the electronic data bases Ovid, Scopus, PEDro, Medline, the Cochrane Library, CINAHL and the Allied and Complementary Medicine Database (AMED). The search terms were levodopa, Parkinson's disease, gait, gait analysis and rehabilitation.

Search limits included articles that were written in English and published in a peer reviewed journal. The search was confined to articles published since 1990. These constraints were chosen for practicality purposes and to provide the reader with up to date information. Only studies using adult participants were included. Conference abstracts and qualitative studies, studies using deep brain stimulation with levodopa and studies using other PD medication with levodopa were excluded.

The search resulted in 299 articles. All abstracts with any of the search terms in the title were read. Relevant studies were read in full to see if they met the inclusion / exclusion criteria. The reference lists from retrieved relevant studies were searched for further articles. This process continued until no new articles were found. See Figure 1 for the flow diagram showing the study selection process.

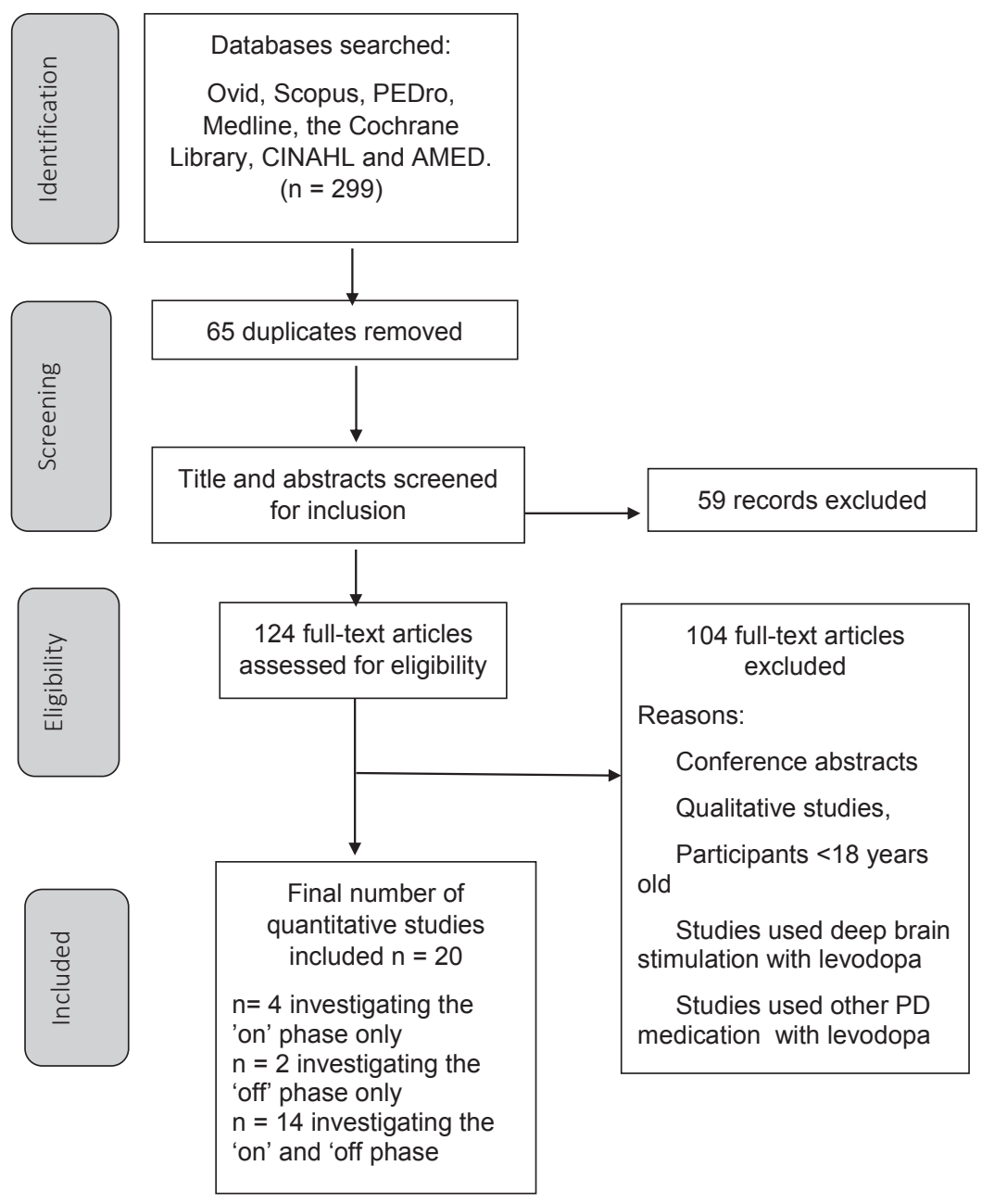

Figure 1: Flow chart of the literature search and selection process. 
Table 1: PD gait in the 'off' phase of the levodopa medication cycle: a summary of findings

\begin{tabular}{|c|c|c|}
\hline $\begin{array}{l}\text { Authors } \\
\text { (Year) }\end{array}$ & $\begin{array}{l}\text { Length of time since } \\
\text { levodopa }\end{array}$ & Main results \\
\hline $\begin{array}{l}\text { Blin et al. } \\
(1991)\end{array}$ & 12 hours off levodopa & Decreased velocity and stride length \\
\hline $\begin{array}{l}\text { Bowes et al. } \\
(1990)\end{array}$ & 12 hours off levodopa & $\begin{array}{l}\text { Decreased stride length and velocity; double support duration within normal } \\
\text { range. }\end{array}$ \\
\hline $\begin{array}{l}\text { Bryant et al. } \\
(2011)\end{array}$ & 12 hours off levodopa & $\begin{array}{l}\text { Decreased velocity, stride length and increased double support time } \\
\text { compared to the 'on' phase. }\end{array}$ \\
\hline $\begin{array}{l}\text { Calinadro et al. } \\
\text { (2011) }\end{array}$ & 12 hours off levodopa & $\begin{array}{l}\text { RMS decreased in } 30 \% \text { of patients and decreased tendoachilles function } \\
\text { compared to 'on' and controls }\end{array}$ \\
\hline $\begin{array}{l}\text { Chien et al. } \\
\text { (2006) }\end{array}$ & 12 hours off levodopa. & $\begin{array}{l}\text { Significant difference between 'off' values and controls in terms of velocity, } \\
\text { stride length, single leg stance, double leg stance - all worse in 'off' values. } \\
\text { No difference in cadence. }\end{array}$ \\
\hline $\begin{array}{l}\text { Cioni et al. } \\
(1997)\end{array}$ & 3-18 hours off levodopa & $\begin{array}{l}\text { When 'off' decreased EMG: Tibialis anterior activation in early stance and } \\
\text { swing phase and decreased heel strike; increased proximal muscle activation } \\
\text { in stance phase, increased hip, knee and ankle flexion in stance on EMG. } \\
\text { Spatiotemporal: decreased velocity and stride length; increased gat cycle } \\
\text { length and stance phase (compared to controls and 'on'). }\end{array}$ \\
\hline $\begin{array}{l}\text { Galli et al. } \\
\text { (2008) }\end{array}$ & 12 hours off levodopa. & $\begin{array}{l}\text { Spatiotemporal: shorter step length decreased speed and increased stance } \\
\text { phase. } \\
\text { Kinematics: decreased total ROM in all joints of lower limb. }\end{array}$ \\
\hline $\begin{array}{l}\text { Kurz et al. } \\
(2010)\end{array}$ & 8 hours off levodopa. & $\begin{array}{l}\text { Kinematics: Structural variations at the ankle joint between 'on' and 'off' } \\
\text { phases. } \\
\text { No significant differences at hip and knee between 'on' and 'off' phase. }\end{array}$ \\
\hline $\begin{array}{l}\text { Lubik et al. } \\
\text { (2006) }\end{array}$ & 12 hours off levodopa. & $\begin{array}{l}\text { Compared to 'on' phase: } \\
\text { - UPDRS sub score decreased by } 40 \% \text {. } \\
\text { - Velocity, cadence, step length and symmetry reduced. } \\
\text { - Increased single leg support, double leg support, and stance and step } \\
\text { time. }\end{array}$ \\
\hline $\begin{array}{l}\text { MacKay-Lyons et al. } \\
\text { (1998) }\end{array}$ & $\begin{array}{l}\text { Measured at } 10 \% \text { intervals } \\
\text { throughout levodopa cycle }\end{array}$ & $\begin{array}{l}\text { Unpredictable variation in spatiotemporal parameters throughout medication } \\
\text { cycle. }\end{array}$ \\
\hline $\begin{array}{l}\text { Moore et al. } \\
(2008)\end{array}$ & 12 hours off levodopa & Reduced stride length, speed compared to 'on' phase. \\
\hline $\begin{array}{l}\text { Morris et al. } \\
(1999)\end{array}$ & 12 hours off levodopa & $\begin{array}{l}\text { Spatiotemporal: Decreased velocity and step length. } \\
\text { Kinematics: Flexed posture, decreased hip, knee and ankle range of motion } \\
\text { during gait } \\
\text { Kinetics: Altered force generation throughout the lower limbs during the } \\
\text { gait cycle. }\end{array}$ \\
\hline $\begin{array}{l}\text { Pourmoghaddam } \\
\text { et al. } \\
\text { (2015) }\end{array}$ & 8 hours off levodopa & $\begin{array}{l}\text { Overall activity of lower limb muscles increased in 'off' phase. } \\
\text { Decreased gait speed in 'off' phase. }\end{array}$ \\
\hline $\begin{array}{l}\text { Schaafsma et al. } \\
(2003)\end{array}$ & 12 hours off levodopa & $\begin{array}{l}\text { Stride variability not related to tremor, rigidity of bradykinesia in 'off' phase. } \\
\text { Stride time and variability were worse in the 'off' phase than 'on' phase }\end{array}$ \\
\hline $\begin{array}{l}\text { Svehlik et al. } \\
(2009)\end{array}$ & 12 hours off levodopa & $\begin{array}{l}\text { Compared to controls, PD patients in 'off' phase; } \\
\text { Spatiotemporal: Walked slower with decreased stride length and cadence } \\
\text { and increased double support times. } \\
\text { Kinematics: Decreased ROM at hip, knee, and ankle joints. Hip extension } \\
\text { and ankle plantarflexion significantly decreased. } \\
\text { Kinetics: Decreased ankle push off power and lift off hip power. }\end{array}$ \\
\hline $\begin{array}{l}\text { Vokaer et al. } \\
\text { (2003) }\end{array}$ & 12 hours off levodopa & Compared to 'on' phase decreased gait velocity and stride length. \\
\hline
\end{tabular}


The appropriate studies were then re-examined using the valid (Moher, Liberati, Tezlaff \& Altman, 2009) and reliable (Maher, Sherrington, Herbert, Moseley \& Elkins, 2003) PEDro Scale to assess the quality of research methodology. The PEDro Scale was chosen as it is regularly used in assessing physiotherapy based randomised controlled trials (Maher et al., 2003), the highest level of evidence. A summary of the PEDro scores is outlined in Appendix 1.

\section{RESULTS}

The literature search found 20 papers in total investigating the effects of levodopa on gait in PD. Fourteen studies investigated the effects of levodopa during the 'on' phase (where the signs and symptoms are reduced) and 'off' phase of the medication cycle; four studies looked at the 'on' phase only compared to age matched controls and two studies looked at the 'off' phase compared to age matched controls. The characteristics of each study are outlined in Appendix 2.

PD gait during the "off" phase" of the levodopa medication cycle

The evidence suggests that during the 'off' phase of the levodopa cycle, the PD gait is considerably slower, with a short shuffling stride length and in a greater lower limb flexor pattern compared to that of age matched healthy controls (Chien et al., 2006: Svehlik et al., 2009). Sixteen papers reviewed gait parameters during the 'off' phase (see Table 1).

\section{Spatiotemporal parameters:}

There were nine studies that evaluated the spatiotemporal parameters of PD gait during the 'off' phase (see Table 1).

\section{Velocity}

All included studies found participants with PD had a reduced gait velocity during the 'off' phase ranging from 0.45 metres per second $(\mathrm{m} / \mathrm{s})-1.05 \mathrm{~m} / \mathrm{s}$ (Blin et al., 1991; Bryant et al., 2011; Chien et al., 2006; Cioni et al., 1997; Moore et al., 2007; Svehlik et al., 2009; Voaker et al., 2003) compared to the 1.19 $-1.65 \mathrm{~m} / \mathrm{s}$ found in the healthy age-matched controls (Chien et al., 2006; Galna, Lord, Burn \& Rochester, 2015; Ostrosky et al., 1994; Sofuwa et al., 2005; Svehlik et al., 2009) (see Appendix 3).

\section{Stride length}

Stride length was also shown to be shorter in participants with $P D$, ranging from 0.49 metres $(m)-1.18 m$ (Cioni et al., 1997; Moore et al., 2007), compared to $1.3 \mathrm{~m}-1.45 \mathrm{~m}$ found in healthy age matched controls (Chien et al., 2006; Svehlik et al., 2009) (see Appendix 3).

\section{Double leg support}

The percentage of the gait cycle spent in the double limb support in healthy older adults is $18-25 \%$ (Chien et al., 2006; Svehlik et al., 2009). During the 'off' phase the percentage rises to 28 - 35\% (Chien et al., 2006; Moore et al., 2007; Svehlik et al., 2009) (See Appendix 3).

\section{Single leg support}

Interestingly there is very little difference in the percentage of time spent in single leg support between the 'off' phase for participants with PD (35\%) and aged matched healthy controls (40\%) (Chien et al., 2006; Svehlik et al., 2009).

\section{Cadence}

Cadence values for participants with PD are comparable to healthy subjects (Chien et al., 2006 \& Svehlik et al., 2009). Bryant et al. (2011) and Ostrosky et al. (1994) found age matched healthy controls had a walking rate of 110 - 140 steps/ minute compared to 111 - 138 steps per minute for participants with PD in the 'off' phase (Chien et al., 2006 \& Svehlik et al., 2009).

Kinematic and kinetic variables:

Morris et al. (1999) found a significant reduction in movement excursion during the 'off' phase, in the hip, knee and ankle, showing decreased range of motion (ROM) during walking compared to healthy age matched controls. The findings of Morris et al. (1999) are in agreement with later studies by Galli, Cimolin, de Pandis, Onorati and Albertini (2008), Morris et al. (2001) and Svehlik et al. (2009). Svehlik et al. (2009), Morris et al. (2001) and Cinoni et al. (1997) also found a non-significant increase in hip and knee flexion during single leg stance phase compared to controls ( $34^{\circ}$ flexion throughout stance, compared to $32^{\circ}$ at the hip and $8^{\circ}$ flexion during stance compared to $3^{\circ}$ flexion at the knee). Likewise Svehlik et al. (2009) and Morris et al. (2001) found the difference between groups was most pronounced at the ankle joint in the sagittal plane. Participants with PD remained in $10^{\circ}$ dorsiflexion at late stance compared to $8^{\circ}$ in age matched controls. Data demonstrated increased dorsiflexion in stance and reduced plantar flexion at toe-off resulting in decreased ankle ROM at push off in the PD group.

Svehlik et al. (2009) found reduced maximum hip extensor moment and power generation in first double support in participants with PD during the 'off' phase of the levodopa cycle, compared to healthy age matched controls. Maximum hip flexor and power generation in the PD group was also reduced compared to controls in the second double support and preswing phase.

At the ankle Svehlik et al. (2009) and Morris et al. (1999) found the moment loading response, maximal extensor moment, power generation and absorption during stance and push off were decreased in participants with PD compared to controls.

PD gait during the "on' phase' of the levodopa medication cycle

There were 18 papers that reviewed gait parameters during the 'on' phase.

\section{Spatiotemporal parameters:}

Velocity, stride length, single leg support time and swing time

Six studies found an increase in gait velocity; stride length, single leg support time and swing time, and a decrease in the percentage of the gait cycle in stance during the 'on' phase of the medication cycle compared to the 'off' phase (see Appendix 3). Although there was an overall improvement in the spatiotemporal parameters, they were still less than that of healthy aged matched controls (see Appendix 3).

\section{Double leg support}

Bryant et al. (2011) found a decreased percentage of the gait cycle in double leg support after levodopa (34\% in the 'off' phase, $30 \%$ in the 'on' phase). These findings are comparable 
to Chien et al. (2006) and Lubik et al. (2006), who both found an $8 \%$ reduction in double stance support after levodopa (see Appendix 3 ) and 0.08 s reduction after levodopa respectively (see Appendix 1).

\section{Cadence}

The normal cadence for healthy age matched controls is on average 110 - 140 steps/minute (Bryant et al., 2011 \& Ostrosky et al., 1994). Bryant et al. (2011), Chien et al. (2006), Cioni et al. (1997) and Vokaer et al. (2003), found cadence for their participants with PD before levodopa ranged from 111 steps/ minute (Bryant et al., 2011) to 138 steps/minute (Vokaer et al., 2003). These values were comparable to that of healthy age matched controls. After levodopa, cadence ranged from 111 steps/ minute (Cioni et al., 1997) to 142 steps/ minute (Vokaer et al., 2003).

Kinematic and kinetic variables:

Galli et al. (2008), Cioni et al. (1997) and Morris et al. (1999) found significant increases in hip, knee and ankle ROM in the sagittal plane for participants with PD, compared to the 'off' phase, with values close to controls after taking their morning dose of levodopa. Kurz and Hou (2010) however found no significant difference in the mean ROM at the hip and knee during the 'on' and 'off' states, indicating levodopa did not change functional ROM at these joints. However, resistance to hip and knee joint changes in response to levodopa in this study may be due to the treadmill acting as an external cueing device.

Despite the use of levodopa, kinematic differences are most pronounced at the ankle joint. Soufa et al. (2005) found ankle ROM during push-off was significantly reduced in the 'on' phase in participants with PD compared to control participants $(19.8 \%)$.

In an electromyographic (EMG) study by Cioni et al. (1997) data showed significant improvement in tibialis anterior activation during the 'on' phase compared to participants with PD in the 'off' phase, although the values were still a lot lower than for age matched control participants. These findings are comparable to later studies by Calinandro et al. (2011) and Mitoma et al. (2000). However despite levodopa, the same studies reported an increase in hip and knee flexion in stance compared to control participants. Conversely Pourmoghaddam, Dettmer, O'Connor, Paloski and Layne (2015), found a decrease in EMG activity of all lower limb muscles with significant reduction in tibialis anterior.

Using pressure sensitive insoles Kimmeskamp and Hennig (2001) and Nieuwboer et al. (1999) found that participants with PD in the 'on' phase have reduced heel strike and increasing forefoot loading especially on the medial aspect of the foot, compared to age matched control participants. These authors also found the amount of forefoot loading was related to disease severity. Pressure sensitive insoles however have been found to have decreased measurement reliability when participants exhibit a shuffling gait pattern, therefore this could have affected the results (Mansfield and Lyons 2003).

Using force plates, Diehl, Schneider, Konietzko \& Hennerici (1992), found during the 'on' phase of the levodopa cycle, participants with moderate to severe PD (Hoehn and Yahr stage 3-4 (Hoehn \& Yahr, 2011)) had a shuffling gait pattern and a ground reaction force (GRF) curve consisting of one narrow peak (not two) (Zijlstra, Rutgers \& Van Weerden, 1998). Similarly, Kimmeskamp and Hennig (2001) and Morris et al. (1999) showed under scaling in the vertical and frontal GRF and decreased ankle joint loading response.

Morris et al. (1999) and Sofuwa et al. (2005) found decreased EMG activity of gastrocnemius in participants with PD during the 'on 'phase of the levodopa cycle compared to healthy age matched control participants.

\section{DISCUSSION}

Levodopa allows dopamine to cross the blood brain barrier (Anderson \& Nutt, 2011) and increase dopamine levels in the basal ganglia, restoring normal movement. The effectiveness of levodopa decreases after several years because the substantia nigra slowly loses its ability to make the enzyme that converts levodopa into dopamine (Anderson \& Nutt, 2011). After this time, the effects of levodopa tend to wear off before the next dose is taken and patients experience fluctuations in their Parkinson's signs and symptoms with definite 'on' (where the signs and symptoms are reduced) and 'off' phases (Contin \& Martinelli, 2010). The fluctuation of signs and symptoms can have a detrimental effect on the person's quality of life and function and can increase the risk of falls (Morris, Huxham, McGinley, Dodd \& lansek, 2001).

Analysing gait during the 'on' phase provides feedback to clinicians on the effects the medication has on movement patterns and function. This information allows doctors to make informed decisions around medication changes as the disease progresses and helps physiotherapists provide appropriate walking aids and treatment plans.

It is also important for clinicians to have knowledge of gait parameters at the end dose or 'off' phase of the medication cycle and of normal values for healthy age matched controls. It allows clinicians to see the effect PD pathology has on gait, aiding the provision of relevant treatment plans. All included studies reviewed had stopped levodopa 8-12 hours (see Table 1) before measurements were taken. Research however has shown that it can take up to three to four weeks for the complete effects of levodopa to leave the body after it is withdrawn (Anderson \& Nutt, 2011). Therefore, during the 'off' phase, the 'short term response' to the drug will have worn off but the 'long term effect' of the drug may still have been in the person's system and having a small effect on gait. However, it may be considered unethical to stop medication for three to four weeks to see the true effects of PD on gait.

The evidence suggests changes in spatiotemporal, kinematic and kinetic lower limb variables ultimately affect gait velocity. All studies looking at spatiotemporal parameters included gait velocity. Gait velocity is a commonly used outcome measure in the clinical setting as it requires very little and non-sophisticated equipment and it is a valid and practical measure of mobility and can reflect a patient's level of function (Prince, Corrveau, Herbert, \& Winter, 1997).

When initial contact occurs at one foot, the toes of the other foot are still in contact with the ground. This is an 
unstable position. During the 'off' phase, people with PD will compensate for decreased balance and postural instability by reducing their heel strike and increasing forefoot loading especially on the medial aspect of the foot, compared to age matched control participants. A decreased heel strike (and push off) may account for the single peak in the GRF curve. Calinandro et al. (2011), Cioni et al (1997) and Mitoma, Hayashi, Yanagisawa \& Tsukagoshi (2000), found levodopa improved tibialis anterior activity in the late swing, early stance phase of gait, allowing adequate foot placement and preventing stumbling.

Kinematic data from Kimmeskamp and Hennig (2001) and Nieuwboer et al. (1999) showed an increase in hip and knee flexion in mid-stance compared to controls. This may be due to the knee generating less power during single stance and decreased power absorption in late stance, resulting in less extension and passive stabilisation of the knee via the hamstrings (Svehlik et al., 2009). Although people with PD may still be more flexed than normal, they are straighter in mid-stance after levodopa (Galli et al., 2008). This suggests that levodopa may 'energise' distal leg muscles restoring functional 'key' parts of gait (Cioni et al., 1997). Whereas non dopaminergic neural structures may control activity in the proximal leg muscles and is not responsive to levodopa (Morris et al., 2001). Pourmoghaddam et al. (2015) suggested levodopa decreases symptoms by decreasing overall coactivity of lower limb muscles allowing for an optimal movement pattern. Their study was however carried out on a treadmill where participants held onto the safety bars to aid balance at a constant speed. Walking on a treadmill has been shown to stimulate peripheral proprioceptive afferents in the upper limb and lower limbs increasing EMG activity (Murray, Spurr, Sepic \& Gardner, 1985), which could have affected the results. The treadmill may also have acted as an external cueing device which has been shown to have a positive effect on PD gait (Pourmoghaddam et al., 2015).

Double leg stance time reduced during the 'on' phase but was still more throughout the whole medication cycle compared to healthy age matched controls (Ostrosky et al., 1999). This may be to compensate for a fear of falling, postural instability and decreased balance which are common characteristics at the end stage of the disease. Similarly an increase in double support time may be due to muscle weakness, dystonia or soft tissue tightness, making it difficult to maintain control of the lower limb muscle during single leg stance (Svehlik et al., 2009).

The little difference in the percentage of time spent in single leg support between the 'on' and 'off' phase for participants with PD and aged matched healthy controls may be because during the natural ageing process step height reduces and double support time increases to compensate for instability (Murray, Sepic, Gardner \& Downs, 1978).

EMG activity of gastrocnemius improved during the 'on' phase compared to the 'off' phase, however the activity was still less than of healthy age matched controls. This would account for the reduced ankle push off power generation and reduced hip flexion (pull off) power seen in participants with PD compared to controls. Ankle push off is an important body propulsion mechanism (Prince et al., 1997) and hip power generation is required to move the leg into swing phase. In PD, decreased ankle (push off) and hip flexion (pull off) power, may limit trunk progression and hip power generation in stance, thus reducing gait velocity, stride length and step height, despite the positive effects of levodopa. Decreased hip and knee extension in single leg stance and reduced plantar flexion of the ankle at toe off may also account for the decreased stride length seen in PD throughput the medication cycle which has also been proven be a cause of reduced velocity (Morris et al., 1999). Judge, Davis \& Ounpuu (1996), found greater ankle strength led to increased gait velocity and stride length and is believed to be the strongest predictor of step length in older adults. Further research is needed to see if the results are applicable to the PD population.

The data suggests all but one of the spatiotemporal parameters of gait appear to be 'dopa sensitive' (Blin et al., 1991). Gait velocity, stride length and foot clearance improve; and stance time reduces during the 'on' phase of the medication cycle. Bryant et al. (2011), Chien et al. (2006), Cioni et al. (1997) and Vokaer et al. (2003), found levodopa did not improve cadence (see Appendix 3). It is still unclear why this temporal characteristic is 'dopa resistant' (Blin et al., 1991). The data suggests cadence cannot be improved by levodopa as it has already reached its normal ceiling value during the 'off' phase. Similarly, there is a growing body of evidence to suggest the velocity and stride length are controlled by the basal ganglia whereas cadence is not (Vokaer et al., 2003). Therefore levodopa could not affect cadence. It is unknown how cadence is regulated (Vokaer et al., 2003).

Despite levodopa improving most spatiotemporal, kinematic and kinetic variables people with PD still have a slower, more shuffling gait throughout the medication cycle, compared to healthy age matched controls.

\section{Limitations}

Whilst laboratory gait analysis allows researchers to set up a standardised protocol easily to ensure the reliability of results, the data collected may not be relevant to the community setting. All studies used a straight walk way over a short distance (3m (Bryant et al., 2011) to $20 \mathrm{~m}$ (Schaafsma et al., 2005) (see Appendix 2), in an uncluttered environment. This has been found to temporarily enhance participants with PDs' performance (Yekutiel, 1993). The unnatural environment also may not highlight any balance or gait problems encountered in everyday life such as crossing uneven or different surfaces, narrow doorways, cluttered environments, crowds, and turning, which have been shown to affect gait and induce freezing in the later stages of PD (Moore et al., 2007). However Graham, Ostir, Fisher and Ottenbacher (2008), found walking over short distances of $10-12 \mathrm{~m}$ a valid measure of velocity. Similarly, people with PD have trouble initiating and terminating gait. Therefore each study eliminated the first and last steps of each trial to allow for a constant speed to be recorded. Graham et al. (2008) also found five to six strides enough to obtain valid spatiotemporal-kinematic data. Therefore the reduced distance available for data collection would not affect the validity of the results.

All studies except Pourmoghaddam et al. (2015) and Kurz et al. (2010), allowed participants to walk at their self-selected walking speed, which would vary considerably between 
individuals (see Appendix 2). Pourmoghaddam et al. (2015) and Kurz et al. (2010) used a treadmill for data collection. Whilst a treadmill allows for a constant speed, it has been shown to decrease stride length (Pourmoghaddam et al. 2015). Similarly both studies allowed upper limb support which may affect gait. All the other studies collected data whilst the participant was walking independently unaided (see Appendix 2). This is surprising considering the majority of the studies used participants in the moderate to severe stages of PD (Hoehn and Yahr staging 3-4), where balance problems are evident (see Appendix 2) and most people with PD would be using a walking aid for community ambulation.

The studies did not consider the influence of the upper limbs, trunk and pelvis on gait. This is surprising, considering a reduced arm swing, axial rigidity and flexed posture are characteristic signs of a Parkinsonian gait (Constantinescu, Leonard, Deeley \& Kurlan, 2007), and are part of and therefore affect the lower limb kinetic chain and gait.

Most of the studies reviewed carried out data collection at one point in time. Only MacKay-Lyons (1998), investigated PD gait 11 times at $10 \%$ intervals over the medication cycle, whilst Galna et al. (2015) investigated PD gait at regular intervals over an 18 month period. Participants' gait pattern may vary from step to step, walk to walk, hour to hour, day to day - especially in individuals with PD, as seen in the review.

\section{Clinical Implications}

Overall levodopa has been shown to improve the spatiotemporal parameters of gait and some kinematic and kinetic factors in the early moderate and severe stages of PD. Clinicians need to be aware that the effectiveness of levodopa wears off after time and the 'on' phase gets progressively shorter as the disease progresses. Therefore timing of therapy with maximum levodopa dose effect is important. Clinical assessment should be conducted at a similar time within the medication cycle to allow for comparability of data. However rehabilitation should also be considered in the 'off' phase so patients and carers can adopt strategies to cope with the variation in gait.

The review highlights variations in gait spatiotemporal, kinematic and kinetic variables throughout the levodopa cycle, via gait analysis. By identifying the gait impairments and seeing how levodopa affects them, physiotherapists are able to provide appropriate strength training, exercise advice, balance and gait re-education, including the provision of walking aids. This will help to reduce the risk of falls and improve a patient's confidence and frequency of mobility, ultimately improving the person's function and quality of life.

Physiotherapists quantify the improvements in their treatment through a variety of outcome measures. Observational gait analysis is a valid tool for evaluating changes in PD gait and for quantifying the improvement made through rehabilitation and or medication (Peppe et al., 2007) and is easy to use in the clinical setting. Clinicians should have a good understanding of normal gait pattern before carrying out gait analysis on participants with PD. Physiotherapists may improve their observational gait analysis skills by watching and/or videoing 'normal' and a variety of pathological gaits and discussing them at peer review. Gait velocity has been shown to have a clinically significant response to levodopa (a change of more than $0.14 \mathrm{~m} / \mathrm{s}$ (Perera, Mody, Woodman \& Studenski, 2006). Gait velocity, the Tinetti Mobility Test and the Unified Parkinson's Disease Rating Scale (UPDRS) are quick, easy, valid and reliable outcome measures to use in the PD population (Siderowf et al., 2002, \& Kostyk, Kegelmeyer, Kloos \& Thomas, 2007). These tests assess a variety of functional tasks including gait, balance, sit to stand and turning; and the UPDRS also assesses activities of daily living, falls and complications of therapy including fluctuations in symptoms, all of which are affected by medication status.

\section{Future Research}

An important role physiotherapists have in the clinical setting is the assessment for and provision of suitable walking aids. Future research should investigate the effect walking aids have on spatiotemporal, kinematic and kinetic variables, and their efficacy and or safety in PD gait. Similarly, researchers could investigate the effects physiotherapists' cueing strategies have on gait during the levodopa cycle. The upper limb, trunk and pelvis have an important role to play during the gait cycle but were not investigated in previous research on PD gait and levodopa. Likewise, the effects of levodopa on community ambulation should be studied as turning, stepping back and enclosed spaces which are necessary for community ambulation, have been shown to affect PD gait (Morris et al., 2001) and were not considered in the current research. Most of the studies collected data in the sagittal plane (see Appendix 2). Future research should consider data collection in the sagittal, transverse and coronal planes which would give a more complete picture of PD gait.

\section{CONCLUSION}

The effects of levodopa on PD gait are variable, depending on the stage of the medication cycle and severity of PD. Despite the improvements in some spatiotemporal, kinematic and kinetic characteristics of gait in response to levodopa, the research has shown some gait parameters are levodopa resistant and the typical Parkinson's gait pattern is still slower, more flexed and shuffling than that of healthy age matched controls throughout the medication cycle. Clinical gait analysis is an important tool to evaluate the effects of levodopa and to guide rehabilitation programmes. Further research is needed to evaluate the effects of levodopa on gait in functionally relevant settings.

\section{KEY POINTS}

1. The effects of levodopa on Parkinson's disease gait are dependent on the stage of the medication cycle.

2. During the 'on' phase of the levodopa cycle, some spatiotemporal, kinematic and kinetic gait parameters appear to improve compared to the 'off' phase.

3. Timing therapy within the medication cycle is important at maximum dose effect, but also rehabilitation should be considered in the 'off' phase.

4. Future research should explore the effects of levodopa on gait in functionally relevant environments and situations. 


\section{DISCLOSURES}

The author is currently studying for a Post Graduate Diploma in Health Sciences: Rehabilitation at AUT. This article has been adapted from the author's assignment for the Clinical Gait Analysis paper. The paper was funded in part by the PACT Accrued Fund from Middlemore Hospital, Counties Manukau DHB, Auckland. The author declares no conflict of interest during the writing of this review.

\section{ACKNOWLEDGMENTS}

I acknowledge the Faculty of Health and Environmental Sciences at Auckland University of Technology, and Michelle McRobbie, Annabel Williams and Lisa Grant from Pukekohe Hospital, Pukekohe, Auckland for their support in the writing of this paper.

\section{ADDRESS FOR CORRESPONDENCE}

Emily Cecilia Schaaf, Physiotherapist, Pukekohe Hospital, 1 Tuakau Road, Pukekohe, Auckland, 2120. Telephone: 092370600 Ext: 5687. Email: emilyshields81@gmail.com.

\section{REFERENCES}

Anderson, E., \& Nutt, J. (2011). The long-duration response to levodopa: Phenomenology, potential mechanisms and clinical implications. Parkinsonism and Related Disorders, 17(8), 587-592. doi: 10.1016/j.parkreldis.2011.03.014

Blin, O., Ferrandez, A. M., Pailhous, J., \& Serratrice, G. (1991). Dopa-sensitive and dopa-resistant gait parameters in Parkinson's disease. Journal of the Neurological Sciences, 103(1), 51-54. doi: 10.1016/0022-510X(91)90283-D

Bowes, S., Clark, P., Leeman, A., O'Neill, C., Weller, C., Nicholson, P., . . Dobbs, R. (1990). Determinants of gait in the elderly parkinsonian on maintenance levodopa/carbidopa therapy. British Journal of Clinical Pharmacology, 30(1), 13-24. doi: 10.1111/j.1365-2125.1990.tb03738.x.

Bryant, M.S., Rintala, D.H., Hou, J.G., Lai, E.C., \& Protas, E.J. (2011). Effects of levodopa on forward and backward gait patterns in persons with Parkinson's disease. Neurorehabilitation, 29(3), 247-252. doi: 10.3233/ NRE-2011-0700.

Caliandro, P., Ferrarin, M., Cioni, M., Bentivoglio, A. R., Minciotti, I., D'Urso, P. I., . . Padua, L. (2011). Levodopa effect on electromyographic activation patterns of tibialis anterior muscle during walking in parkinson's disease. Gait and Posture, 33(3), 436-441. doi: 10.1016/j. gaitpost.2010.12.020.

Chien, S., Lin, S., Lin, S., Liang, C., Soong, Y., Hsin, Y., . . Chen, S. (2006) The efficacy of quantitative gait analysis by the GAITRite system in evaluation of parkinsonian bradykinesia. Parkinsonism and Related Disorders, 12(7), 438-442. doi: 10.1016/j.parkreldis.2006.04.004.

Cioni, M., Richards, C.L., Malouin, F., Bedard, P.J., \& Lemieux, R. (1997). Characteristics of the electromyographic patterns of lower limb muscles during gait in patients with Parkinson's disease when OFF and ON L-dopa treatment. The Italian Journal of Neurological Sciences, 18(4), 195-208. doi: 10.1007/BF02080464.

Constantinescu, R., Leonard, C., Deeley, C., \& Kurlan, R. (2007). Assistive devices for gait in Parkinson's disease. Parkinsonism and Related Disorders, 13(3), 133-138. doi: 10.1016/j.parkreldis.2006.05.034.

Contin, M., \& Martinelli, P. (2010). Pharmacokinetics of levodopa. Journal of Neurology, 257(S2), 253-261. doi: 10.1007/s00415-010-5728-8.

Diehl, R.R., Schneider, U., Konietzko, M., Hennerici, M. Quantitative analysis of gait in neurological gait disorders. in: M.J. Woollacott, F.B. Horak (Eds.) Posture and gait control mechanisms. University of Oregon Books, Portland; 1992:47-50.

Espay, A.J., Dwivedi, A.K., Payne, M. et al. (2211), Methylphenidate for gait impairment in Parkinson's disease: a randomized clinical trial. Neurology, 76 (2011), pp. 1256-1262. doi: 10.1212NNL.0b013e3182143537.
Fox, S.H., Katzenschlager, R., Lim, S.-Y., Ravina, B., Seppi, K., Coelho, M., Poewe, W., Rascol, O., Goetz, C.G. and Sampaio, C. (2011), The Movement Disorder Society Evidence-Based Medicine Review Update: Treatments for the motor symptoms of Parkinson's disease. Movement Disorders, 26: S2-S41. doi: 10.1002/mds.23829.

Friedman, J.H. (2012). Gait disorders in the elderly. Medicine and Health, Rhode Island. 95:84.

Galli, M., Cimolin, V., de Pandis, F., Onorati, P., \& Albertini, G. (2008). Evaluation of the effects of levodopa treatment in Parkinson patients using gait analysis. Gait and Posture, 28, S13-S13. doi: 10.1016/j. gaitpost.2007.12.027.

Galna, B., Lord, S., Burn, D.J., \& Rochester, L. (2015). Progression of gait dysfunction in incident Parkinson's disease: Impact of medication and phenotype. Movement Disorders, 30(3), 359-367. doi: 10.1002/ mds. 26110 .

Graham, J.E., Ostir, G.V., Fisher, S.R., \& Ottenbacher, K.J. (2008). Assessing walking speed in clinical research: a systematic review. Journal of Evaluating Clinical Practice, 14(4), 552-562. doi: 10.1111/j.13652753.2007.00917.x.

Graybiel, A.M. (2000). The Basal Ganglia. Current Biology, 10(14), R509-R511. doi: 10.1016/S0960-9822(00)00593-5. Henderson, E.J et al. (2016). Rivastigmine for gait stability in patients with Parkinson's disease (ReSPonD): a randomised, double-blind, placebo-controlled, phase 2 trial. The Lancet Neurology , 15(3), 249 - 258. doi: 10.1016/S14744422(15)00389-0.

Hoehn, M., \& Yahr, M. (2011). Parkinsonism: Onset, progression, and mortality. Neurology, 77(9), 874-874 doi: 10.1212/01 wnl.0000405146.06300.91.

Judge, J.O., Davis, R.B., \& Ounpuu, S. (1996). Step length reductions in advanced age: The role of ankle and hip kinetics. The Journals of Gerontology. Series A, Biological Sciences and Medical Sciences, 51(6), M303-M312. doi: 10.1093/gerona/51A.6.M303.

Kelly, V.E., Eusterbrock, A.J., \& Shumway-Cook, A. (2012). The effects of instructions on dual-task walking and cognitive task performance in people with Parkinson's disease. Parkinson's Disease, Article ID 671261, 9 pages. doi: 10.1155/2012/671261.

Kimmeskamp, S., \& Hennig, E.M. (2001). Heel to toe motion characteristics in Parkinson patients during free walking. Clinical Biomechanics, 16(9), 806-812. doi: 10.1016/S0268-0033(01)00069-9.

Kostyk, S.K, Kegelmeyer, D.A., Kloos, A.D. \& Thomas, K.M (2007). Reliability and validity of the Tinetti Mobility Test for individuals with Parkinson's disease. Physical Therapy, 87:1369-1378. doi: 10.2522/ptj.20070007.

Kurz, M.J., \& Hou, J.G. (2010). Levodopa influences the regularity of the ankle joint kinematics in individuals with Parkinson's disease. Journal of Computational Neuroscience, 28(1), 131-136. doi: 10.1007/s10827-0090192-0.

Lubik, S., Fogel, W., Tronnier, V., Krause, M., König, J., \& Jost, W.H. (2006). Gait analysis in patients with advanced Parkinson disease: Different or additive effects on gait induced by levodopa and chronic STN stimulation. Journal of Neural Transmission, 113(2), 163-173. doi: 10.1007/s00702-005-0310-8.

Nieuwboer, A., De Weerdt, W., \& Dom, R. (1998). Plantar force distribution in parkinsonian gait: A comparison between patients and age-matched control subjects. Physiotherapy, 84(8), 402-403. doi: 10.1016/S00319406(05)61479-4.

MacKay-Lyons, M. (1998). Variability in spatiotemporal gait characteristics over the course of the L-dopa cycle in people with advanced Parkinson disease. Physical Therapy, 78(10), 1083-1094.

Maher, C.G., Sherrington, C., Herbert, R.D., Moseley, A.M., \& Elkins, M. (2003). Reliability of the PEDro scale for rating quality of randomized controlled trials. Physical Therapy, 83(8), 713-721.

Mitoma, H., Hayashi, R., Yanagisawa, N., \& Tsukagoshi, H. (2000). Characteristics of parkinsonian and ataxic gaits: A study using surface electromyograms, angular displacements and floor reaction forces. Journal of the Neurological Sciences, 174(1), 22-39. doi: 10.1016/S0022510X(99)00329-9. 
Moher, D., Liberati, A., Tetzlaff, J., \& Altman, D.G. The PRISMA Group (2009). Preferred reporting items for systematic review and meta-analyses: The PRISMA statement. PLoS Med, 6(6): e1000097. doi: 10.1371/journal. med1000097.

Morris, M.E., McGinley, J., Huxham, F., Collier, J., \& lansek, R. (1999). Constraints on the kinetic, kinematic and spatiotemporal parameters of gait in Parkinson's disease. Human Movement Science, 18(2), 461-483. doi: 10.1016/S0167-9457(99)00020-2.

Morris, M.E., Huxham, F., McGinley, J., Dodd, K., \& lansek, R. (2001). The biomechanics and motor control of gait in Parkinson disease. England: Elsevier Ltd. doi: 10.1016/S0268-0033(01)00035-3.

Moore, S.T., MacDougall, H.G., Gracies, J., Cohen, H.S., \& Ondo, W.G. (2007). Long-term monitoring of gait in Parkinson's disease. Gait \& Posture, 26(2), 200-207. doi: 10.1016/j.gaitpost.2006.09.011.

Moore, S.T., MacDougall, H.G., Gracies, J., \& Ondo, W.G. (2008). Locomotor response to levodopa in fluctuating Parkinson's disease. Experimental Brain Research, 184(4), 469-478. doi: 10.1007/s00221-007-1113-y.

Murray, M.P., Sepic, S.B., Gardner, G.M., \& Downs, W.J. (1978). Walking patterns of men with Parkinsonism. American Journal of Physical Medicine, 57(6), 278-294.

Murray, M.P., Spurr, G.B., Sepic, S.B., Gardner, G.M., \& Mollinger, L.A. (1985). Treadmill vs. floor walking: Kinematics, electromyogram, and heart rate. Journal of Applied Physiology, 59(1), 87-91

Ostrosky, K. M., Van Swearingen, J.M., Burdett, R.G., \& Gee, Z. (1994). A Comparison of Gait Characteristics in Young and Old Subjects. Physical Therapy, 74 (7), 637-44

Peppe, A., Chiavalon, C., Pasqualetti, P., Crovato, D., \& Caltagirone, C. (2007). Does gait analysis quantify motor rehabilitation efficacy in Parkinson's disease patients? Gait and Posture, 26(3), 452-462. doi: 10.1016/j.gaitpost.2006.11.207.

Perera, S., Mody, S., Woodman, R.C., \& Studenski, S.A. (2006). Meaningful change and responsiveness in common physical performance measures in older adults. Journal of the American Geriatrics Society, 54(5), 743-749.

Pourmoghaddam, A., Dettmer, M., O'Connor, D.P., Paloski, W.H., \& Layne, C.S. (2015). Identification of changing lower limb neuromuscula activation in Parkinson's disease during treadmill gait with and without levodopa using a nonlinear analysis index. Parkinson's Disease, Article ID 497825, 8 pages. doi: 10.1155/2015/497825

Prince, F., Corrveau, H., Herbert, R., Winter, D.A. (1997). Gait in the Elderly. Gait and Posture, 5(2), 128-135.

Rodriguez-Oroz, M. (2009). Initial clinical manifestations of Parkinson's disease: Features and pathophysiological mechanisms. Lancet Neurol, 8(12), 1128-1139. doi: 10.1016/S1474-4422(09)70293-5.

Schaafsma, J. D., Giladi, N., Balash, Y., Bartels, A. L., Gurevich, T., \& Hausdorff, J. M. (2003). Gait dynamics in Parkinson's disease: Relationship to parkinsonian features, falls and response to levodopa. Journal of the Neurological Sciences, 212(1), 47-53. doi: 10.1016/S0022$510 \times(03) 00104-7$

Siderowf, A., McDermott, M., Kieburtz, K., Blindauer, K., Plumb, S., \& Shoulson, I., Parkinson Study Group (2002.). Test-retest reliability of the unified Parkinson's disease rating scale in patients with early Parkinson's disease: results from a multicentre clinical trial. Movement Disorders, 17(4):758-763. doi: 10.1002/mds.10011.

Smith, Y., Bevan, M.D., Shink, E., \& Bolam, J.P. (1998). Microcircuitry of the direct and indirect pathways of the basal ganglia. Neuroscience, 86(2) 353-387 doi: 10.1016/S0306-4522(98)00004-9.

Sofuwa, O., Nieuwboer, A., Desloovere, K., Willems, A., Chavret, F., \& Jonkers, I. (2005). Quantitative gait analysis in Parkinson's disease: Comparison with a healthy control group. Archives of Physical Medicine and Rehabilitation, 86(5), 1007-1013. doi: 10.1016/j.apmr.2004.08.012.

Statistics New Zealand (2013). 2013 Census products and services. Available from www.stats.govt.nz. ISBN 978-0-478-40818-8 (online).

Švehlík, M., Zwick, E.B., Steinwender, G., Linhart, W.E., Schwingenschuh, P., Katschnig, P.Enzinger, C. (2009). Gait analysis in patients with Parkinson's disease off dopaminergic therapy. Archives of Physical

\section{Appendix 1}

A summary of the PEDro scores of the studies used in the review.

\begin{tabular}{lc}
\hline Study & PEDro score (out of 11) \\
\hline Blin et al. (1991) & 6 \\
Bowes et al. (1990) & 7 \\
Bryant et al. (2011) & 7 \\
Caliandro et al. (2011) & 6 \\
Chien et al. (2006) & 6 \\
Cioni et al. (1997) & 6 \\
Galli et al. (2008) & 6 \\
Galna et al. (2015) & 6 \\
Lubik et al. (2005) & 5 \\
Kimmeska-mp \& Hennig (2001) & 4 \\
Kurz \& Hou (2010) & 6 \\
MacKay-Lyons (1998) & 6 \\
Mitoma et al. (2000) & 6 \\
Moore et al. (2008) & 6 \\
Morris et al. (1999) & 6 \\
Pourmoghaddam et al. (2015) & 5 \\
Schaafsma et al. (2003) & 6 \\
Sofuwa et al. (2005) & 6 \\
Svehilk et al. (2009) & 6 \\
\hline & 6 \\
Vokaer et al. (2003) & 6 \\
\hline
\end{tabular}




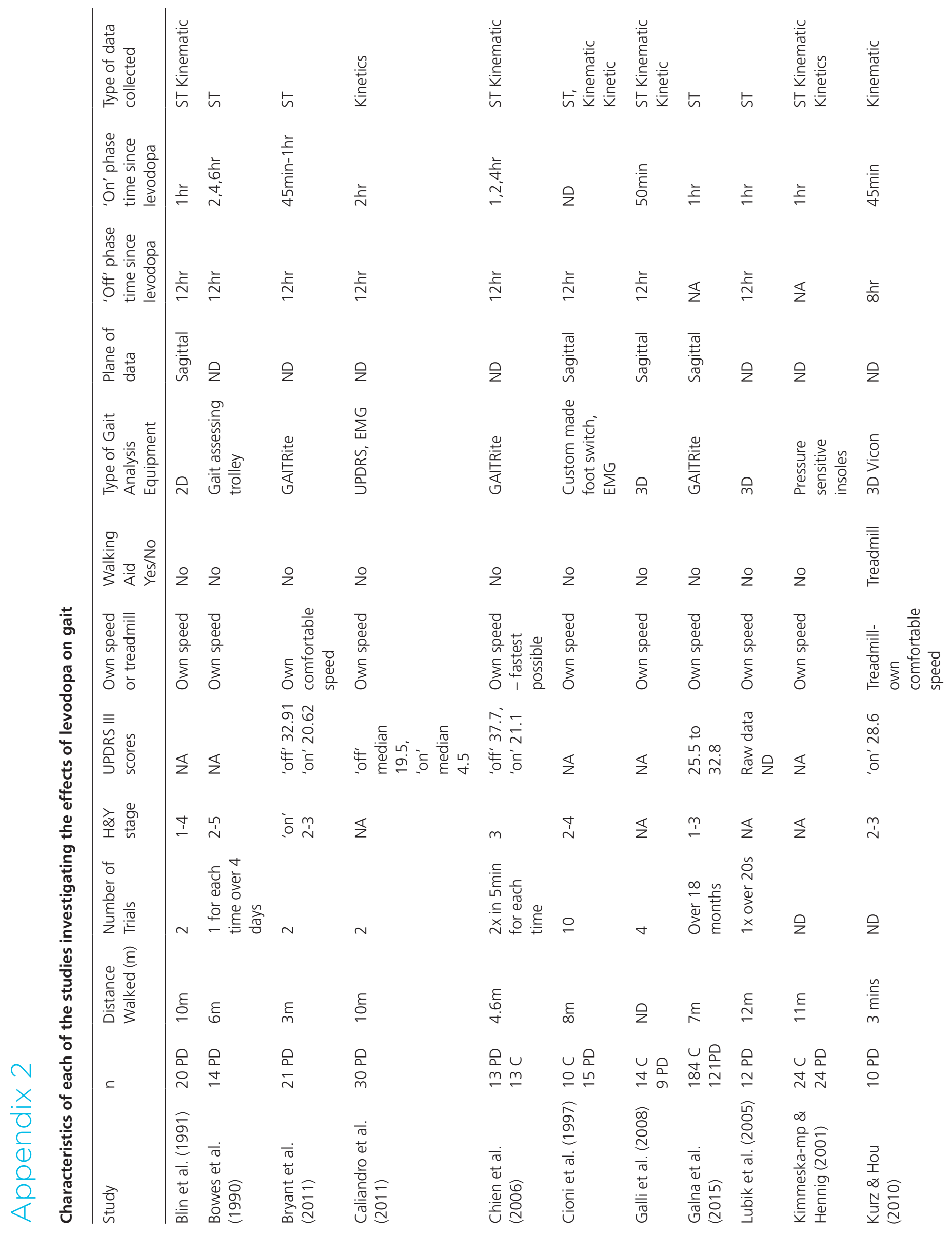




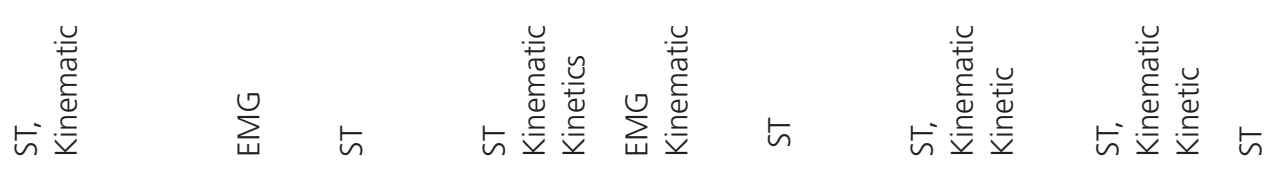

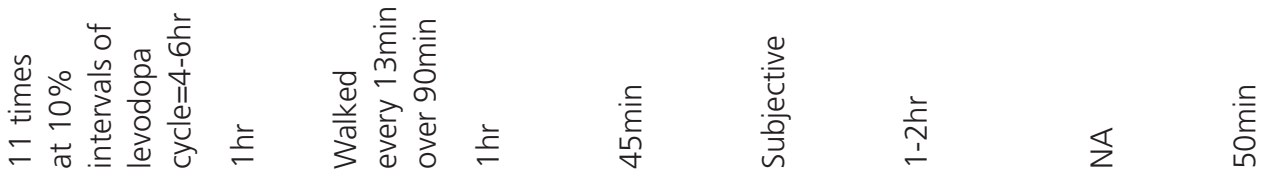

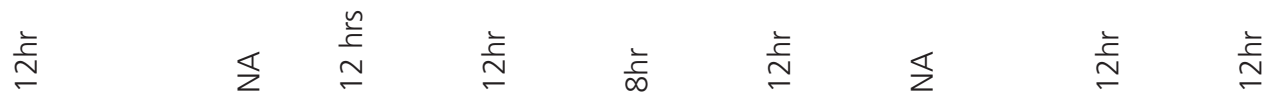

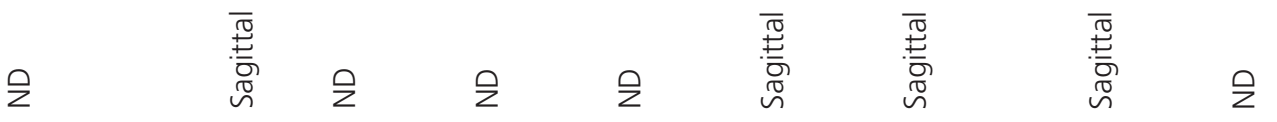

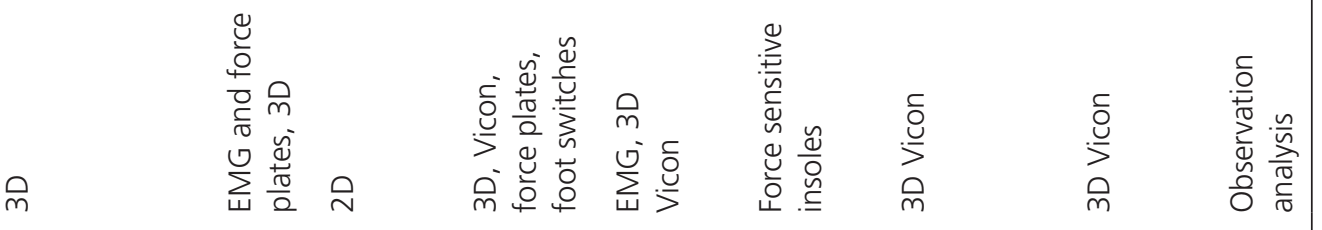

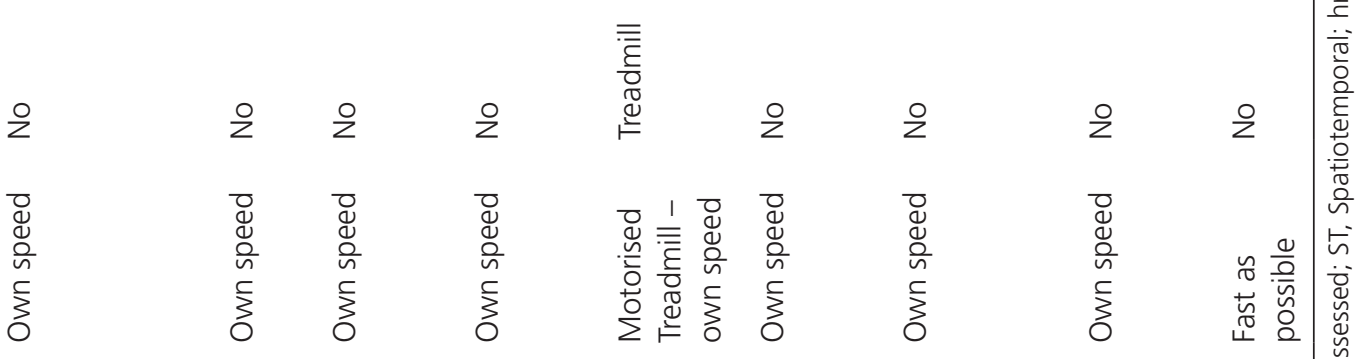

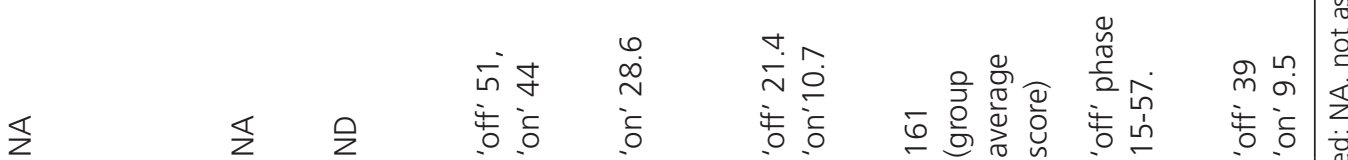
㲾 $m \sim$ है

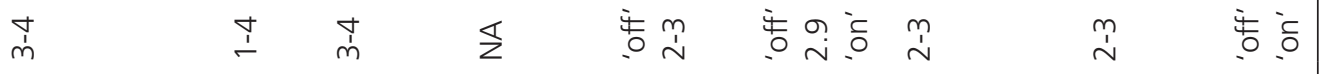

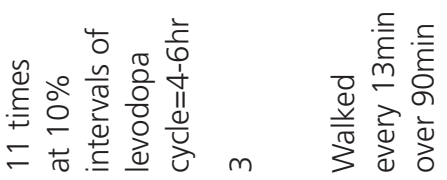

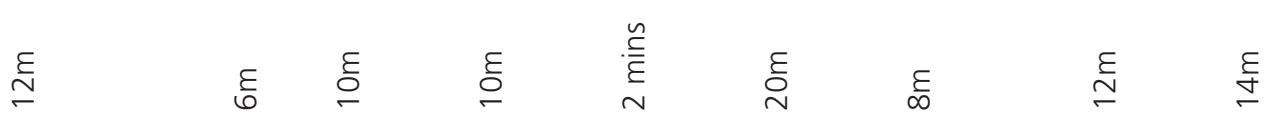

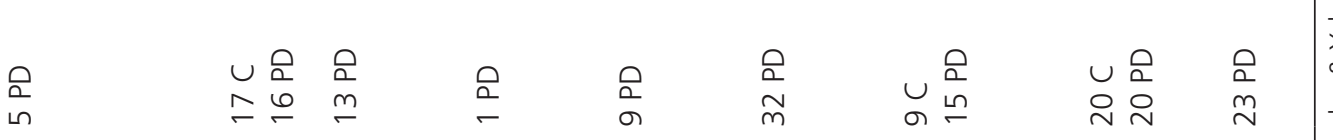

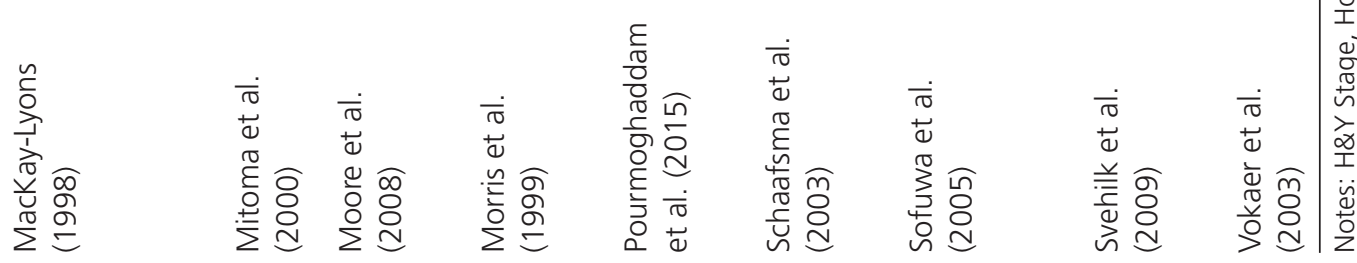




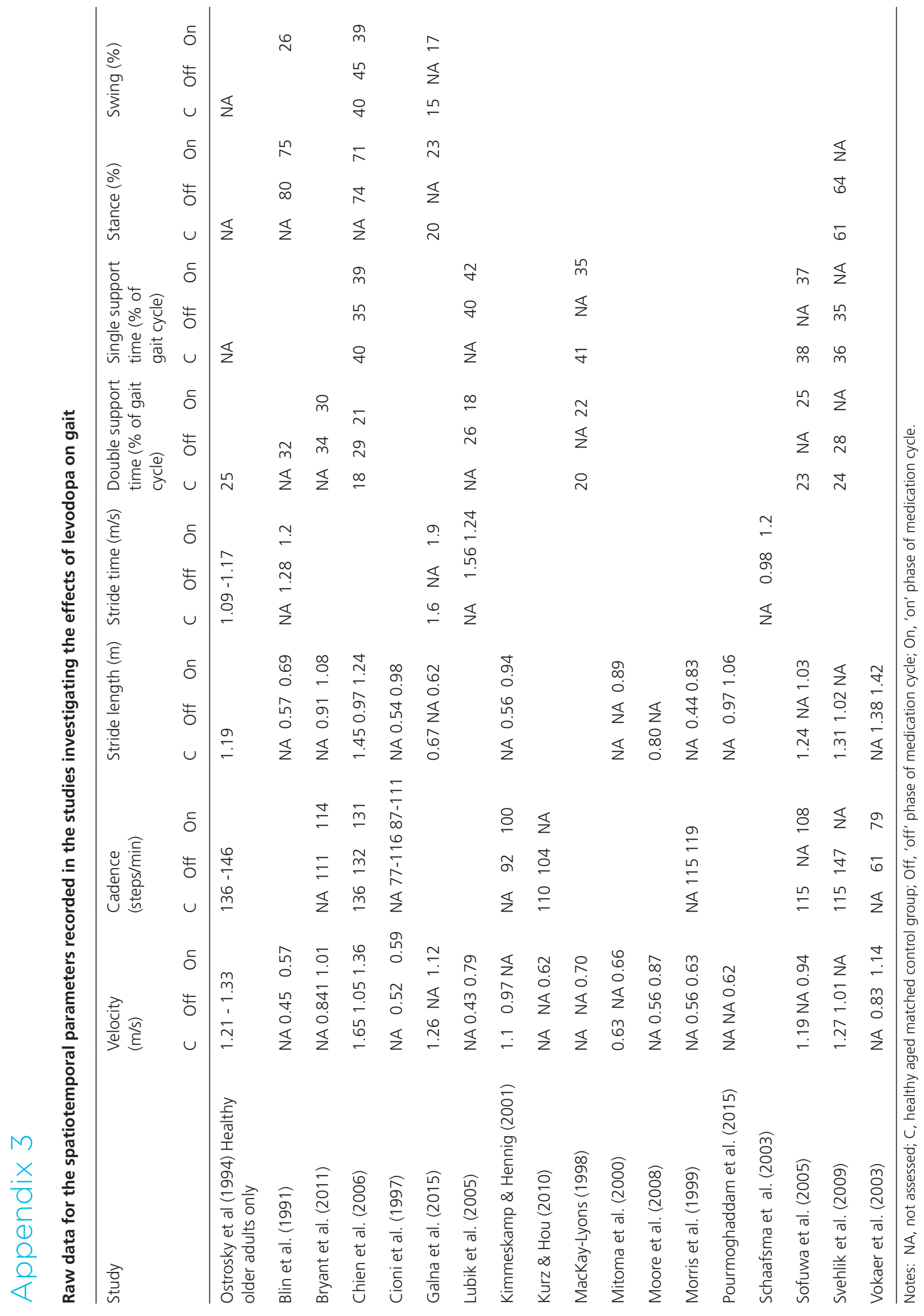




\section{What are the outcomes and views of people with mobility limitations after participating in a community circuit group?}

Verna Stavric BSC PT, MHSC

Lecturer, AUT University, Auckland, New Zealand

Suzie Mudge $P h D$

Post-Doctoral Fellow, Centre for Person Centred Research, AUT University, Auckland, New Zealand

Louise Robinson BHSC Physio

Physiotherapist, Taranaki District Health Board, Taranaki, New Zealand

Michala Mewa BHSc Physio

Physiotherapist, Department of Education and Training, Queensland Government, Australia

\section{ABSTRACT}

Increasing services are addressing the needs of people living with long term conditions. The purpose of this observational study was to determine the impact of community circuit classes on balance and mobility of individuals with neurological conditions. Participants were recruited from people interested in or already taking part in circuit classes provided at a private rehabilitation clinic. Outcomes (4-Stage Balance test, 30 Second Chair Stand test and Timed Up and Go (TUG) were assessed before and after a block of circuit classes (at least six weekly sessions). Risk and fear of falling were measured using the Falls Risk Assessment Tool and the Falls Efficacy Scale respectively. Participants completed a self-report questionnaire to provide their views about the class. All 13 participants completed at least six classes. A difference was found in the TUG $(p=0.05)$ but not in other outcome measures. All participants highly rated the organisation, level of staff skill and amount of assistance provided at the classes, but there was less satisfaction on the challenge and frequency of classes. Participating in circuit classes for a short-term period appears to have a positive impact on mobility and is an enjoyable form of exercise for people with neurological conditions.

Stavric, V., Mudge, S., Robinson, L., Mewa, M. What are the outcomes and views of people with mobility limitations after participating in a community circuit group? New Zealand Journal of Physiotherapy 45(3): 119-125. doi: 10.15619/ NZJP/45.3.03

Key words: Neurological conditions, Rehabilitation, Exercise, Balance, Mobility

\section{INTRODUCTION}

People living with neurological conditions are at high risk of falling. Those with stroke fall approximately three times within the first six months after discharge from hospital and people with Parkinson's disease (PD) and multiple sclerosis (MS) have at least one significant fall within the first year of diagnosis (Coote, Finlayson, \& Sosnoff, 2014). In addition, the injuries caused by falls can often produce further impairments or physical disabilities and lead to reduced confidence, independence and participation in meaningful activities (Sattin, 1992; Tinetti, Doucette, Claus, \& Marottoli, 1995).

Exercise not only plays an important role in the rehabilitation and management of the primary impairments of these neurological conditions, but also helps prevent the secondary effects of inactivity (Goodwin, Richards, Taylor, Taylor, \& Campbell, 2008; Langhorne, Coupar, \& Pollock, 2009; LatimerCheung, 2013). Evidence also suggests that well designed exercise programmes can reduce the risk of falls and improve or maintain physical independence and functional mobility (Coote et al., 2014; Eng et al., 2003; English, Hillier, Stiller, \& Warden-Flood, 2007; Marigold et al., 2005). One option that offers supervised exercise opportunities for community dwelling people living with a neurological condition is Circuit
Class Therapy (CCT). This is defined as a tailored intervention involving the performance or practice of exercises and functional tasks that target specific problems such as balance, strength and walking (English et al., 2007). CCT is provided in a group setting where people move between stations set up in a circuit. It is a practical way of providing structured and repetitive task practice, tailoring the exercises to the individual and progressing them as required, and has been shown to increase mobility and balance (English et al., 2007; Wevers, van de Port, Vermue, Mead, \& Kwakkel, 2009).

One facility that delivers CCT is a private rehabilitation clinic based in Auckland, New Zealand. The clinic offers two classes per week, providing CCT for community dwellers who live with neurological conditions and report mobility and balance limitations. These CCT classes are called 'Balance-Fit' and 'Move!' with the latter specifically designed for people living with PD. Each of the CCT classes are offered in six week blocks. At the clinic, 13 stations are set up for each of the CCT classes. The stations comprise elements of resistance training, aerobic training and functional training and are tailored to the patient population. For example, in the PD Move! class, there are dual task stations and flexibility stations. Clients spend three minutes 
at each station, after which they rotate to the next station. CCT classes are one hour in duration. Classes are as inclusive as possible with criteria for participation primarily based around participants being able to safely engage and in the perceived benefit in joining.

Supervision is provided by one or two registered physiotherapists. This ratio is improved through the use of undergraduate physiotherapy students who volunteer at the classes. This format provides a learning experience for the student and extra supervision for the client, while keeping costs down, making the classes affordable.

A one-off screening assessment of falls risk, functional ability and balance is performed on registration to the CCT. However, the clinic does not formally re-administer the measures after completion of a CCT block. Although people currently attending these CCT sessions have reported positive changes in their daily life, the objective change as a result of these classes has not been measured, nor has formal feedback on the CCT been recently sought.

Therefore, the aim of this observational study was to evaluate the impact of an existing CCT on community dwellers, living with a neurological condition, at risk of falling due to impaired balance and mobility. At the end of the study, participants had the opportunity to provide feedback in the form of a self-report questionnaire regarding their experience of CCT.

\section{METHODS}

\section{Participants}

Potential participants were those who were already enrolled in, or eligible to attend one or both of the clinic's two CCT classes. To be eligible, potential participants needed to meet the criteria of the clinic CCT and be able to attend for at least six classes over the data collection period (five months). Ethics for this study was approved by the AUT University Ethics Committee (AUTEC) (approval 15/32).

\section{Assessment}

Participant data were collected at two time periods (Time 1 (T1)) and Time 2 (T2)) midway through 2015. Demographic data and written consent were collected at the first testing session. Participants who joined the CCT prior to 2015 were scheduled for T1 testing when they agreed to participate. For some clients who chose to participate and who had been coming to the classes for a while, Time 1 assessments were repeated before they began a new block of classes. For participants who joined the CCT in 2015, their initial screening data, collected by the physiotherapist at the clinic, were used for T1 data and written consent was obtained before the first CCT class. T2 testing occurred once participants had completed at least six classes of CCT. This involved a re-assessment of the initial measures as well as a questionnaire that asked about participants' views on the CCT itself. See Figure 1 for an overview of the assessment periods in relation to the CCT.

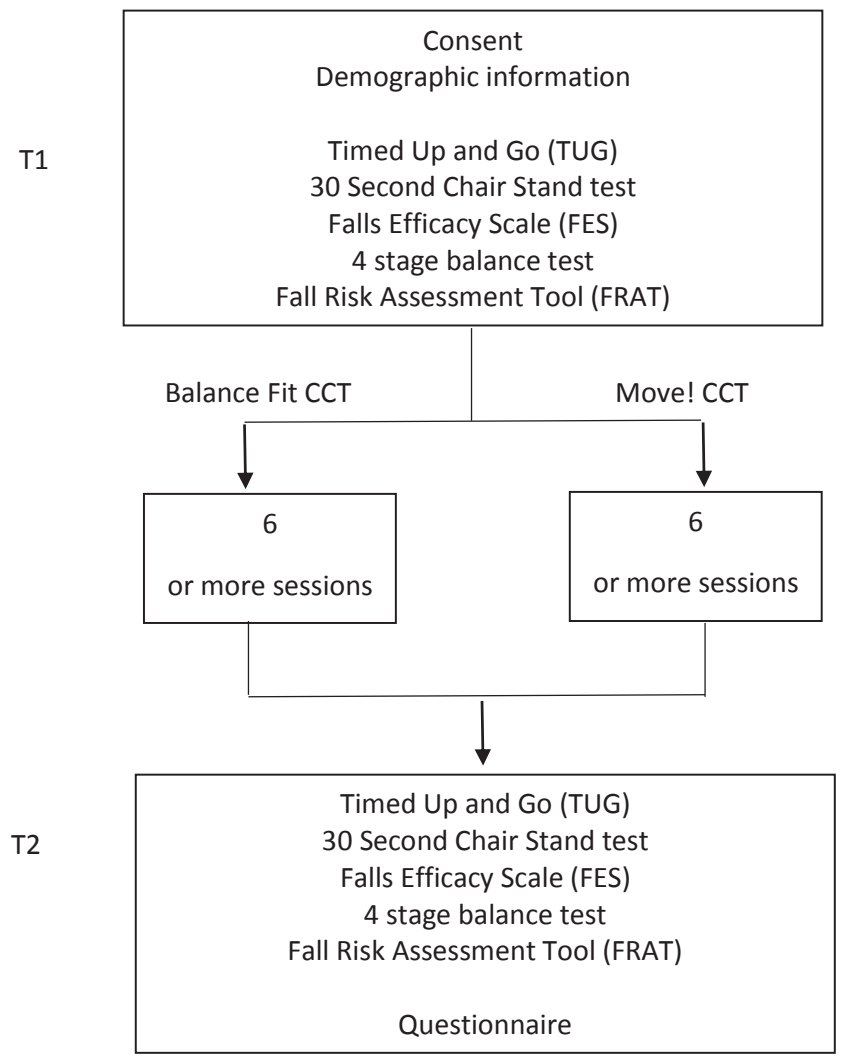

\section{Figure 1: Overview of assessment periods, assessment content and CCT classes}

\section{Outcome measures}

The Timed Up and Go (TUG), the 30 Second Chair Stand test and the 4-Stage Balance test were used to measure mobility, muscle strength and falls risk (Jones, Rikli, \& Beam, 1999; Podsiadlo \& Richardson, 1991; Rossiter-Fornoff, Wolf, Wolfson, \& Buchner, 1995). Confidence during activities of daily living was assessed with the Falls Efficacy Scale (FES) (Tinetti, Richman, \& Powell, 1990) and falls risk was measured using the Falls Risk Assessment Tool (FRAT) (Stapleton et al., 2009).

A questionnaire was developed to ask participants about their perceptions on their abilities as a result of participating in the class and for feedback on the CCT itself. Refer to appendix A for the CCT Questionnaire.

\section{Analysis}

Differences between $\mathrm{T} 1$ and $\mathrm{T} 2$ data were determined using either paired t-tests (TUG, 30 Second Chair Stand test and 4-Stage Balance test) or Wilcoxon Rank-Sum tests (FRAT and FES). Significance was set at 0.05 (two-tailed) for all tests. Questionnaire results were manually tabulated and summarised using basic frequency statistics. Free-text feedback was collated from the comments section of each questionnaire and categorised by topic.

\section{RESULTS}

\section{Participants}

Thirteen clients attending the CCT classes consented to participate in the study between March and August 2015. The majority of the participants were over 65 years of age and 
over half were living with PD. The proportion of people living with PD and MS resulted in $77 \%$ of participants living with a progressive neurological condition. Table 1 presents baseline characteristics.

\section{Table 1: Participant Characteristics}

\begin{tabular}{|c|c|c|}
\hline \multicolumn{3}{|l|}{ Baseline Characteristics } \\
\hline Variable & Number & Percentage (\%) \\
\hline \multicolumn{3}{|l|}{ Sex } \\
\hline Male & 7 & 54 \\
\hline Female & 6 & 46 \\
\hline \multicolumn{3}{|l|}{ Age (years) } \\
\hline $60-64$ & 2 & 15 \\
\hline $65-69$ & 5 & 38 \\
\hline $70-74$ & 4 & 31 \\
\hline $75-79$ & 2 & 15 \\
\hline \multicolumn{3}{|l|}{ Diagnosis } \\
\hline Parkinson's disease & 8 & 62 \\
\hline Stroke & 2 & 15 \\
\hline Transient ischaemic attack & 1 & 8 \\
\hline Multiple sclerosis & 2 & 15 \\
\hline \multicolumn{3}{|l|}{ Classes attended } \\
\hline Move! & 7 & 54 \\
\hline Balance-Fit & 5 & 38 \\
\hline Both & 1 & 8 \\
\hline \multicolumn{3}{|l|}{ Assistive Devices } \\
\hline Walker & 2 & 15 \\
\hline Walking stick & 2 & 15 \\
\hline None & 9 & 69 \\
\hline
\end{tabular}

Outcome measures

Scores from all tests at both time points (T1 and T2) are shown in Table 2. The mean TUG showed a significant change between $\mathrm{T} 1$ and T2 $(p=0.05)$ but there was no change in the other outcome measures (4-Stage Balance, 30 Second Chair Stand, FES and FRAT).

\section{Questionnaire}

Seven of the thirteen participants (54\%) reported improved balance after six weeks of CCT and six participants (46\%) reported their self-confidence and socialisation had also improved. See Figure 2.

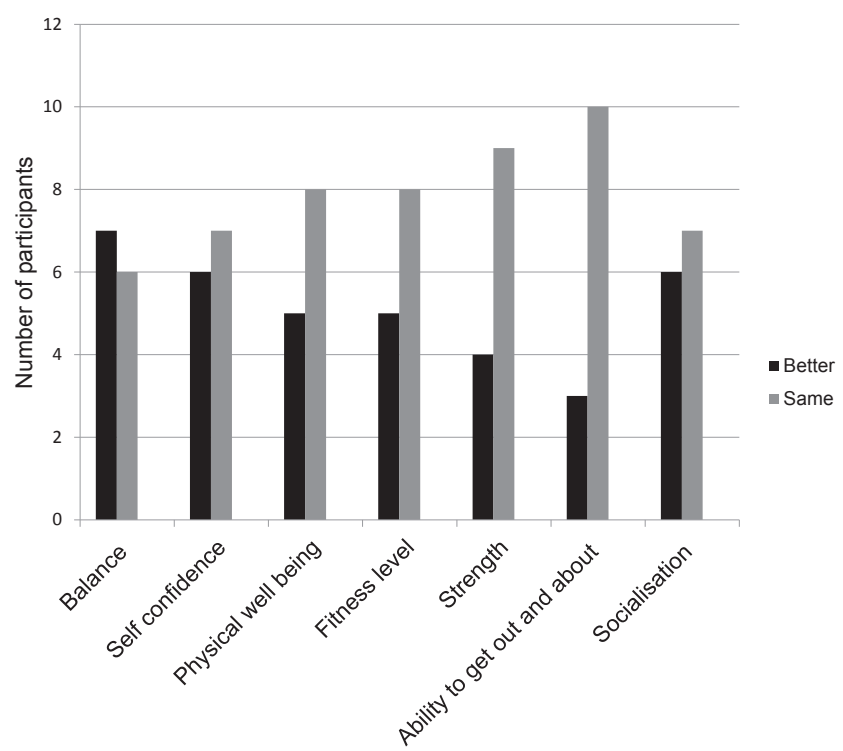

Figure 2: Participant perceived changes as a result of participating in the CCT as reported in the T2 questionnaire

Free text comments suggested that socialisation was a valued component of the CCT. Participants specifically stated how valuable and enjoyable it was to exercise alongside others with similar conditions. Comments ranged from, "It is interesting to see how other people with Parkinson's disease are coping." to "Before I felt sorry for myself thinking why did the stroke happen to me? Now I can see other people and I'm not alone, so I have been able to come to terms with my stroke".

Table 2: Results - Means, Standard deviations (SD) of T1 and T2 measures

\begin{tabular}{|c|c|c|c|c|c|c|}
\hline \multirow[b]{2}{*}{ Outcome } & \multicolumn{3}{|c|}{ Mean and SD } & \multirow[b]{2}{*}{ SD } & \multicolumn{2}{|r|}{ Significance $\left(P^{*}\right)$} \\
\hline & $\mathrm{T} 1$ & SD & $\mathrm{T} 2$ & & Mean difference & \\
\hline Timed Up and Go (s) & 19.9 & 13.6 & 15.7 & 9.1 & -4.2 & $0.05^{*}$ \\
\hline 30 second sit to stand (reps) & 9.4 & 6.7 & 10.4 & 6.2 & 1.0 & 0.2 \\
\hline 4 Stage Balance Test (s) & 30.5 & 9.2 & 31.1 & 0.6 & 0.6 & 0.8 \\
\hline Outcome & $\mathrm{T} 1$ & & $\mathrm{~T} 2$ & & & $(P * *)$ \\
\hline Falls Efficacy Scale & 87.5 & 25.9 & 86.5 & 30.5 & -0.9 & 0.2 \\
\hline Falls Risk Assessment Tool & 9.5 & 3.3 & 9.6 & 3.4 & 0.2 & - \\
\hline
\end{tabular}

Notes: $\mathrm{T} 1$, measurement time point $1 ; \mathrm{T} 2$, measurement time point 2 ; SD, standard deviation; ${ }^{*}$, Paired t-test; ${ }^{*}$, Wilcoxon Rank Sum 
Over two-thirds of participants perceived the CCT organisation, staff skill level and amount of staff assistance provided as excellent. Two out of the thirteen responses rated the frequency and challenge of the classes as average and one response reported that frequency of classes was poor. See Figure 3. Free text comments from some participants spoke about how availability to attend classes was affected by transportation and needing to attend other appointments. Other comments showed differing responses to the question of challenge. For example, "Feel the challenge of exercises improves condition." as well as, "Could be harder." and "Things change, you can never suit everybody."

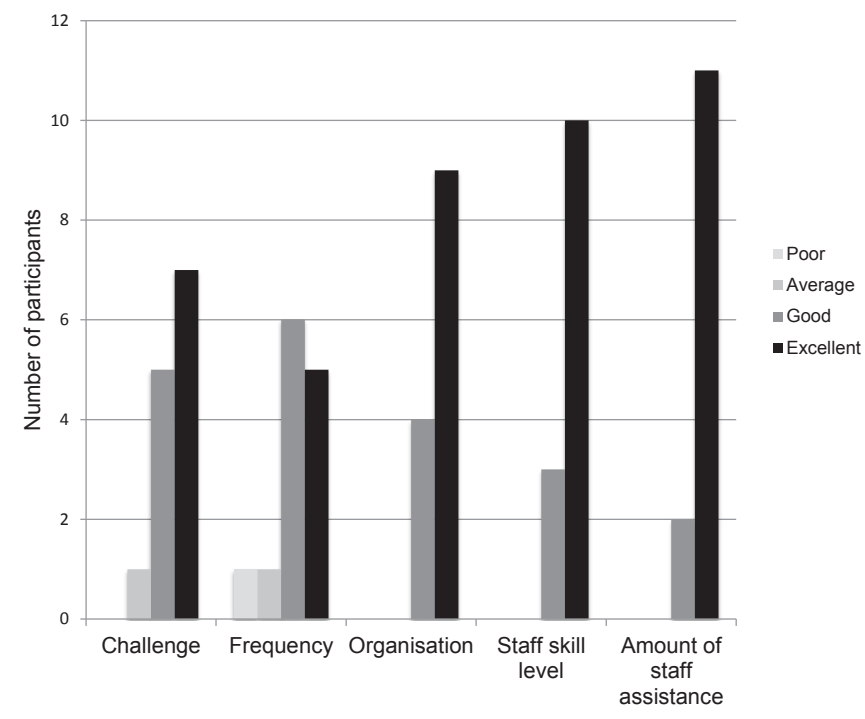

Figure 3: Participant feedback on CCT components as reported at $\mathrm{T} 2$ questionnaire

\section{DISCUSSION}

An important finding of this study was a significant improvement in the TUG scores following at least six sessions of CCT. The average improvement was 4.2 seconds, which is above the minimally detectable difference for people living with stroke and PD (2.9 seconds and 3.5 seconds respectively) (Flansbjer, Holmback, Downham, Patten, \& Lexell, 2005; Huang et al., 2011). The TUG and gait measures have been shown to have higher sensitivity to change than other balance measures (van lersel, Munneke, Esselink, Benraad, \& Olde Rikkert, 2008), perhaps explaining why we may have seen a change in the TUG but not in the FRAT, both of which are measures of falls risk. Because the FRAT is not a physical assessment measure, it may represent different factors contributing to falls risk, which may account for changes in the TUG, but not in the FRAT.

Despite the high proportion (77\%) of participants in our study living with a progressive neurological condition, we were able to detect a positive change. The results of both the outcome measures and the questionnaire suggest that even a small amount of exercise can affect a clinically important change in a group of people with a neurological condition with mobility limitations.
Clinically, physical improvement is encouraging for a number of reasons. Firstly, for this population, exercise and physical activity are even more reduced than in people of the same age with no neurological condition (English et al., 2007; Kunkel, Fitton, Burnett, \& Ashburn, 2015; Motl, McAuley, \& Snook, 2005; van Nimwegen et al., 2011). This group are at even greater risk of secondary complications (Smith, Saunders, \& Mead, 2012; Stavric \& McNair, 2012; van Nimwegen et al., 2011). As such, the need for accessible and effective exercise opportunities is high. We have demonstrated that exercise, in this form of CCT, can have positive effects.

Secondly, the model of the CCT format allows for exercise that would otherwise be difficult to access. Often, barriers such as inaccessible facilities and/or equipment, anxiety and lack of confidence with exercise and staff without appropriate knowledge prevent people from engaging in exercise or any form of physical activity (Ellis et al., 2013; Kayes, Mcpherson, Taylor, Schlüter, \& Kolt, 2011). Therefore, the clinic staff attempted to minimise some of those barriers by providing CCT in an accessible and supportive environment. The feedback from the questionnaires would suggest that the setting was conducive to exercise and socialisation. This is consistent with other studies (Song, Kim, \& Park, 2015). The staff also attempted to offer the CCT at a frequency and intensity that is achievable for most of the users. The results from this study would suggest that even a small amount of therapy and exercise can effect changes in mobility.

Thirdly, the participants were already clients who had been participating in the CCT. As such, they would have likely experienced the most dramatic changes when they first began exercising (Swain, 2005). The finding that changes can still be seen in this group is encouraging and shows that improvements can continue as long as the intervention is appropriate in terms of challenge and support.

Lastly, the lack of change (or deterioration) in the remainder of the outcome measures over the course of the study period should be viewed in a positive light. In contrast to much of the previous CCT literature whose participants were living with stroke, the majority of our participants were living with progressive conditions. As such, the goal of rehabilitation, and CCT, may not necessarily be to improve impairment and function but to also maintain function or slow deterioration.

This study is an example of a real clinical situation attempting to measure the impact of a low cost, low dose intervention that is currently being carried out and may be feasible for other clinical facilities. There was little extra cost to run the study and to analyse the data. However, the process and the results have benefited both the clinicians and participants. They have shown how everyday practice can impact people's function and how this is perceived by clients of a service.

The CCT programme in this study differed to the clinical trials in the literature with respect to dose and setting. Although many studies based in the inpatient setting provided CCT as much as five times per week (Blennerhassett \& Dite, 2004; Chisari, Venturi, Bertolucci, Fanciullacci, \& Rossi, 2014; English et al., 2007), 85\% of our participants reported the frequency of classes as either excellent or good. Free-text comments 
related to this question highlighted that participants had other appointments they needed to attend and transportation was a challenge for some. These comments resonate with previous work highlighting the competing factors that impact a person's participation in physical activity (Mudge et al., 2013).

However, we acknowledge that because this was an ongoing clinical programme, our design was limited in that we did not have a control group. We also recognise that we did not control the amount of additional physical activity in which participants engaged. Some participants were involved in more than the minimally required six classes, so the dose of exercise was not uniform. We also recognise the sample size was small; however, it was representative of more than half the participants at the classes.

Lower limb strength did not change over the study period, which is not surprising, as participants were not exercising at sufficient frequency to drive strength improvements (Whaley, Brubaker, Otto, \& Armstrong, 2006). The outcome measure used to assess for strength may also not have been responsive to show a change in this time. Selection of an alternative strength outcome measure could have been considered. However, this class is currently running and we wanted to replicate the initial screening that was routinely done. As well, static standing balance (as measured by the 4-Stage Balance test) showed no significant change; however, half the participants scored 100\% at T1. This ceiling effect clearly limited the amount of change that could be detected at T2. An alternative standing balance measure such as the Functional Reach test (Weiner, Duncan, Chandler, \& Studenski, 1992) may have been a more sensitive test.

The clinical implications of these findings may lead therapists to further explore how to address the frequency and challenge level of intervention delivered in a group setting, as highlighted by the class questionnaire. Reviewing and ensuring the most appropriate outcome measures are used would also help with capturing change. From a research perspective, there may be other questions that do not form part of the clinical situation and that the physical exercise classes will not answer but that could be interesting in the research environment. For example, exploring the impact of these classes on the participants' confidence, independence and participation in meaningful activities would be a natural extension of this study.

\section{CONCLUSION}

In summary, this study found that, for people living with a neurological condition, participating in a small amount of CCT improved their mobility. People participating in these CCT classes also valued them and perceived benefits from them. This study also provides a real world example of performing clinically based research for the benefit of both patient and clinician.

\section{KEY POINTS}

1. A small amount of targeted exercise can improve mobility for people with neurological conditions.

2. Clinically based research is possible with minimal cost.

3. Circuit class groups are enjoyed by participants and provide a low cost alternative physiotherapy intervention.

\section{DISCLOSURES}

No funding was obtained for this study. One of the authors is the Director of the private rehabilitation clinic (provider of intervention).

\section{ACKNOWLEDGEMENTS}

The authors wish to thank the participants and clinic staff who made this study possible.

\section{ADDRESS FOR CORRESPONDENCE}

Verna Stavric, Private Bag 924006, Auckland, 1146. Telephone: +6499219999 ext 7060. Email: verna.stavric@aut.ac.nz.

\section{REFERENCES}

Blennerhassett, J., \& Dite, W. (2004). Additional task-related practice improves mobility and upper limb function early after stroke: a randomised controlled trial. Australian Journal of Physiotherapy, 50, 219-224. doi: 10.1016/S0004-9514(14)60111-2.

Chisari, C., Venturi, M., Bertolucci, F., Fanciullacci, C., \& Rossi, B. (2014). Benefits of an intensive task-oriented circuit training in Multiple Sclerosis patients with mild disability. NeuroRehabilitation, 35(3), 509-518. doi: 10.3233/NRE-141144.

Coote, S., Finlayson, M., \& Sosnoff, J. J. (2014). Level of mobility limitations and falls status in persons with multiple sclerosis. Archives of Physical Medicine and Rehabilitation, 95(5), 862. doi: 10.1016/j. apmr.2013.10.018.

Ellis, T., Boudreau, J. K., DeAngelis, T. R., Brown, L. E., Cavanaugh, J. T., Earhart, G. M., Dibble, L. E. (2013). Barriers to exercise in people with Parkinson disease. Physical Therapy, 93(5), 628-636. doi: 10.2522/ ptj.20120279.

Eng, J. J., Chu, K. S., Kim, C. M., Dawson, A. S., Carswell, A., \& Hepburn, K. E. (2003). A community-based group exercise program for persons with chronic stroke. Medicine and Science in Sports and Exericse, 35(8), 1271 1278. doi: 10.1249/01.MSS.0000079079.58477.0B

English, C. K., Hillier, S. L., Stiller, K. R., \& Warden-Flood, A. (2007). Circuit class therapy versus individual physiotherapy sessions during inpatient stroke rehabilitation: a controlled trial. Archives of Physical Medicine and Rehabilitation, 88, 955-963. doi: 10.1016/j.apmr.2007.04.010.

Flansbjer, U. B., Holmback, A. M., Downham, D., Patten, C., \& Lexell, J. (2005). Reliability of gait performance in men and women with hemiparesis after stroke. Journal of Rehabilitaition Medicine, 37, 75-82 doi: 10.1080/16501970410017215.

Goodwin, V. A., Richards, S. H., Taylor, R. S., Taylor, A. H., \& Campbell, J. L. (2008). The effectiveness of exercise interventions for people with Parkinson's disease: A systematic review and meta-analysis. Movement Disorders, 23(5), 631-640. doi: 10.1002/mds.21922.

Huang, S., Hsieh, C., Wu, R., Tai, C., Lin, C., \& Lu, W. (2011). Minimal detectable change of the timed 'up \& go' test and the dynamic gait index in people with Parkinson disease. Physical Therapy, 91(1), 114-121. doi: 10.2522/ptj.20090126.

Jones, C. J., Rikli, R. E., \& Beam, W. C. (1999). A 30-s chair-stand test as a measure of lower body strength in community-residing older adults. Research Quarterly for Exercise and Sport, 70, 113-119. doi: 10.1080/02701367.1999.10608028.

Kayes, N. M., Mcpherson, K. M., Taylor, D., Schlüter, P. J., \& Kolt, G. S (2011). Facilitators and barriers to engagement in physical activity for people with multiple sclerosis: a qualitative investigation. Disability and Rehabilitation, 33(8), 625-642. doi: 10.3109/09638288.2010.505992.

Kunkel, D., Fitton, C., Burnett, M., \& Ashburn, A. (2015). Physical inactivity post-stroke: a 3-year longitudinal study. Disability and Rehabilitation, 37(4), 304-310. doi: 10.3109/09638288.2014.918190.

Langhorne, P., Coupar, F., \& Pollock, A. (2009). Motor recovery after stroke: a systematic review. The Lancet Neurology, 8(8), 741-754. doi: 10.1016/ S1474-4422(09)70150-4. 
Latimer-Cheung, A. E., Pilutti, L. A., Hicks, A. L., Martin Ginis, K. A., Fenuta, A. M., MacKibbon, K. A., \& Motl, R. W. . (2013). Effects of exercise training on fitness, mobility, fatigue, and health-related quality of life among adults with multiple sclerosis: A systematic review to inform guideline development. Archives of Physical Medicine and Rehabilitation, 94(9), 1800-1828. doi: 10.1016/j.apmr.2013.04.020.

Marigold, D. S., Eng, J. J., Dawson, A. S., Inglis, J. T., Harris, J. E., \& Gylfadóttir, S. (2005). Exercise leads to faster postural reflexes, improved balance and mobility, and fewer falls in older persons with chronic stroke. Journal of the American Geriatrics Society, 53(3), 416-423. doi: 10.1111/j.1532-5415.2005.53158.x.

Motl, R. W., McAuley, E., \& Snook, E. M. (2005). Physical activity and multiple sclerosis: a meta-analysis. Multiple Sclerosis Journal, 11(4), 459-463. doi: 10.1191/1352458505ms11880a.

Mudge, S., Kayes, N. M., Stavric, V., Channon, A., Kersten, P., \& McPherson, K. M. (2013). Living well with disability: Needs, values and competing factors. International Journal of Behavioral Nutrition and Physical Activity, 10(100). doi: 10.1186/1479-5868-10-100.

Podsiadlo, D., \& Richardson, S. (1991). The Timed "Up \& Go": a test of basic functional mobility for frail elderly persons. Journal of the American Geriatrics Society, 39. doi: 10.1111/j.1532-5415.1991.tb01616.x.

Rossiter-Fornoff, J. E., Wolf, S. L., Wolfson, L. I., \& Buchner, D. M. (1995). A cross-sectional validation study of the FICSIT common data base static balance measures. The Gerontological Society of America, 50(6), 291-297. doi: 10.1093/gerona/50A.6.M291.

Sattin, R. W. (1992). Falls among older persons: A public health perspective. Annual Review of Public Health, 13, 489-508. doi: 10.1146/annurev. pu.13.050192.002421.

Smith, A. C., Saunders, D. H., \& Mead, G. (2012). Cardiorespiratory fitness after stroke: a systematic review. International Journal of Stroke, 7(6), 499510. doi: 10.1111/j.1747-4949.2012.00791.x.

Song, S. H., Kim, J. Y., \& Park, S. D. (2015). The effect of class-based taskoriented circuit training on the self-satisfaction of patients with chronic stroke. Journal of Physical Therapy Science, 27(1), 127-129. doi: 10.1589/ jpts.27.127.
Stapleton, C., Hough, P., Oldmeadow, L., Bull, K., Hill, K., \& Greenwood, K. (2009). Four-item fall risk screening tool for subacute and residential aged care: The first step in fall prevention. Australasian Journal on Ageing, 28(3), 139-143. doi: 10.1111/j.1741-6612.2009.00375.x.

Stavric, V. A., \& McNair, P. J. (2012). Optimizing muscle power after stroke: a cross-sectional study. Journal of Neuroengineering and Rehabilitation, 9(1), 67. doi: 10.1186/1743-0003-9-67.

Swain, D. P. (2005). Moderate or vigorous intensity exercise: which is better for improving aerobic fitness? Preventive Cardiology, 8(1), 55-58. doi: 10.1111/j.1520-037X.2005.02791.x.

Tinetti, M. E., Doucette, J., Claus, E., \& Marottoli, R. (1995). Risk factors for serious injury during falls by older persons in the community. Journal of the American Geriatrics Society, 43(11), 1214. doi: 10.1111/j.15325415.1995.tb07396.x.

Tinetti, M. E., Richman, D., \& Powell, L. (1990). Falls efficacy as a measure of fear of falling. Gerontology, 45(6), 239-243. doi: 10.1093/ geronj/45.6.P239.

van lersel, M. B., Munneke, M., Esselink, R. A. J., Benraad, C. E. M., \& Olde Rikkert, M., G M. (2008). Gait velocity and the timed-up-and-go test were sensitive to changes in mobility in frail elderly patients. Journal of Clinical Epidemiology, 61, 186-191. doi: 10.1016/j.jclinepi.2007.04.016.

van Nimwegen, M., Speelman, A. D., Hofman-van Rossum, E. J., Overeem, S., Deeg, D. J., Borm, G. F., . . Munneke, M. (2011). Physical inactivity in Parkinson's disease. Journal of Neurology, 258(12), 2214-2221. doi: 10.1007/s00415-011-6097-7.

Weiner, D. K., Duncan, P. W., Chandler, J., \& Studenski, S. A. (1992). Functional reach: a marker of physical frailty. Journal of the American Geriatrics Society, 40(3), 203-207. doi: 10.1111/j.1532-5415.1992. tb02068.x.

Wevers, L., van de Port, I., Vermue, M., Mead, G., \& Kwakkel, G. (2009). Effects of task-oriented circuit class training on walking competency after stroke: a systematic review. Stroke, 40, 2450-2459. doi: 10.1161/ STROKEAHA.108.541946.

Whaley, M. H., Brubaker, P. H., Otto, R. M., \& Armstrong, C. M. (Eds.). (2006). ACSM's guidelines for exercise testing and prescription (7th ed.). Philadelphia, Pa: Lippincott Williams \& Wilkins. 


\section{Circuit Group Class Questionnaire}

1. In thinking about the period since you started this most recent 6 week course, please rate the following:

\begin{tabular}{|l|l|l|l|l|l|}
\hline & Poor & Average & Good & Excellent & $\begin{array}{l}\text { Not } \\
\text { Applicable }\end{array}$ \\
\hline Challenge of classes & & & & & \\
\hline Frequency of classes & & & & & \\
\hline Organisation of classes & & & & & \\
\hline Skill level of staff & & & & & \\
\hline Amount of assistance provided by staff & & & \\
\hline COMMENTS & & & \\
\hline
\end{tabular}

2. What days and times would suit you the best? Check all that apply.

\begin{tabular}{|l|l|l|l|l|l|l|}
\hline & Monday & Tuesday & Wednesday & Thursday & Friday & Saturday \\
\hline Mornings & & & & & & \\
\hline Afternoons & & & & & & \\
\hline Evenings (after 4pm) & & & & & & \\
\hline COMMENTS & & & & \\
\hline
\end{tabular}

3. In thinking about your participation in the group class for this most recent $\mathbf{6}$ week course, have you noticed changes in the following?

\begin{tabular}{|l|l|l|l|}
\hline & Better & Same & Worse \\
\hline Balance & & & \\
\hline Self confidence & & & \\
\hline Physical well being & & & \\
\hline Fitness level & & & \\
\hline Strength & & & \\
\hline Ability to get out and about & & & \\
\hline Socialisation & & & \\
\hline Other: & & & \\
\hline COMMENTS & & \\
\end{tabular}

4. What do you like most about the group class?

5. What would you like to see changed about the group class? 


\section{Validation of back pain questionnaire in a popoulation of New Zealand adolescents}

Helen Macdonald MPHTY, Dip MDT

Private Practitioner, Southern Rehabilitation, Nelson, New Zealand (at the time of this study the author was enrolled in the Master of Physiotherapy programme, University of Otago)

Gillian M Johnson PhD, MSc, Dip Phty

Former Associate Professor, Centre for Health, Activity and Rehabilitation Research, School of Physiotherapy, University of Otago, New Zealand

\section{ABSTRACT}

This study aimed to examine the content, convergent and discriminant validity of the Adolescent Back Pain Questionnaire (ABPQ) which was developed to gather lifestyle choices information regarding New Zealand (NZ) teenagers' experience of low back pain (LBP). Twenty volunteers (mean age 16.41, SD 1.66 years) were recruited from a secondary school, private physiotherapy clinics and a local medical centre. Of these, fifteen participants (mean age 15.50, SD1.59 years) had been diagnosed and/or had presented to physiotherapy with LBP and the remaining five participants (mean age 15.84, SD 0.93 years) had no history of LBP. All participants completed both the on-line ABPQ and the Nordic Back Pain Questionnaire (NBPQ), applied in random order, followed by an individual face-to-face interview regarding their preferences and opinions about the questionnaires. The results showed that responses to the ABPQ demonstrated convergent and discriminant validity as a self-report measure across four domains of LBP namely: life-time LBP prevalence, pain intensity, care seeking, and aetiology of LBP. Further, the language and comprehension contained in the ABPQ was found to be acceptable to NZ adolescents and the ABPQ clearly discriminated between those with, and those without, LBP; thereby providing a basis for the use of the instrument when screening for this condition in the NZ adolescent population.

Macdonald, H., Johnson, G.M. Validation of back pain questionnaire in a popoulation of New Zealand adolescents. New Zealand Journal of Physiotherapy 45(3): 126-134. doi: 10.15619/NZJP/45.3.04

Key words: Adolescent, Low back pain, Questionnaire, Validity

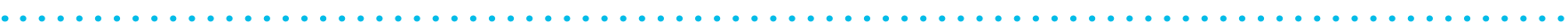

\section{INTRODUCTION}

Low back pain (LBP) and its impact on peoples' daily lives and work is an expensive and ongoing health issue both internationally (Balague Dudler \& Nordin, 2003; Dagenais, Caro, \& Haldeman, 2008; Fairbank, 2015) and in New Zealand (Accident Compensation Corporation, 2012). LBP begins to appear prior to adolescence but the incidence of this condition increases throughout the teenage years with a sharp increase in life time prevalence from 12-15 years (Hill \& Keating, 2009), and by late adolescence the prevalence rate mirrors that found in the adult population (Balague et al, 1995; Balague, Troussier \& Salminen, 1999; Leboeuf-Yde et al, 2011; Swain et al, 2014). There is renewed interest in the prevalence and aetiology of adolescent LBP as it has been proposed that the key to understanding and preventing LBP in adulthood lies in identifying relevant factors in the earlier formative years (Jeffries, Milanese \& Grimmer-Somers, 2007; O'Sullivan et al, 2012; Rees et al, 2011). Although much data has been gathered internationally on the incidence of LBP in adolescents and its effect on lifestyle and possible causes (Leboeuf-Yde et al, 2011), there is less information available on the incidence, aetiology and behaviour of LBP in the New Zealand secondary school population (Trevelyan \& Legg 2010, 2011). Furthermore, there is a need for a robust questionnaire that incorporates information on LBP that is specific to adolescents in the context of the New Zealand healthcare system and lifestyle.
In New Zealand, physiotherapists play a key role in the management of patients across the spectrum of LBP presentations, including those within the adolescent population. Meaningful data that further enhances physiotherapists' knowledge of incidence, presentation patterns and functional impact of LBP is required to implement appropriate and timely therapeutic interventions. Additionally, implementation of preventative strategies, prior to the known time incidence of LBP, could reduce disability and improve physical participation in work and society throughout life. Consequently, the researchers considered existing questionnaires which could be readily used to gather data on LBP across a broad spectrum of New Zealand adolescents such as the Roland Morris Disability Questionnaire, the Oswestry Disability Questionnaire and the Hanover Functional Ability Questionnaire (Pellise et al, 2009; Roland \& Fairbank, 2000; Watson et al, 2002). However, it was noted that a number of questionnaire options for assessing LBP were strongly focused on functional loss and disability and designed to gather data from individuals already diagnosed with LBP (Davidson \& Keating, 2002).

The Standardised Nordic Questionnaire on Musculoskeletal Symptoms often referred to as the Nordic Back Pain Questionnaire (NBPQ) (Kuorinka et al, 1987), has been used extensively as the primary measurement instrument in studies investigating LBP (Bjorksten et al, 1999; Leboeuf-Yde et 
al, 2011) and contains appropriate domains to investigate incidence and aetiology of LBP. However, the NBPQ is not specifically designed for an adolescent population and the wording contained in this questionnaire reflects an occupational as opposed to a school environment. To this end, a multidimensional questionnaire entitled the Adolescent Back Pain Questionnaire (ABPQ) was designed to study influences relevant to adolescent populations and their experience of LBP by incorporating questions within the context of the New Zealand lifestyle. The ABPQ (Appendix 1) was designed to serve as an accompaniment to other directly recorded physical measures such as body weight and height that were planned to be undertaken concurrently with the questionnaire.

A number of factors were taken into account when developing the $A B P Q$ to ensure high quality data applicable to the New Zealand population. Ethnicity is a key social indicator and according to Jeffries et al (2007), the failure to collect this information when designing questionnaires on adolescent LBP is a common oversight. The ethnicity data in the ABPQ was categorised according to the recommendations by Statistics New Zealand (Statistics NZ, 2005). The generic definition of LBP itself is also problematic due to the fact that the low back is often linked with other regions such as the neck (Jeffries et al, 2007). In this study, in accord with the methods used by Pellise et al (2009) and Watson et al (2002), participants were required to meet two criteria in order to be classified as having LBP namely: 1). The presence of LBP in the shaded area on an accompanying body manikin and 2). A positive response to the question, Have you ever experienced pain in the shaded area in the figure above in the last month that lasted one day or longer (Appendix 1, Question 4). Six prevalence time frames (currently experiencing LBP, one month, six months, one year, three years and lifetime) were included so as to provide a detailed profile of the participants' LBP experiences and to enable comparisons with previous studies and their LBP data. Information on the participants' LBP treatment seeking history was incorporated (Appendix 1, Question 10) as an additional dimension of the LBP experience. A criticism of LBP questionnaires is that the specified functional activities are too broad and unspecific to capture patients' more nuanced activity limitations (Lygren et al, 2014). The nine functional activities included in the ABPQ (Appendix 1, Question 11) were taken from the modified Hanover Back Pain Disability Questionnaire (Jones \& MacFarlane, 2009). Although these activities were originally designed for 11-14 year old school children, the options provided included a range of dynamic and static loading activities that were also applicable to the target age group in this study.

It is important to measure the validity of any instrument or measure used to collect data either for clinical or research purposes (Anastasi, 1986). The validity of a questionnaire reflects the extent to which the measurement tool accurately assesses the intended construct (Kimberlain \& Winterstein, 2008). Therefore, a questionnaire used to establish the experience of LBP in adolescents must ask questions that clearly cover all aspects of that experience such as pain intensity, duration and effect and the questions need to be designed to accurately gather data that is sensitive to these constructs (Weresh et al, 1997). It is also necessary to establish that the questionnaire is suitable for the target population by ensuring the language is appropriate and easily understandable and that the format of the questionnaire allows answers to be fully completed and subsequently, analysed successfully (Weresh et al, 1997).

As both the NPBQ and the ABPQ cover the domains of LBP prevalence, intensity, frequency, duration, functional impact, care seeking and cause of LBP; the NPBQ was the questionnaire used to explore convergent validity of the ABPQ. Therefore the aim of this investigation was to explore the validity of the ABPQ and to examine the ability of the instrument to discriminate between New Zealand teenagers (aged 13 to 19 years) who have and have not experienced LBP.

\section{METHOD}

\section{Design}

A cross-sectional observational study design was carried out on a sample of New Zealand adolescents.

Ethical permission for the study was granted by the University of Otago Human Ethics Committee (Approval \#12/043 24/1/2012) and after taking consultation with the Ngäi Tahu Research Consultation Committee, (University of Otago, 24/1/2012). All participants received a full information sheet and provided written informed consent before entering into the study. Further, for those participants aged less than 16 years, written informed consent was also gained from the parents/ legal guardians if this additional consent was deemed to be necessary.

\section{Participants and Recruitment}

Participants were recruited from those individuals attending private physiotherapy clinics, a local medical centre and pupils from the co-educational secondary schools within the Nelson region. Recruitment methods consisted of letters and follow-up phone calls to physiotherapists and general practitioners seeking volunteers. Posters, class announcements and personal contact with teachers were utilised as recruitment approaches for volunteers in the secondary schools.

All participants were required to be able to access the on-line questionnaire independently. The other inclusion criteria were set according to the participant's group allocation: those with (Group I) and without (Group II) LBP. Entry criteria for Group I were adolescents aged between 13-19 years, who had experienced LBP which was sufficient to warrant treatment from a health professional (doctor, physiotherapist or osteopath). For Group II, participants were required to be aged between 13-19 years, never have experienced LBP and not be undergoing treatment for any health problems at the time of the study. All of the latter participants were recruited solely from a local secondary school. Exclusion criteria for both Group I and Group Il participants were those individuals who had a history of spinal surgery and those that were unable to write or read without assistance.

\section{Procedures}

The questionnaire was loaded into Survey Monkey (Survey Monkey Inc. USA), an online tool which enables customized design of surveys and questionnaires. The questionnaire consisted of two parts ( $A$ and $B$ ). Part A of the questionnaire was an adapted version of the NBPQ with minor wording changes 
which were designed to reflect a school rather than a work environment and Part B consisted of 12 questions comprising the $A B P Q$ including the experience of LBP (Appendix 1). Each participant completed the questionnaire in a dedicated computer and space set up for the purposes of the study. On completion of the on-line questionnaire, the content and utility of the ABPQ was discussed with each of the participants in a face-to-face structured interview comprising nine questions conducted by one of the investigators (HM) (Appendix 2). The questions in the faceto-face interview were designed to gather the participants' views on content and comprehensibility of language and wording. Questions were also included to identify any difficulties or areas of ambiguity associated with any of the questions. Participants were also asked to consider their preference for delivery mode when answering a questionnaire. Each of the participant's responses and comments were recorded directly onto an electronic spreadsheet during the interview.

\section{Measures}

The domains of LBP experience, life time prevalence of LBP, duration, frequency, intensity, functional loss, care seeking and the participants' views on the aetiology of their LBP problem were identified within the two questionnaires. The responses of five of the seven domains found to be common to both the $A B P Q$ and the NBPQ (namely life-time LBP prevalence, intensity, care seeking, functional loss and aetiology of LBP) were used for the analysis. For the purposes of quantitative analysis the response options for each of the five domains were assigned numeric values and pooled when necessary as follows:

Life-time prevalence: "No pain ever" was scored 0 and "back pain during your lifetime": was scored 1.

Intensity: The Numeric Rating Scale (NRS) responses from 1-10 in the $\mathrm{ABPQ}$ were converted to the corresponding intensity ratings on the NBPQ where $0=$ no pain, $1-3=$ mild pain, $4-6=$ moderate pain, 7-8 = severe pain, and 9-10 = very severe pain.

Care seeking: The responses in the $\mathrm{ABPQ}$ on care seeking were pooled: $0=$ not seen, 1 = seen by GP, 2 = seen by school or medical centre nurse, 3 = seen by physiotherapist, osteopath or chiropractor, 4 = seen by GP and physiotherapist.

Functional loss: Scores derived from the ABPQ were assigned to impact either school, leisure activities or school and leisure activities respectively, where: $0=$ no functional loss, $1=$ loss of school activity, 2 = loss of leisure activity and $3=$ loss of both school and leisure activities. This grouping enabled some comparison but was not a direct form of comparable scoring between the two question sets.

Cause of LBP: Scores; $0=$ no cause, $1=$ accident, 2 = sporting activity, 3 = activity at school, $4=$ activity at home, $5=$ other cause. These categories enable direct comparison. The sequence of Part A and B appearing in the on-line questionnaire was generated using an on-line randomization website (Randomness and Integrity Service Ltd).

\section{Data Analysis}

Convergent validity was assessed by determining the association between the responses to the ABPQ and the NBPQ questions, using Spearman's Rho correlation coefficients. Statistical significance was set at $p<0.05$.

Discriminant validity was assessed by percentage comparisons of the responses obtained from the $A B P Q$, examining those participants who reported "no LBP ever" and those that reported "LBP at least once" across the four domains of pain intensity (NRS), functional loss, causative factors (accident, sports activity, school or home activity) and care-seeking (physiotherapy, general practitioner, osteopath or other health practitioner).

Content validity: Responses from the participants' one-on-one interviews were assigned to one of the respective themes of the four content domains: question suitability, comprehension, appropriateness and preference, along with any additional comments they provided. A frequency count was taken of the number of responses for each domain. The additional free comments were analysed thematically for common threads of thoughts, feelings and opinions regarding the questionnaires.

\section{RESULTS}

Twenty people participated in the study; the data from one participant were excluded from analysis as it was incomplete. Nineteen volunteers (mean age 16.41, SD 1.66 years, range 14.0 -19.9 years) fully completed the on-line questionnaire between March and July 2012. Eighteen participants reported being of NZ European descent (94.74\%) and one reported being both NZ Māori and NZ European descent (5.26\%). Seven participants (37\%) were male and 12 participants (63\%) were female. Thirteen of the participants completed the questionnaire in a physiotherapy clinic and another six participants answered the questionnaire in their school office. The investigating physiotherapist (HM) conducted a one-to-one interview with each participant on completion of the questionnaire.

Table 1: Spearman's Rho correlation coefficients

\begin{tabular}{lcc}
\hline Question domain & Spearman's Rho $\left(r_{s}\right)$ & Significance level $(p)$ \\
\hline Pain intensity & .594 & $.007^{* *}$ \\
Care patterns & .973 & $.000^{* *}$ \\
Function loss & .351 & .141 \\
Aetiology & .741 & $.000^{* *}$ \\
Life time prevalence & .880 & $.000^{* *}$ \\
\hline
\end{tabular}

Note: ** Highly significant 


\section{Convergent validity}

The correlation coefficients for ABPQ and NBPQ responses across five domains are detailed in Table 1. Strong significant correlations occurred between the ABPQ and NBPQ domains of life time prevalence of $\operatorname{LBP}\left(r_{s}=0.880, p<0.001\right)$ causative factors of $\operatorname{LBP}\left(r_{s}=0.741, p<0.001\right)$ and care seeking behaviour for $\operatorname{LBP}\left(r_{s}=0.973, p<0.001\right)$. A moderate correlation was also demonstrated for pain intensity levels (NRS) for the ABPQ and ranked equivalents in the NBPQ $\left(r_{s}=0.594, p=0.007\right)$. A weak, non-significant correlation was found between the domain of functional loss between the two question sets $\left(r_{s}=0.351, p=\right.$ $0.141)$.

\section{Discriminant validity}

The percentage analysis of the ABPQ responses showed a clear distinction between those with and those without LBP with $100 \%$ of the participants without LBP reporting no functional loss, no care seeking and no life time prevalence of LBP (Table 2). The participants with no LBP did not report any care seeking, functional loss or events associated with the aetiology of LBP (Figures 1-3).

Table 2: Comparison of participants reporting low back pain and those reporting no back pain across three domains in the Adolescent Back Pain Questionnaire (ABPQ).

\begin{tabular}{lcc}
\hline ABPQ domains & Low back pain $(\mathrm{n}=14)$ & No low back pain $(\mathrm{n}=5)$ \\
\hline Care seeking & 8 & 0 \\
No care seeking & 6 & 5 \\
Functional loss & 11 & 5 \\
No functional loss & 3 & 5 \\
No aetiology & 5 & 0 \\
Accident & 1 & 0 \\
Sports & 5 & 0 \\
School activities & 1 & 0 \\
Lifting activity & 3 & 0 \\
Not sure & 1 & 0 \\
Posture & 1 & 0 \\
\hline
\end{tabular}

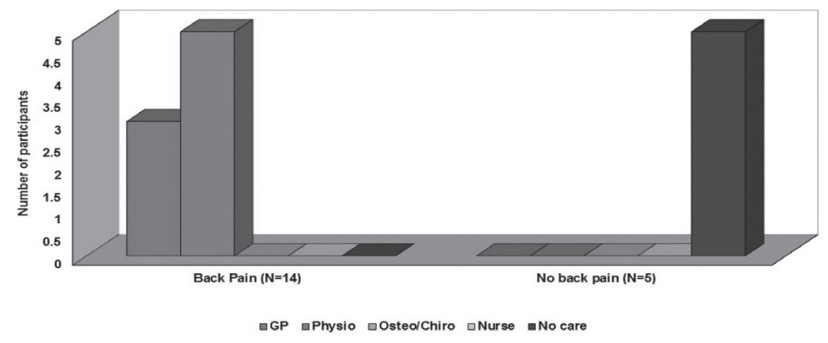

Figure 1: Health care seeking patterns for participants with $(n=14)$ and without low back pain $(n=5)$.

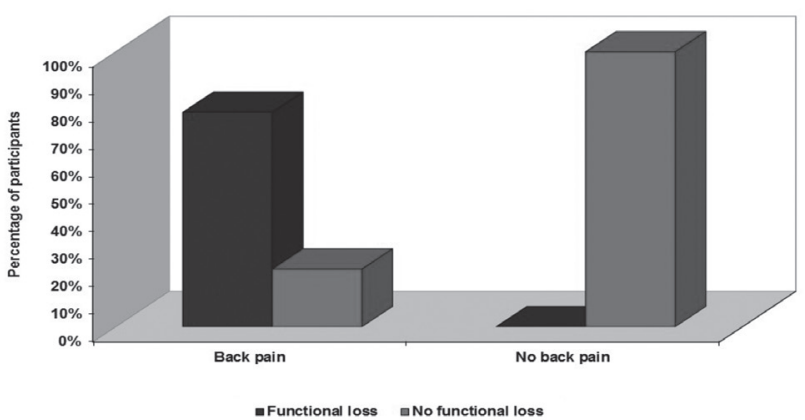

Figure 2: Functional loss expressed by participants with $(n=14)$ and without low back pain $(n=5)$.

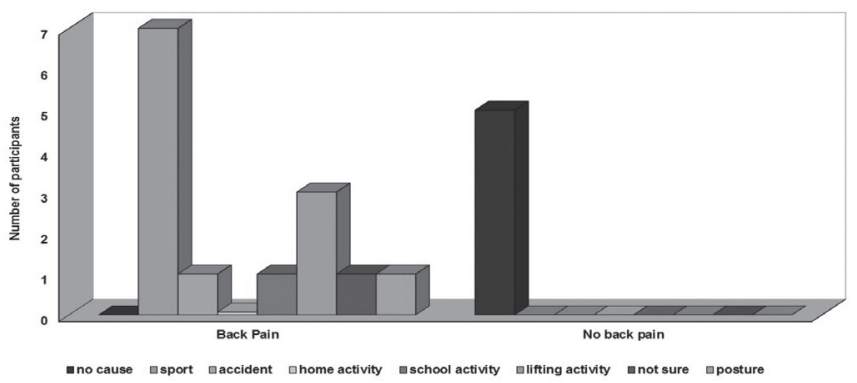

Figure 3: The number of participants reporting known cause of their low back pain.

Content validity

Suitability: In response to the interviewer's questions a clear majority of the participants found both the ABPQ and the NBPQ easy to understand, suitable for the target age group and did not require assistance to complete the questions.

Preference: Eight participants preferred the $A B P Q$, one participant preferred the NBPQ with ten of the participants expressing no preference. The use of the online delivery of the questionnaire was favoured by the majority of the participants. However six of the participants stated that either a paper or online delivery was satisfactory. 
Comprehension: One participant required explanation of the meaning of "leisure" while completing the questionnaires and on interview suggested that "after school activities" could have been more appropriate wording. The same participant sought clarification from her mother on the time frame since pain onset.

Themes: Three participants identified the same pain prevalence question in the ABPQ as confusing. Participants were asked to indicate if they had ever experienced LBP for one day or more, or had experienced LBP for a day or more in the last month, six months, twelve months or, in the last three years (Appendix 1, Question 4). Two participants suggested changes to wording: The inclusion of "I don't know" option for cause of back pain and a suggestion for including a section on pain description. All participants were positive about the overall experience of participating in the survey.

\section{DISCUSSION}

This study sought to validate the ABPQ which had been tailored for New Zealand adolescents when screening for LBP presentations. The results showed that convergent validity was indicated with four of the five domains examined: life time prevalence, levels of back pain, causative factors, treatment choice and pain intensity levels (Table 1). The low correlation obtained for the fifth domain, functional loss, may be explained by the dichotomous nature of this variable (school or leisure) in the NBPQ, whereas in contrast, the ABPQ provided nine possible response options of graded activities. The results also indicated that the questions contained in the ABPQ clearly distinguished between those participants with and without a history of LBP when information was sought regarding seeking care for LBP, functional loss and aetiology of LBP (Figures 1-3). The finding that the participants expressed a preference for the ABPQ over that of the NBPQ may be explained by the unfamiliar terms and wording used in the NBPQ such as the term "back trouble" in this questionnaire in comparison with the more direct wording of "back pain" found in the ABPQ. Information gathered from the interviews following completion of the two questionnaires also indicated the participants had a clear preference for an online mode of delivery.

One of the limitations in the current study was the small number of participants in the 13 year old age bracket that were able to be recruited so that comprehension and understanding for adolescents in this age group was not able to be verified for the $A B P Q$. The recruitment of adolescents with back pain for this study who were actively undergoing treatment for LBP proved difficult due to the low numbers actually seeking treatment and is a further acknowledged limitation of the study. The New Zealand population is ethnically diverse with $30.7 \%$ of the population being either Māori, Pacific peoples or Asian (Statistics, New Zealand), and it is accepted that the study population was not representative of the demographic profile in New Zealand. The current study sampled a population in a semi-urban environment, and in a small geographical area, so that it is anticipated that results may vary in larger population groups and in different regions of New Zealand where the ethnicity and socio-economic factors are more variable. In terms of strengths, the opportunity to have one-on-one interviews with each participant immediately following the completion of the questionnaire assisted in gathering accurate responses and ensured that they were not diluted by time recall issues. Having a single interviewer for all the sessions was a further strength in the study design which served to minimise the potential for inter-reliability issues in the procedural aspects of the interviews.

Clinically, in a final iteration, there is potential for the APBQ to be used by physiotherapists as part of an overall patient information gathering process when assessing adolescents presenting with LBP. The results of the study also demonstrate to physiotherapists the value in reviewing the scope and language contained in widely utilized questionnaires to ensure their applicability for their target population of interest.

There are several recommendations for future research so as to strengthen the validity of this tool for clinical use. Based on a mean prevalence rate at 12 months of $0.33 \%$ (Calvo-Munzo, Gomez-Conesa \& Sandez-Meca, 2013), it is estimated that a sample size of 237 participants is needed to establish a true difference (margin of error $5 \%$ with a statistical power of $90 \%$ ) (Raosoft Sample size calculation Inc., 2004) in future iterations in the validation process of the questionnaire. Additionally, the low care seeking behaviour identified in this study may be related directly to the negligible impact on quality of life and/ or function and leads to questions regarding what constitutes an episode of LBP. To further explore the discriminating ability of this questionnaire, participants with other disabilities and other painful non-LBP conditions could be included to ensure the tool did not record other generalised symptoms in LBP specific domains. An age/sex matched population sample of the subgroups with and without LBP would add weight to results and reduce potential bias. Definitions of LBP prevalence have been developed to reduce heterogeneity in frequency estimates in epidemiological studies of LBP and it is acknowledged that duration of LBP experience is the most difficult variable on which to gain consensus (Dionne et al, 2008). In the light of the comments made by several of the participants regarding pain prevalence in the current $A B P Q$ it would also be worth revisiting this section to ascertain if minor adjustments could be made to improve clarity including that of incorporating "I don't know" options where appropriate. Incorporating the suggestions made by the participants into an updated version would ensure it is devoid of language and terms that might be unfamiliar or confusing to an adolescent population. Online questionnaires have the advantages of reduced personnel resources with the ability to contact a larger population and it has been shown there is an excellent correlation between online questionnaires and face-to-face interviews (Raat et al, 2007; Soetokino et al, 1997; Staes et al, 2000). Furthermore, the high internet usage in New Zealand (93.8\% of the population) (http://www. internetworldstats.com/stats.htm) indicates there is a favourable climate for utilising the internet. Study into web-based accessibility of the ABPQ beyond that able to be carried out in the current study would serve to further improve the clinical utility of this tool for changing healthcare practices.

\section{CONCLUSION}

This study shows that the ABPQ demonstrates good convergent and discriminant validity, in addition to exhibiting acceptable 
content validity and utility in the New Zealand school-age adolescent population. Participants indicated a preference for the ABPQ over the NBPQ in terms of content and language along with preference for an online mode of delivery. Physiotherapists can be confident that the use of the ABPQ in its current format will differentiate those adolescents presenting with and without LBP.

\section{KEY POINTS}

1. The construct validity of four out of five domains in the ABPQ was demonstrated when examined in relation to the widely used NBPQ.

2. As an instrument in its current format, the ABPQ clearly distinguishes between those adolescents with, and those without, LBP.

3. The language used and content contained in the ABPQ is appropriate for the target population of New Zealand adolescents, who also indicate a preference for an on-line delivery mode of this instrument.

4. Physiotherapists can be confident that the current version of the ABPQ will differentiate those adolescents presenting with and without LBP.

\section{DISCLOSURES}

No funding was obtained for the study. The authors report no conflicts of interest.

\section{ACKNOWLEDGEMENTS}

Thank you to the involved School staff and pupils, general practitioners and physiotherapists based in Richmond, Nelson. The contribution of Dr Peter McKenzie, Specialist musculoskeletal physician is also acknowledged.

\section{ADDRESS FOR CORRESPONDENCE}

Helen Macdonald, 2-01, 355 Lower Queen Street, 7020, Nelson, New Zealand; Telephone: 643544 0327. Email: helen. macdonald@southernrehab.co.nz.

\section{REFERENCES}

Accident Compensation Corporation ACC 6075 (2012). Moving and Handling people. The New Zealand Guidelines. Section 2. Retrieved from http://www.acc.co.nz/preventing-injuries/at-work/industry-specific-safety/ moving-and-handling-people-nz-guidelines/WPC094566. [Accessed 15/08/12]

Anastasi, A. (1986). Evolving concepts of test validation. Annual Review of Psychology, 37, 1-15.

Balague, F., Dudler, J., \& Nordin, M. (2003). Low-back pain in children. Lancet 361, 1403-1404. doi: 10.1016/S0140-6736\%2803\%2913148-0.

Balague, F., Skovron, M., Nordin, M., Dutoit, G., Rer, P. L., \& Waldburger, M. (1995). Low back pain in school children: a study of familial and psychological factors. Spine, 20, 1265-1270.

Balague, F., Troussier, B., \& Salminen, J. (1999). Non-specific low back pain in children and adolescents: risk factors. European Spine Journal, 8, 429-438.

Bjorksten, M. G., Boquist, B., Talback, M., \& Edling, C. (1999). The validity of reported musculoskeletal problems. A study of questionnaire answers in relation to diagnosed disorders and perception of pain. Applied Ergonomics, 30, 325-330.
Calvo-Munoz, I., Gomez-Conesa, A., \& Sandez-Meca, J. (2013). Prevalence of low back pain in children and adolescents: a meta-analysis. BMC Paediatrics, 13, 14. doi: 10.1186/1471-2431-13-14.

Davidson, M., \& Keating, J. L. (2002). A comparison of five low back disability questionnaires: reliability and responsiveness. Physical Therapy, 82, 8-24.

Dagenais, S., Caro, J \& Haldeman, S. (2008). A systematic review of low back pain cost of illness studies in the United States and internationally. The Spine Journal, 8(1), 8-20. doi: 10.1016/j.spinee.2007.10.005.

Dionne, C. E., Dunn, K. M., Croft, P. R., Nachemson, A. L., Buchbinder, R. Walker, B. F., Von Korff, M. (2008). A consensus approach toward the standardization of back pain definitions for use in prevalence studies. Spine, 33(1), 95-103. doi: 10.1097/BRS.0b.

Fairbank, J. C. T., \& Pynsent, P. B. (2000). The Oswestry Disability Index. Spine, 25, 2940-2953.

Fairbank, Jeremy C. T. (2015). 2014 ISSLS Presidential Address. Spine, 40(10), 669-673.

Hill, J. J. \& Keating, J. L. (2009). A systematic review of the incidence and prevalence of low back pain in children. Physical Therapy Reviews, 14(4), 272-284. doi: 10.1179/108331909X12488667116899.

Jeffries, L. J., Milanese, S. F., \& Grimmer-Somers, K. A. (2007). Epidemiology of adolescent spinal pain: A systematic overview of the research literature. Spine, 32, 2630-2637. doi: 10.1097/BRS.0b013e318158d70b.

Jones, G. T. \& Macfarlane, G. J. (2009). Predicting persistent low back pain in school children: a prospective cohort study. Arthritis \& Rheumatism, 61(10), 1359-1366. doi: 10.1002/art.24696.

Kimberlin, C. L., \& Winterstein, A. G. (2008). Validity and reliability of measurement instruments used in research. American Journal of HealthSystem Pharmacy, 65, 2276-2284. doi: 10.2146/ajhp070364.

Kuorinka, I., Jonsson, B., Kilbom, A., Vinterberg, H., Bieringsorensen, F., Andersson, G., \& Jorgensen, K. (1987). Standardized Nordic Questionnaires for the analysis of musculoskeletal symptoms. Applied Ergonomics, 18, 233-237. doi: 10.1016/0003-6870(87)90010-x.

Leboeuf-Yde, C., Fejer, R., Nielsen, J., Kyvik, K. O., \& Hartvigsen, J. (2011). Consequences of spinal pain: do age and gender matter? A Danish crosssectional population-based study of 34,902 individuals 20-71 years of age. BMC Musculoskeletal Disorders, 12, 39. doi: 10.1186/1471-2474-12-39.

Lygren, H., Strand, L. I., Anderson, B., \& Magnussen, H. L. (2014). Do ICF core sets for low back pain include patients' self-reported activity limitations because of back problems? Physiotherapy Research International, 19(2), 99-107.

O'Sullivan, P.B., Beales, D.J., Smith A.J., \& Straker, L.M. (2012). Low back pain in 17 year olds has substantial impact and represents an important public health disorder: a cross sectional study. BMC Public Health, 12, 100. doi: 10.1186/1471-2458-12-100.

Pellise, F., Balague, F., Rajmil, L., Cedraschi, C., Aguirre, M., Fontecha, C. G., Pasarin, M., \& Ferrer, M. (2009). Prevalence of low back pain and its effect on health-related quality of life in adolescents. Archives of Pediatrics \& Adolescent Medicine. 63(1), 65-71.

Raat, H., Mangunkusumo, R. T., Landgraf, J. M., Kloek, G., \& Brug, J. (2007). Feasibility, reliability, and validity of adolescent health status measurement by the Child Health Questionnaire Child Form (CHQ-CF): internet administration compared with the standard paper version. Quality of Life Research, 16(4), 675-685.

Raosoft Sample size calculation Inc, 2004 Retrieved from http://www.raosoft. com/. [Accessed 01/07/16].

Randomness and Integrity Service Ltd. Random. Org. Retrieved from https:// www.random.org/ [Accessed 11/08/12]

Rees, C. S., Smith, A. J., O'Sullivan, P. B., Kendall, G. E., \& Straker, L. M. (2011). Back and neck pain are related to mental health problems in adolescence. BMC Public Health, 11, 382. doi: 10.1186/1471-2458-11382. 
Roland, M. \& Fairbank, J. (2000). The Roland Morris Disability Questionnaire and the Oswestry Disability Questionnaire. Spine 25(24), 3115-3124.

Soetikino, R., Mrad, R., Pao, V., \& Lenert, L. (1997). Quality of life research on the internet: feasibility and potential biases in patients with ulcerative colitis. Journal American Medical Informatics Association, 4, 426-435.

Staes, F., Stappaerts, K., Lesaffre, E., \& Vertommen, H. (2003). Low back pain in Flemish adolescents and the role of perceived social support and effect on the perception of back pain. Acta Paediatrica, 92(4), 444-451.

Staes, F., Stappaerts, K., Vertommen, H., Nuyens, G., Coppieters, M., \& Everaert, D. (2000). Comparison of self-administration and face-to-face interview for surveys of low back pain in adolescents. Acta Paediatrica, 89(11), 1352-1357.

Statistics NZ - Informing society using official statistics, Ethnicity New Zealand Standard Classification (V1.0), 2005; Wellington, New Zealand. Retrieved from http://www.stats.govt.nz/ [Accessed 01/07/12].

Survey Monkey Inc [US]. https://www.surveymonkey.com/user/sign-in/ [Accessed 15/08/12].

Swain, M. S., Henschke, N., Kamper, S. J., Gobina, I., Ottova-Jordan, V., \& Maher, C. G. (2014). An international survey of pain in adolescents. BMC Public Health, 14, 447. doi: 10.1186/1471-2458-14-447.

Trevelyan, F. C., \& Legg, S. J. (2010). The prevalence and characteristics of back pain among school children in New Zealand. Ergonomics, 53(12), 1455-1460.

Trevelyan, F. C., \& Legg, S. J. (2011). Risk factors associated with back pain in New Zealand school children. Ergonomics, 54(3), 257-262. doi: 10.1080/00140139.2010.547608.

Watson, K. D., Papageorgiou, A. C., Gareth, T., Jones, G. T., Stewart Taylor, S., Symmons, D. P., Silman, A. J., \& Macfarlane, G. J. (2002). Low back pain in schoolchildren: occurrence and characteristics. Pain, 97(1-2), 8792

Weresh, M. J., Gabel, R. H., Brand, R. A., \& Tearse, D. S. (1997). Popliteus function in ACL-deficient patients. Scandinavian Journal of Medicine \& Science in Sports, 7(1), 14-19. 


\section{Appendix 1}

\section{Adolescent Back Pain Questionnaire}

\section{Questions}

Answer options

1. What is your date of birth?

$\mathrm{dd} / \mathrm{mm} / \mathrm{yyyy}$

2. Which ethnic group or ethnic groups do you belong to?

NZ/European

Maori

Samoan

Cook Island

Tongan

Chinese

Indian

Other ethnicity eg

Dutch

Japanese

Tokoleaun

3

Do you currently have low back pain?

Yes/No

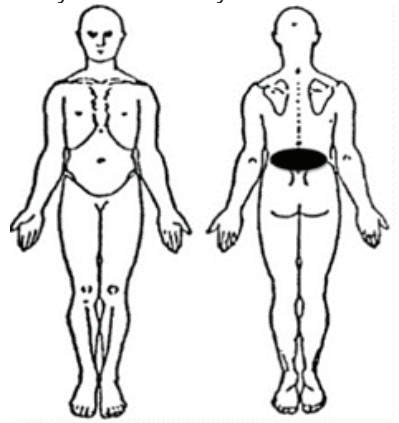

A) In the past month, have you experienced any pain in the shaded area in the figure above that

Yes/No lasted one day or longer?

B) In the past 6 months, have you experienced any pain in the shaded area in the figure above that lasted one day or longer?

C) In the past 12 months, have you experienced any pain in the shaded area in the figure above that lasted one day or longer?

D) In the past 3 years, have you experienced any pain in the shaded area in the figure above that lasted one day or longer?

E) Have you ever experienced pain in the shaded area in the figure above that lasted one day or longer?

Yes/No

$6 \quad$ Thinking back over the past 12 months, how many days have you had low back pain that lasted one day or more?

How bad was the pain at its worst during the past 12 months on a scale $0-10$ where 0 represents no pain and 10 the worse pain you can imagine?

8

How long does your low back pain usually last?
a) less than 12 hours
b) $12-24$ hours
c) 1-7days
d) $7+$ days 
10 Have you visited any of the following in the past 12 months for your low back pain?
a) Doctor
b) Physiotherapist
c) School nurse
d) Not seen by anyone
e) Other health professional

11 Does your low back pain make any of the following daily activities difficult?
a) reaching for a book from a high shelf
Yes/No
b) carrying a school bag to schoo
Yes/No
c) sitting on a school chair for a 45 minute lesson
Yes/No
d) standing in a queue for 10 minutes
Yes/No
e) sitting up in bed from a lying position
Yes/No
f) bending down to put on socks
Yes/No
g) getting up from an armchair at home
Yes/No
h) running fast such as running to catch a bus
Yes/No
i) sports activities at school
Yes/No
j) none of these above activities bother me
Yes/No

12 What do you think caused your low back pain?
a) accident
Yes/No
b) sporting activity
Yes/No
c) lifting activity
Yes/No
d) home activity
Yes/No
e) school activity
Yes/No
f) other
Yes/No

\section{Appendix 2}

\section{Face-to face participant questions}

1. Were the questions understandable - did each of the questions make sense to you and enable you to provide answers quite easily?

2. There were two separate questionnaires - one with a blue background and one with a green background. Thinking back on your experience in answering the questions - were the questionnaires both easy to understand or was one better than the other? If so can you give any examples of why you preferred one over the other?

3. Did you answer the questions without having to ask for assistance?

4. Do you think the questions are asked in a way that is appropriate for your age group?

5. Did you think the wording and terms used in the questions are easily understood and, that you would expect your age group to understand?

6. Do you think doing the questionnaire online was the best way to do this survey?

7. Can you identify any questions or wording that could be improved or clarified?

8 Do you think we need to add any questions that were not included about the experience of low back pain in teenagers?

9. Is there anything you would like to add about your experience here today? 


\title{
The characteristics and experiences of international physiotherapy graduates seeking registration to practise in Australia.
}

\author{
Jonathan Foo BPhysio (Hons) \\ Higher degree by research candidate, Department of Physiotherapy, Monash University, Australia
}

Michael Storr BPhysio

Senior Lecturer, Department of Physiotherapy, Monash University, Australia

Stephen Maloney BPhysio, MPH, PhD

Deputy Head of Department, Department of Physiotherapy, Monash University, Australia and Director of Education, School of Primary and Allied Health Care, Faculty of Medicine, Nursing and Health Sciences, Monash University, Australia

\section{ABSTRACT}

This study aimed to identify the characteristics, and explore the experiences, of international physiotherapy graduates seeking registration to practise in Australia. Participants of a clinical-skills revision workshop run by an Australian University for internationally trained physiotherapists seeking to apply for registration were surveyed between 2013 and 2014. Survey questions focused on the experience of the registration process, and what it meant to participants. Data were analysed with descriptive statistics and thematic analysis. Seventy-three survey responses were received. Most participants were under 40 years old (88\%), 48\% were permanent Australian residents, and 37\% had a Master's level degree or higher. The median years since graduation was eight (interquartile range 6-12), 85\% of participants spoke more than one language, and 56\% reported that they would consider working in a rural location. Thematic analysis revealed insights into the risks perceived by participants while seeking registration to practise, affecting their personal wellbeing, professional development and recognition, partners and children, and resources. International physiotherapy graduates have potential to improve healthcare provision and address Australia's growing health workforce needs, through their experience, diversity, and willingness to work in rural locations. However, international physiotherapy graduates also perceive significant risks associated with seeking registration to practise.

\section{Foo, J., Storr, M., Maloney, S. (2017) The characteristics and experiences of international physiotherapy graduates seeking registration to practise in Australia. New Zealand Journal of Physiotherapy 45(3): 135-142. doi: 10.15619/ NZJP/45.3.05}

Key words: Physiotherapy, Physical therapy, Registration, Professional regulation, Skilled migration, Workforce

\section{INTRODUCTION}

International migration of the health workforce continues to grow, with the total number of migrant doctors and nurses working in Organisation for Economic Co-operation and Development (OECD) countries increasing by $60 \%$ over the last decade (Dumont \& Lafortune, 2016). Increases in health workforce migration may be attributed to increases in globalisation, as well as increased demand for health services which domestic workforce production is unable to satisfy (Aluttis, Bishaw, \& Frank, 2014; World Health Organization, 2010a). When conducted ethically and responsibly, health workforce migration has been reported to increase the circulation of knowledge, provide valuable remittances back to exporting countries, fill workforce shortages, and promote cultural exchange (Forcier, Simoens, \& Giuffrida, 2004).

Demand for physiotherapy in Australia is strong, driven by an ageing population and improvements in access to services (Department of Employment, 2016). As a result, there is currently a physiotherapy skills shortage, particularly in regional locations and senior roles (Health Workforce Australia, 2014). As of $2012,15 \%$ of the Australian physiotherapy workforce obtained their initial qualification outside of Australia (Health
Workforce Australia, 2014). These individuals can be referred to as international physiotherapy graduates (IPGs).

Due to differences in physiotherapy education and practice between countries, it is necessary to regulate the practice of IPGs, in order to maintain standards of care and to protect the public (Cahalin, Matsuo, Collins, Matsuya, \& Caro, 2008; Grant, 2008). In Australia, all physiotherapists must be registered with the Physiotherapy Board of Australia (www. physiotherapyboard. gov.au). As a part of the registration process, IPGs are assessed by the Australian Physiotherapy Council (APC) (https:// physiocouncil.com.au). The APC has two main pathways for assessing IPGs for general registration, the Standard Assessment Pathway, and the Equivalence of Qualification Pathway. The former assesses the skills and knowledge of an IPG through both written and clinical examinations. The latter is designed for IPGS who hold qualifications that may be considered substantially comparable to an approved Australian entry level qualification, and does not involve any examinations. In the Standard Assessment Pathway, prior to undertaking examinations, candidates have the option to apply for limited registration, which allows for supervised practice, as long as they hold an 
eligible basic physiotherapy qualification. As of June 2016, there were 27,667 physiotherapists with general registration, and 330 registered under a supervised practice limited registration (Physiotherapy Board of Australia, 2016). IPGs who hold full registration with the Physiotherapy Board of New Zealand are exempt from the aforementioned assessment pathways under the Trans Tasman Mutual Recognition Agreement, and are able to apply directly for registration.

Research into health professional skilled migration has previously focused on factors motivating migration (Cocks \& Cruice, 2010; Sapkota, van Teijlingen, \& Simkhada, 2014), and experiences of skilled migrants once they have commenced work (Kyle \& Kuisma, 2013; Moran, Nancarrow, \& Butler, 2005). However, little attention has been paid to the experiences of skilled migrants during their first hurdle to working in another country - the process of seeking registration to practice.

The aims for this study were:

1. To identify the characteristics of international physiotherapy graduates seeking general registration to practise in Australia.

2. To explore the experiences of international physiotherapy graduates in their process of seeking general registration to practise in Australia.

\section{Table 1: Summary of questions, response type, and analysis method used}

\begin{tabular}{|c|c|c|}
\hline Question & Response type & Analysis method \\
\hline Gender, age, residency & Multiple choice & Frequency analysis \\
\hline Nationality (able to nominate more than one) & Free text & $\begin{array}{l}\text { Frequency analysis. Grouped according to World } \\
\text { Confederation for Physical Therapy region. }\end{array}$ \\
\hline Qualification level & Free text & $\begin{array}{l}\text { Frequency analysis. Organised by highest qualification } \\
\text { level as reported by participant. Classifications may not } \\
\text { align with the Australian Qualifications Framework. }\end{array}$ \\
\hline Years since qualification & Free text & Normality test applied. Treated as non-parametric data. \\
\hline Languages spoken & Free text & Frequency analysis \\
\hline Perceived costs to obtain registration & Free text & $\begin{array}{l}\text { Normality test applied. Cost treated as parametric data. } \\
\text { Hours treated as non-parametric data. }\end{array}$ \\
\hline Work intentions & $\begin{array}{l}\text { Free text, multiple } \\
\text { choice }\end{array}$ & $\begin{array}{l}\text { Frequency analysis. Participants were free to select } \\
\text { multiple options. }\end{array}$ \\
\hline Perception of registration process & 5-point Likert scale & $\begin{array}{l}\text { Frequency analysis. Likert scale options: much too easy, } \\
\text { too easy, appropriate, too hard, much too hard. }\end{array}$ \\
\hline $\begin{array}{l}\text { Reason for seeking registration in Australia, } \\
\text { importance of obtaining registration in } \\
\text { Australia, impact if registration unsuccessful, } \\
\text { perceived factors leading to successful } \\
\text { registration, perceived factors leading to } \\
\text { unsuccessful registration }\end{array}$ & Free text & Thematic analysis \\
\hline
\end{tabular}

\section{METHODS}

\section{Design}

This study utilised a mixed method design. Quantitative data were collected on perceived costs to obtain registration, time since graduation, and ratings of the registration process. Qualitative data collection included participant characteristics, work intentions, and open response questions exploring the experiences of individuals seeking general registration to practise in Australia. A phenomenological framework was adopted in designing open response questions.

A questionnaire composed of multiple choice responses, 5-point Likert scales, and free text responses was developed. The questionnaire was hosted online via survey tool Survey Monkey (www.surveymonkey.com). See Table 1 for the list of questions.
Participants

IPGs intending to obtain registration in Australia through the APC Standard Assessment Pathway were eligible to participate. Participants were identified from a 'practical skill revision workshop' held by the Physiotherapy Department at Monash University, Australia. This workshop provided IPGs coaching to undertake the Clinical Assessment component of the Standard Assessment Pathway. Workshop participants were invited to participate via email, together with an explanatory statement and website link to the online questionnaire. Three rounds of data collection occurred, corresponding to three offerrings of the 'practical skill revision workshop' between July 2013 and July 2014 
Ethical approval was received from the Monash University Human Research Ethics Committee. Participation in the anonymous online survey was taken as implied consent.

\section{Data analysis}

Table 1 summarises the data analysis method used for different types of questions. Participant characteristics were analysed using frequency analysis in Microsoft Excel (2007). Years since graduation and costs of registration were considered for parametric/non-parametric qualities using a D'Agostino and Pearson omnibus normality test in GraphPad Prism (version 6.07, GraphPad Software Inc., California, US). Data not passing the normality test (alpha level 0.05) were presented as medians and interquartile ranges (IQR); data which did pass the normality test were presented as medians and standard deviations (SD).

Work intentions and perceptions of the registration process were analysed using frequency analysis. Long free-text response qualitative data were analysed using thematic analysis, as indicated in Table 1. Analysis was conducted according to the approach described by Braun and Clarke, including familiarisation of the data, generating initial codes, searching for themes, reviewing themes, defining and naming themes, and producing the report (Braun \& Clarke, 2006). Two investigators independently followed these steps after each of the first two data collection iterations. Thematic saturation was achieved after the second iteration and the investigators agreed on a final set of themes. The last iteration was analysed by one investigator confirming that no further themes emerged. Thematic analysis was conducted using the software NVivo (version 10, QSR International Pty Ltd., Melbourne, Australia).

\section{RESULTS}

\section{Participant characteristics}

A total of 73 survey responses were received. A summary of participant characteristics is presented in Table 2 . The largest number of participants were of Indian nationality $(n=41,56 \%)$, English was the most common first language ( $n=26,36 \%)$, and participants identified a total of 19 different languages which they were comfortable speaking.

Table 2: Summary of participant characteristics

\begin{tabular}{|c|c|c|c|}
\hline Characteristic & Option & $\mathrm{n}$ & $\%$ \\
\hline \multirow[t]{2}{*}{ Gender } & Female & 62 & $85 \%$ \\
\hline & Male & 11 & $15 \%$ \\
\hline \multirow[t]{5}{*}{ Age range } & $20-29$ & 27 & $37 \%$ \\
\hline & $30-39$ & 37 & $51 \%$ \\
\hline & $40-49$ & 8 & $11 \%$ \\
\hline & $50-59$ & 0 & $0 \%$ \\
\hline & $60+$ & 1 & $1 \%$ \\
\hline \multirow[t]{5}{*}{ Nationality by WCPT region* } & Asia Western Pacific & 50 & $64 \%$ \\
\hline & Europe & 20 & $26 \%$ \\
\hline & Africa & 4 & $5 \%$ \\
\hline & North America Caribbean & 2 & $3 \%$ \\
\hline & South America & 2 & $3 \%$ \\
\hline \multirow[t]{2}{*}{ Permanent Australian resident } & No & 38 & $52 \%$ \\
\hline & Yes & 35 & $48 \%$ \\
\hline \multirow[t]{5}{*}{ Highest qualification level } & Doctoral & 1 & $1 \%$ \\
\hline & Masters & 26 & $36 \%$ \\
\hline & Bachelor & 33 & $45 \%$ \\
\hline & Diploma & 3 & $4 \%$ \\
\hline & Not specified & 10 & $14 \%$ \\
\hline Years since graduation & \multicolumn{3}{|c|}{ Median: 8; IQR: 6-12; Range: 2-25 } \\
\hline Number of languages spoken & \multicolumn{3}{|c|}{$1(n=11,15 \%) ; 2(n=30,41 \%) ; 3(n=27,37 \%) ; 4(n=3,4 \%) ; 5(n=2,3 \%)$} \\
\hline
\end{tabular}

Note: * Participants may indicate multiple nationalities. India is no longer recognised as a WCPT member organisation country, but has been included in the Asia Western Pacific region according to geography 
Costs of seeking registration

Participants perceived a mean total cost of AU\$12,948 (SD AU\$4,595) associated with the registration process (including assessment fees, training costs, transportation, living expenses, and lost income). Participants estimated a median of 785 hours (IQR 325-1200 hours) time spent preparing for assessments as part of the registration process.

\section{Work intentions}

Fifty-seven participants responded to the question on work location. Of these, $56 \%(n=32)$ reported that they would consider working in a rural location $(>100 \mathrm{~km}$ from central business district). Of those not open to working in a rural location, 12 participants cited family reasons for their stance. Fifty-six participants responded to the question on intended practice area(s). Of these, across the three primary physiotherapy disciplines, 59\% $(n=33)$ planned to find work in a musculoskeletal focused role, followed by $27 \%(n=15)$ in neurological, and $20 \%(n=11)$ in cardio-respiratory. Participants indicated interest in a range of practice settings, including rehabilitation $(63 \%)$, aged care $(37 \%)$, tertiary hospital $(36 \%)$, and community health (34\%). Specialties of interest included paediatrics, oncology, women's health, sport, research, and higher education.

Perceptions of the registration process

IPGs perceived the administrative process as appropriate (31\%), too hard $(30 \%)$, or much too hard $(39 \%)$. No participants thought that the process was too easy or much too easy. Similarly, with regards to the examination process, the majority of participants believed that the process was much too hard (44\%), too hard (40\%), or appropriate (15\%). One participant believed that the examination process was too easy.

Thematic analysis findings

Thematic analysis identified themes across four major domains: (1) personal, (2) professional, (3) social, and (4) resource. Each theme was further sub-divided into risks and rewards, presenting two perspectives on the same domain, and have been summarised together with the identified codes in Table 3. The following section presents a selection of quotes which illustrate the nature of each theme.

Table 3: Summary of identified themes and codes dichotomised into the sub-themes risk and reward

\begin{tabular}{|c|c|c|}
\hline Theme & Risk codes & Reward codes \\
\hline Personal & $\begin{array}{l}\text { - Personal goal } \\
\text { - Previous effort } \\
\text { - Individual pride } \\
\text { - Individual identity } \\
\text { - Negative emotion } \\
\text { - Lack of direction }\end{array}$ & $\begin{array}{l}\text { - Improved quality of life } \\
\text { - Residency in Australia } \\
\text { - Change in environment } \\
\text { - Recognition of knowledge } \\
\text { - Enjoyment }\end{array}$ \\
\hline Professional & $\begin{array}{l}\text { - Eligibility to practise as physiotherapist } \\
\text { - Previous education and experience as a physiotherapist }\end{array}$ & $\begin{array}{l}\text { - Better working environment } \\
\text { - High standards of practice } \\
\text { - Career opportunities }\end{array}$ \\
\hline Social & $\begin{array}{l}\text { - Partner in Australia } \\
\text { - Family in Australia }\end{array}$ & - Contribute to society \\
\hline Resource & $\begin{array}{l}\text { - Time } \\
\text { - Finances }\end{array}$ & - Financial \\
\hline
\end{tabular}

Theme: Personal, Sub-theme: Risk

For some participants, working as a physiotherapist is more than an occupation, it is also a lifelong goal. The uncertain outcome of the registration process puts this goal at risk, particularly for participants whose resources will only allow one attempt at the registration process: 'It's a lifetime dream to be an Australian physiotherapist, it's my passion.'

Similarly, participants reported that physiotherapy forms a large part of their identity, and linked it to their past efforts in obtaining their qualifications and their experience (and thus overlaps with the theme of professional risk). The identity developed from these past efforts may be put at risk due to the uncertainty around whether the IPG will be allowed to practise as a physiotherapist: 'Because I am a physio and this is what I do (it's an identity thing...).'

Applicants believed that the registration process negatively affected their mental and physical health, and were pessimistic about how they would cope emotionally if they were to be unsuccessful:

Because of all the stress this process gave me, I was going to have a breakdown. I went to a psychologist for 2 months and I had some physical problems.

[... I would] feel very ashamed, depressed, worthless and directionless. 
These negative emotions may be linked to the actual registration process itself, in which participants reported feeling a lack of control, under supported, and noted that they would have preferred more transparency throughout the process.

...rules, regulations and requirements are unclear and unreasonable and seem to change all the time. All of this makes it an extremely stressful process to go through. Luck with getting suitable patients and examiners that judge you fairly seems to play a big role in being successful..

Theme: Personal, Sub-theme: Reward In exchange for the difficulties in becoming registered, many participants saw registration as a pathway for short or long term migration: 'I want to live my whole life here in Australia so it is very important for me to get registered...' Other participants had already migrated to Australia and wanted to return to the physiotherapy workforce: '[l would] like to return to the profession I enjoyed working in...'

Other personal motivations for migration to Australia included work-life balance and being able to travel. Participants saw registration as affirmation of their value to society, rewarded through 'stable income that is reflective of level of knowledge and expertise.'

Theme: Professional, Sub-theme: Risk

The registration process determines whether the IPG is eligible to practise in Australia. If unsuccessful, the applicant must then find an alternative occupation: 'I will be either a home-maker or forced to take another job to support family finances.'

Many participants had several years of working experience. Through skilled migration, they risk their formal training as well as all accumulated experiences and professional development: 'I don't want to throw my education and experience away.'

In particular, participants who had specialised felt that they were unnecessarily restricted by the registration process, as there is no specialty specific registration for physiotherapy in Australia:

In my case - I qualified over 20 years ago - I don't feel it's appropriate to examine me in areas I've never worked in and am highly unlikely to work in the future... I do feel discriminated against due to my age!

Theme: Professional, Sub-theme: Reward Many participants viewed physiotherapy standards in Australia to be higher than their home country, carrying with it the opportunity to learn new skills and further their professional development: '... high standard for physiotherapy that exists in this country. Good courses, positions in research and different techniques.'

Good future job prospects with an expanding market, along with superior working environments are potential factors which draw IPGs to Australia:

Applied for a job on a 12 month contract under limited registration - liked the job prospects, experience, salary and work/life balance and decided to stay longer.

Theme: Social, Sub-theme: Risk

Migration is not always driven by personal goals or professional prospects, it can also be driven by relationships with partners and family. Thus, failure to obtain registration can have repercussions on these relationships if this means applicants are not able to migrate to Australia or must return home if on a temporary visa.

If I cannot succeed in Australia, it might jeopardise my marriage and everything around it.

The love of my life is here, and I don't want to raise my future children in South Africa.

Some participants were already settled in Australia together with their family, and registration would not affect their residency. However, these applicants risked their financial stability and ability to provide for their family on their registration outcome: 'No future of good stable income and hence affects ability to provide for the children beyond the basic needs.'

Theme: Social, Sub-theme: Revvard

Whilst the concept of social risk came through quite strongly, there were limited instances of participants identifying social rewards. One concept that did come through was the wish to contribute to society: 'I am very dedicated to my profession and I am also interested in doing some research work to give my contribution to the vast field of physiotherapy.'

Theme: Resource, Sub-theme: Risk

The financial risk of registration was twofold. Firstly, participants identified that assessment costs are very expensive.

I completely agree with the need to make sure all therapists have the necessary skills to practise safely and effectively, but the level of difficulty it takes to become a registered therapist is a bit too much... both written and clinical; which is a huge financial and emotional burden on the candidate and their family.

Secondly, due to visa work restrictions and needing to be in Australia to undertake certain examinations, participants may have a restricted income and incur further indirect costs: 'Plus for my clinicals I had to quit my job and come to Australia where for [3 to 4] months I cannot have any income.'

Participants invest a significant amount of time into the registration process, from filling out the paperwork, travelling to and from examinations, sitting exams, and study time. Indirectly, participants also risk time invested into obtaining their degree as well as past experiences: 'Again it takes 2 years to get your registration and your exams (if you don't fail).'

Theme: Resource, Sub-theme: Reward Resource reward is closely linked to professional reward in that participants identified higher wages, compared to physiotherapy in their home country, or compared to working in a different occupation in Australia: 'Physio assistants earn minimum pay and there is little scope for salary increase despite length of service.'

\section{DISCUSSION}

This study identified the characteristics of IPGs seeking registration to practise in Australia, their perceived costs and time investments into the registration process, work intentions if successful in obtaining registration, and their rating on the difficulty of the registration process. Furthermore, IPG individual 
experiences of the registration process have been conceptualised through thematic analysis, into the themes of personal, professional, social, and resource risk and reward. In this discussion, the study findings will be compared to the findings of other published literature on health professions migration, and explore how IPGs may contribute to health care systems. The strengths and limitations of this study will be discussed, ending with an exploration of future directions.

Compared to the national population of physiotherapists under supervised practice limited registration, and the general Australian physiotherapy population, there was a higher proportion of females in this study (IPG $85 \%$, limited registration $69 \%$, general registration 68\%) (Physiotherapy Board of Australia, 2016). The IPGs and those under limited registration were younger, $88 \%$ and $93 \%$ under 40 years old respectively, than the general Physiotherapy population (60\% under 40 years old) (Physiotherapy Board of Australia, 2016). This is highly relevant given concerns regarding health workforce shortages, driven by an ageing health workforce approaching retirement, and an ageing population creating increased service demand (Health Workforce Australia, 2014; World Health Organization, 2014).

The majority of IPGs came from the Asia Western Pacific and European regions. Differences in country of training and practice will influence how difficult the skilled migrant finds the registration process, as well as workplace integration (Mulholland, Dietrich, Bressler, \& Corbett, 2013). Of particular concern regarding protection of the public is whether physiotherapists are trained for direct access. Many popular migration destinations, such as Australia, New Zealand, the United Kingdom, and Canada, have direct patient access to physiotherapy services without requiring referral. However, $31 \%$ of countries do not educate physiotherapists for direct access (Bury \& Stokes, 2013), and therefore IPGs from these countries may find the assessment for registration process more difficult than those who have been trained in settings similar to Australia. Outcomes of the interim assessments of international medical graduates for specialist recognition reported by the Medical Board of Australia show that 90\% of candidates from the United Kingdom were recognised as substantially comparable, compared to $15 \%$ of candidates from India (Medical Board of Australia, 2015). It is interesting to note that the majority of IPGs found the registration process too difficult. Factors contributing to this perception appear similar to those identified by IPGs registering in Canada, and include processes being too complex, a lack of process clarity, and the large consumption of time and finances (Mulholland et al., 2013). While it is often difficult to change regulatory processes, clearer explanations and transparency of registration processes, and guidance on planning time and finances may better support IPGs in their registration efforts.

Similarly, the results indicate a potential need for psychological and emotional support for IPGs and their families, given the stressors they experience during the registration process. International occupational therapists undertaking registration in New Zealand have reported similar emotional consequences to those identified in this study, reporting a lack of support, negative feedback from peers and the registration authority, and feelings of grieving due to loss of their professional identity (Mpofu \& Hocking, 2013). Psychological and emotional issues also extend to other aspects of migration, with the inability to find employment and having to begin a new life being linked to experiencing social isolation and loneliness, which is thought to contribute to emotional, social, and mental health issues (Day, 2016; Ogunsiji, Wilkes, Jackson, \& Peters, 2012). In general, migrants experience lower quality of health and health care, partially contributed to by cultural differences and language barriers (Day, 2016). The inclusion of IPGs into the health workforce may help address these causative factors, through increased diversity, enhanced cultural awareness, and a wider range of languages spoken (Mpofu \& Hocking, 2013).

According to www.payscale.com (using September 2015 data), the median yearly Indian physiotherapist income is just under 200,000 Indian Rupees, or approximately AU\$4,000 after conversion to Australian Dollars (October 2016 exchange rate: 1 Indian Rupee $=0.02$ Australian Dollars). Therefore, for an Indian physiotherapist, the results indicate that it would cost over 3 years of income to apply for registration in Australia. This financial outlay is just one of the many 'risks' perceived by IPGs seeking registration. Balanced against risks are the potential 'rewards', which in this study were similar to the motivating factors identified in other studies of health professional migration. These motivating factors include better pay, career opportunities, better work conditions, and family motivators (Buchan \& Perfilieva, 2006; Dywili, Bonner, \& O’Brien, 2013; Sapkota et al., 2014). In the United Kingdom, but not found in this study, travel is a major motivator for skilled migration, with many participants reporting short term stay intentions, which is likely due to the United Kingdom's close geography to popular travel destinations (Cocks \& Cruice, 2010; Moran et al., 2005).

Domestic training of physiotherapists may be insufficient to meet health workforce shortages in regional areas and senior roles. Retention of graduate physiotherapists in regional areas is poor, and several years are needed for changes in domestic training to trickle-down into the senior workforce (Bacopanos \& Edgar, 2016). In comparison, IPGs come 'work-ready', with an average of eight years since obtaining initial physiotherapy degree and $56 \%$ willing to work in a regional location. IPGs may be an under-utilised resource, with almost half of participants reporting status as a permanent Australian resident. Decision makers could consider whether there is scope for bonded registration types, as has been used in medicine to increase clinicians in rural and remote areas (Deloitte Access Economics, 2011). This could be implemented by bonding practice to rural and regional locations, with the incentive of fast-tracked or reduced fee registration processes.

\section{Strengths and limitations}

The strengths of this study are that it explores several aspects of physiotherapist mobility. It presents a narrative to the reader which describes who these people are, what they perceive are the risks and rewards of the registration and migration process, the tangible costs involved, and their work intentions if successful. While this study has focused on the Australian experience, as noted throughout the discussion, there are many similarities of this experience to health workforce migration in other English speaking, high-income countries, such as 
New Zealand, the United Kingdom, and Canada (Moran et al., 2005; Mpofu \& Hocking, 2013; Mulholland et al., 2013). Understanding the experiences of IPGs may assist domestically trained physiotherapists in being more empathetic towards their international migrant colleagues, and reduce barriers to workforce integration.

The characteristics and work intentions of IPGs identified in this study may be of interest to policy makers, health service managers, and other decision makers, for their potential to contribute to the healthcare system. Application of these findings to other professions and countries should be made in consideration with the registration process, the profile of the profession, and migrant characteristics. For example, issues relating to the difficulty and costs of registration will be different between Australia and New Zealand, as they have different assessment for registration processes, conducted by the Australian Physiotherapy Council and Physiotherapy Board of New Zealand, respectively. However, the expectations of physiotherapy competence are likely to be similar, as these countries use a shared standard of competence, the Physiotherapy Practice Thresholds in Australia and Aotearoa New Zealand (Physiotherapy Board of Australia \& Physiotherapy Board of New Zealand, 2015).

Readers should interpret the results with consideration of the study limitations. The authors of this study strove to balance representing a range of diverse migration phenomenon with understanding individual experiences, and chose to use a questionnaire based data collection. However, a more in-depth exploration of specific experiences may be obtained through use of focus groups or interviews. The data presented may not be representative of the general IPG population, as the recruitment was conducted through an optional workshop. It is possible that participants who attend such workshops are more motivated, have more disposable income, have a better information network, or are more concerned about their ability to complete examinations successfully. Furthermore, the workshop was held in Australia, which may influence the number of permanent residents represented. Some participants had already attempted the registration examinations before, while others had not, which may have influenced their perspectives. Lastly, note that this study focused on the experiences of IPGs, and did not evaluate the validity or reliability of the registration process. Thus, from the results, no conclusions can be drawn on the difficulty of the registration process, and whether or not the process unnecessarily limits the movement of IPGs.

\section{Future directions}

Further research may wish to use the findings on perceived risks and rewards to guide investigation into targeted IPG support structures, including the best medium (e.g. face to face, online chat room, videos) and best content (e.g. information on the process, examination revision resources, social services). Efforts to instigate change may be best approached through collaboration with multiple stakeholders, including the existing support organisations (such as the Australian Alliance of Physiotherapists Trained Abroad), professional associations, local regulatory bodies, and the International Network of Physiotherapy Regulatory Authorities (http://www.inptra.org/).
Future work should keep in mind recommendations from the World Confederation for Physical Therapy, encouraging regulation which is "not more burdensome than necessary" (WCPT, 2011); and the 2030 Agenda for Sustainable Development, which highlights that adverse effects on migrants should be mitigated (World Health Organization, 2016).

\section{CONCLUSION}

International physiotherapy graduates appear to have great potential for addressing Australia's growing health workforce needs and for improving health care provision. The regulation of migrant health workers has typically focused on protection of the public. In this study, we add evidence for the need to consider the migrant perspective, and the impact regulation has on them and their families. Consideration of migrant perceived risks and rewards may be a step forward in developing a more equitable registration experience, reducing barriers to workforce mobility, and ensuring maximum benefit for all involved.

\section{KEY POINTS}

1. International physiotherapy graduates appear to have the necessary experience, and willingness to work, to meet Australia's health workforce shortages in regional locations and senior roles.

2. Applying for registration to practise in Australia is associated with several risks to international physiotherapy graduates and their families. Failure to consider the applicant perspective may deter the potential international workforce.

3. The participants in this study indicated that they believed the regulation process was too difficult. Regulation of international physiotherapy graduates should aim to provide maximum benefit to all involved, without being unnecessarily burdensome.

\section{PERIMISSIONS}

Ethics approval was received from the Monash University Human Research Ethics Committee (project number CF13/1589 - 2013000817). Return of the anonymous questionnaire was taken as implied consent.

\section{DISCLOSURES}

No funding was obtained for this study. The last author coordinated the clinical-skills revision workshop from which participants were recruited. To avoid participant coercion, this author was not involved in participant recruitment. No other conflicts of interest are present.

\section{ACKNOWLEDGEMENTS}

The authors would like to thank the participants of this project for their valuable contribution, without which this study would not have been possible.

\section{ADDRESS FOR CORRESPONDENCE}

Jonathan Foo, Monash University, Department of Physiotherapy, PO Box 527, Frankston, Victoria 3199, Australia. Telephone: +61 3990 44240. Email: jon.foo@monash.edu. 


\section{REFERENCES}

Aluttis, C., Bishaw, T., \& Frank, M. W. (2014). The workforce for health in a globalized context - global shortages and international migration. Global Health Action, 7, 23611. doi:10.3402/gha.v7.23611.

Bacopanos, E., \& Edgar, S. (2016). Employment patterns of Notre Dame graduate physiotherapists 2006-12: targeting areas of workforce need. Australian Health Review, 40(2), 188-193. doi:10.1071/AH14244.

Braun, V., \& Clarke, V. (2006). Using thematic analysis in psychology. Qualitative Research in Psychology, 3(2), 77-101. doi:10.1191/1478088706qp063oa.

Buchan, J., \& Perfilieva, G. (2006). Health worker migration in the European Region: Country case studies and policy implications. Copenhagen: WHO Retrieved from http://www.euro.who.int/en/health-topics/Health-systems/ health-workforce/publications/2006/health-worker-migration-in-theeuropean-region-country-case-studies-and-policy-implications-2006.

Bury, T. J., \& Stokes, E. K. (2013). A global view of direct access and patient self-referral to physical therapy: implications for the profession. Physical Therapy, 93(4), 449-459. doi:10.2522/ptj.20120060.

Cahalin, L. P., Matsuo, Y., Collins, S. M., Matsuya, A., \& Caro, F. (2008). Educational and professional issues in physical therapy - an international study. Physiotherapy Theory \& Practice, 24(5), 344-356; quiz 357-349. doi:10.1080/09593980802278926.

Cocks, N., \& Cruice, M. (2010). The experiences and perspectives of overseas trained speech and language therapists working in the United Kingdom. International Journal of Speech Language Pathology, 12(3), 271-282. doi:10.3109/17549500903215318.

Day, G. E. (2016). Migrant and refugee health: advance Australia fair? Australian Health Review, 40(1), 1-2.

Deloitte Access Economics. (2011). Review of the rural medical workforce distribution programs and policies. Australia: Department of Health and Ageing. Retrieved from https://www.health.gov.au/internet/main/ publishing.nsf/Content/foi-disc-log-2011-12/\$File/FOI\%20235-1011\%20 document\%201.pdf

Department of Employment. (2016). Labour market research - health professions Australia 2015-16: Australian Government Department of Employment. ISSN 2203-9619. Retrieved from https://docs.employment. gov.au/system/files/doc/other/aushealthprofessions_0.pdf.

Dumont, J., \& Lafortune, G. (2016). International migration of doctors and nurses to OECD countries: recent trends and policy implications. OECD policy brief prepared for the High-Level Commission on Health Employment and Economic Growth, World Health Organization. Retrieved from http://www.who.int/hrh/com-heeg/International_migration_online. pdf?ua $=1$.

Dywili, S., Bonner, A., \& O'Brien, L. (2013). Why do nurses migrate? - a review of recent literature. Journal of Nursing Management, 21(3), 511 520. doi:10.1111/j.1365-2834.2011.01318.x.

Foo, J. S., Storr, M., \& Maloney, S. (2016). Registration factors that limit international mobility of people holding physiotherapy qualifications: A systematic review. Health Policy, 120(6). doi:10.1016/1. healthpol.2016.04.008.

Forcier, M. B., Simoens, S., \& Giuffrida, A. (2004). Impact, regulation and health policy implications of physician migration in OECD countries. Human Resources for Health, 2(1), 12. doi:10.1186/1478-4491-2-12.

Grant, M. (2008). Globalisation of the Regulation of Physiotherapy Practice - an overview of current approaches to regulation and potential for improvements: INPTRA. Retrieved from http://www.inptra.org/Portals/0/ Articles/RegulationOfPhysiotherapyPractice.pdf.
Health Workforce Australia. (2014). Australia's Health Workforce Series - Physiotherapists in Focus. Retrieved from http://iaha.com.au/wpcontent/uploads/2014/03/HWA Australia-Health-Workforce-Series Physiotherapists-in-focus_vF_LR.pdf.

Kyle, H., \& Kuisma, R. (2013). The experiences of overseas trained physiotherapists working in the United Kingdom National Health Service. Physiotherapy, 99(2), 172-177. doi:10.1016/j.physio.2012.08.001.

Medical Board of Australia. (2015). Report on specialist medical colleges' specialist pathway data. Reporting period: 1 January 2015 - 31 December 2015. Retrieved from http://www.medicalboard.gov.au/documents/ default.aspx?record=WD16\%2f21505\&dbid=AP\&chksum=D7PmZOuQvSH CEw8ayrJH8g\%3d\%3d.

Moran, A., Nancarrow, S., \& Butler, A. (2005). "There's no place like home" a pilot study of perspectives of international health and social care professionals working in the UK. Australia and New Zealand Health Policy, 2,25

Mpofu, C., \& Hocking, C. (2013). "Not Made Here": occupational deprivation of non-English speaking background immigrant health professionals in New Zealand. Journal of Occupational Science, 20(2), 131 145. doi:10.1080/14427591.2012.729500.

Mulholland, S. J., Dietrich, T. A., Bressler, S. I., \& Corbett, K. G. (2013) Exploring the integration of internationally educated occupational therapists into the workforce. Canadian Journal of Occupational Therapy, $80(1), 8-18$

Ogunsiji, O., Wilkes, L., Jackson, D., \& Peters, K. (2012). Beginning Again: West African women's experiences of being migrants in Australia. Journal of Transcultural Nursing, 23(3), 279-286. doi:10.1177/1043659612441018.

Physiotherapy Board of Australia. (2016). Registrant Data: Reporting period 1 April 2016 - 30 June 2016. Retrieved from http://www. physiotherapyboard.gov.au/About/Statistics.aspx.

Physiotherapy Board of Australia \& Physiotherapy Board of New Zealand. (2015). Physiotherapy practice thresholds in Australia and Aotearoa New Zealand. Retrieved from https://www.physioboard.org.nz/physiotherapypractice-thresholds-australia-aotearoa-new-zealand.

Sapkota, T., van Teijlingen, E., \& Simkhada, P. (2014). Nepalese health workers' migration to the United Kingdom: A qualitative study. Health Science Journal, 8(1)

World Confederation of Physical Therapy. (2011). Policy statement: Regulation of the physical therapy profession. Retrieved from http:// www.wcpt.org/policy/ps-regulation.

World Health Organization. (2010a). OECD Policy Brief - International Migration of Health Workers. Retrieved from http://www.who.int/hrh/ resources/oecd-who_policy_brief_en.pdf.

World Health Organization. (2010b). WHO Global Code of Practice on the International Recruitment of Health Personnel. Geneva: World Health Organization. Retrieved from http://www.who.int/hrh/migration/code/ practice/en/.

World Health Organization. (2014). Migration of Health Workers - WHO code of practice and the global economic crisis. Switzerland: WHO press. Retrieved from http://www.who.int/hrh/migration/14075 MigrationofHealth Workers.pdf.

World Health Organization. (2016). Report of the High-Level Commission on Health Employment and Economic Growth - Working for health and growth: investing in the health workforce. Retrieved from http://www. who.int/hrh/com-heeg/reports/en/ 


\section{A Health Enhancement Programme for physiotherapy students: a mixed methods pilot study}

Kristin Lo BPT (Honours)

Senior Lecturer, Department of Physiotherapy, Monash University, Melbourne, Australia.

Alison Francis-Cracknell B.App.Sci (Phty), GCHPE

Clinical Education Manager, Department of Physiotherapy, Monash University, Australia.

Craig Hassed, MBBS

Associate Professor, Department of General Practice, Monash University, Australia.

\section{ABSTRACT}

Health professional students have a high incidence of fitness to practise issues, including stress and may need strategies to support their wellbeing. The 331 first year Bachelor of Physiotherapy students enrolled in our programme between 2009 and 2013 undertook a 3-4 week wellness programme. They completed the Perceived Stress Scale (PSS), Fantastic Lifestyle Assessment questionnaire and the World Health Organisation Quality of Life Brief (WHOQOL-BREF) scale before and after the programme. Thematic analysis was used to interpret qualitative data. A non-clinically significant increase in the PSS coincided with increased assessment load during the semester which is a potential confounding variable thus randomised controlled trials taking this into account are indicated. Increases in the Fantastic Lifestyle Assessment across the 4-week programme indicated a healthier lifestyle had been adopted. Participants enjoyed the mindfulness (being aware of the present moment) activities, resources, sharing of discussion, content on healthy behaviours and goal setting. Practical activities in tutorials, and the lecturer and tutorial staff were viewed positively. There were a number of suggested changes to the programme content. To our knowledge this is the first documented wellness programme for physiotherapy students. A number of quantitative studies exist regarding health professional wellness courses, but minimal qualitative data exist. This article aims to address this.

Lo, K., Francis-Cracknell, A., Hassed, C. A Health Enhancement Programme for physiotherapy students: a mixed methods pilot study. New Zealand Journal of Physiotherapy 45(3): 143-153. doi: 10.15619/NZJP/45.3.06

Key words: Health education, Physiotherapy specialty, Social determinants of health, Education, Student health occupations

\section{INTRODUCTION}

Stress amongst university students is a serious issue. In a cross-sectional survey of 1,168 students attending the health services at three large Australian universities, approximately half of the students reported psychological distress (Stallman \& Shochet, 2009). Distress is defined as psychological discomfort that interferes with the activities of daily living (Weissman, Pratt, Miller, \& Parker, 2015). The majority of severely distressed students had not sought any professional assistance for mental health problems (Stallman \& Shochet, 2009).

Due to the demands of continuous assessment, knowledge retention, confronting circumstances associated with health service provision and long contact hours, health professional students are at risk of mental health issues including burnout. Burnout is described as a combination of emotional exhaustion, depersonalisation, and a reduced sense of accomplishment (Maslach \& Jackson, 1981). A review of mental health issues, including burnout in medical students, indicates that the prevalence rate may be between 45-71\% (IsHak et al., 2013). A study of physiotherapy student stress and psychological morbidity demonstrated that $27 \%$ of the 125 undergraduate students surveyed scored above the threshold on the General Health Questionnaire. This indicated probable psychological morbidity (Walsh, Feeney, Hussey, \& Donnellan, 2010). This was higher than in the general population. Stress in nurses has been shown to result in anxiety, disturbances to sleep, loss of confidence and self-esteem issues (Bennett, Lowe, Matthews, Dourali, \& Tattersall, 2001; Dallender, Nolan, Soares, Thomsen, \& Arnetz, 1999; Hillhouse \& Adler, 1997). Stress can also result in unhealthy lifestyle behaviours (Tully, 2004), stressrelated health issues (Tyler \& Cushway, 1998) and even suicide (Feskanich et al., 2002).

Consequently Seritan and colleagues (2012) highlighted the need for culture change and advocated for health professional curricula to include evidence-based strategies to support student wellbeing. A systematic review of randomised controlled trials by Fjorback et al., (2011) and a meta-analysis by Regehr et al., (2013) demonstrated that strategies such as Mindfulness Based Stress Reduction reduce stress in university students. Mindfulness has been described as the practice of non-judgmental awareness of the present moment (KabatZinn, 2009). These findings have encouraged Mindfulness Based Stress Reduction to be considered for inclusion in health professional curricula (Erogul, Singer, Mclntyre, \& Stefanov, 2014).

Since 2012 there has been a rapid increase in the evaluation of wellbeing curricula (Lo et al., 2017). The interventions to enhance wellbeing have included mindfulness, psychoeducation, cognitive-behavioural techniques and relaxation. A systematic 
review and meta-analysis of randomised controlled trials (Lo et al., 2017) evaluating group interventions to improve health professional student mental health found that while mindfulness interventions reduced stress, psychoeducation reduced depression. Cognitive-behavioural and relaxation interventions both reduced anxiety, depression and stress. Wellness programmes have been delivered to nursing, medical, pharmacy, psychology and dental students. However, there has been no research investigating wellness programmes delivered to physiotherapy students. The review by Lo and colleagues demonstrated that multimodal interventions may provide additional benefits across a number of areas of mental health.

A multimodal intervention developed for the medical students at Monash University has been evaluated (Hassed, De Lisle, Sullivan, \& Pier, 2009). This Health Enhancement Programme (HEP) includes mindfulness, a stress release programme and a lifestyle programme based on the acronym ESSENCE. ESSENCE highlights the importance of Education, Stress management, Spirituality, Exercise, Nutrition, Connectedness and Environment in fostering wellbeing. Evaluation of this programme demonstrated that $90.5 \%$ of medical students were personally applying the mindfulness practices taught. Improved student wellbeing was noted on all measures and reached statistical significance for the depression and hostility subscales of the Global Severity Index of the Symptom Checklist-90-R (SCL90) but not the anxiety subscale of the SCL-90. The SCL-90 is a 90 -item self-report scale that assesses psychological issues (Derogatis, 1976). Significant results were also found for the psychological domain but not the physical domain of the Australian version of the World Health Organisation Quality of Life Brief (WHOQOL-BREF) questionnaire. This was the first study to demonstrate overall improvement in student wellbeing in the period prior to exams. The study findings suggest that the decline in wellbeing that occurs during the pre-exam period is avoidable.

Our study involves the application of this Health Enhancement Programme to first year physiotherapy students at Monash University. To our knowledge this is the first documented wellbeing programme incorporated into a physiotherapy undergraduate course. There is an established need for the wellbeing of physiotherapy students to be addressed with proactive strategies, however specific strategies to improve wellbeing of physiotherapy students have not been investigated. There is potential for the findings of this study to inform curricula and not only benefit the physiotherapy profession, but have applications in other health care professional programmes. The question we wished to address was 'Does the Health Enhancement Programme lead to improved outcomes on the Perceived Stress Scale, Fantastic Lifestyle Assessment Questionnaire or World Health Organisation Quality of Life Brief (WHOQOL-BREF) questionnaire in physiotherapy students'?

\section{METHOD}

\section{Study Design}

Pre-post scores on the lifestyle perceptions of physiotherapy students were collected using an anonymous online survey. Students constructed their own unique identification code to ensure anonymous completion of the survey. Data were collected pre-programme at the beginning of the first tutorial in week 1 (T1). The post-programme measures were collected at the end of the last tutorial (T2). At the end of the programme, students were also asked what they enjoyed about the programme, what could be changed and any other comments they had. Assessors were blinded to the completion of the survey data.

Ethical approval was granted by the Monash University Human Research Ethics Committee (CF10/1321 - 2010000703).

\section{Participants}

All students enrolled in the first year of the Bachelor of Physiotherapy programme at Monash University between 2009 and 2013 were eligible to participate in the study. The data were a convenience sample. We used the Harvard sample size calculator with the following parameters: significance level (adjusted for sidedness) $=0.025$, standard deviation $=5.92$, power $=0.8$, difference in means $=3$, location of mean in one group as a percentile of the other group = undefined. This yielded a required sample size of 126 participants.

\section{Intervention}

The Bachelor of Physiotherapy course at Monash University is a four year undergraduate degree. Given there are demands associated with adjusting to university, the Health Enhancement Programme was introduced into semester two of first year. At this time students had completed one semester of musculoskeletal theory and completed some coursework in inter-professional groups. The structure of the course is such that first year has a focus on musculoskeletal theory and practice. Second year has a focus on cardiorespiratory and neurological theory and practice. Third year includes theory and practice in specialist areas such as Women's and Men's Health, Amputees and Emergency Health. Year four covers employment preparation, Indigenous health and applied research skills. Woven throughout the four years is curriculum covering personal and professional development topics, research skills and inter-professional education. Clinical education commences in Year two with three half day visits progressing to 15 weeks during Year three and 17 weeks in Year four. An estimate of the ratio between face-to-face classes and self-directed learning would be approximately 60:40\%. The Health Enhancement Programme commenced in 2009. In the first iteration, the programme ran for three consecutive weeks with three 1 hour lectures and three 1.5 hour tutorial classes. The tutorial classes gave the students an opportunity to practise skills. After receiving student feedback, the programme was then expanded in 2010 to a 4-week programme with an additional 1 hour lecture and 1.5 hour tutorial. This enabled concepts to be more fully expanded whilst fitting within the constraints of available time within the existing curriculum structure. The tutorial group size was between 14-20 students and each tutorial included a mindfulness practice.

For the 4-week programme, Week 1 introduced the concepts of education / behaviour change and lifestyle modification. This included information on the ESSENCE model, the course outline, the relationship between mental health and lifestyle and an introduction to mindfulness. Prochaska and DiClemente's stages of change were included (DiClemente, Prochaska, \& Gibertini, 
1985). The stress performance curve was also an inclusion (Nixon, Murray, \& Bryant, 1979) as was Motivational Interviewing (Miller \& Rollnick, 2012). Information of clinical and personal relevance was highlighted in the course. SMART goals were also discussed (Doran, 1981). SMART goals are Specific, Measurable, Attractive, Realistic and Timely goals which help facilitate change. The week 1 tutorial learning objectives were to:

1. Describe 'mindfulness' and how this applies to health and wellbeing.

2. Identify basic key components of Motivational Interviewing and how it applies to personal and health care settings.

3. Describe the ESSENCE model of health and wellbeing.

4. Outline the stages of behaviour change using the ProchaskaDiClemente Cycle.

Week 2 focused on stress management / education / the link between mind and body / mindfulness including the relationship between stress and health and clinical applications of mindfulness. The tutorial incorporated a Motivational Interviewing practice and an example of setting SMART goals. The week 2 tutorial learning objectives were to:

1. Describe SMART goals and how to set one.

2. Apply the ESSENCE model of health to one's own personal health goals.

3. Identify examples of mindfulness practice.

4. Identify how Motivational Interviewing techniques may promote client engagement with health goal setting.

Week 3 focused on exercise and nutrition including the health benefits of both healthy eating and physical activity. It also included the discussion of the psychology of eating and weight management. Tutorial 3 included a mindfulness practice to focus on being in the present moment whilst eating food. Learning objectives were to:

1. Describe the Australian Dietary Guidelines

2. Analyse the relevance of the Australian Dietary Guidelines to one's own eating habits.

3. Describe the influence of exercise and nutrition on health and wellbeing.

4. Identify how exercise and nutrition impact on one's own health and wellbeing currently and in the future.

Week 4 concluded with a discussion of spirituality, connectedness and environmental factors which may impact on health. The tutorial 4 learning objectives were to:

1. Identify one's own understanding of spirituality / meaning and how this relates to health.

2. Analyse appropriate responses to other's views of spirituality I meaning that may differ from a student's own.

3. Describe connectedness and how this positively and negatively impacts on health and wellbeing.

4. Identify the impact of environmental factors on health and wellbeing.
For further explanation of the Health Enhancement Programme refer to Hassed and colleagues (2009). All students were encouraged to practise at home and a self-reflective journal was assigned at the end of each tutorial as a formative hurdle assessment task. Tutors provided brief comments on these journals and returned them at the following tutorial. If students presented with signs of significant mental health issues or other concerning problems they were referred to health services or on-campus counselling. To highlight the importance of the programme, students were informed that the material was core curriculum and examinable in both written exams and their practical Objective Structured Clinical Exams (OSCEs).

Outcome measures

Students completed the following three questionnaires:

1. The Perceived Stress Scale. The 10-item version of the scale that assesses stress in everyday life was used (Cohen \& Williamson, 1988). This scale has been found to be reliable and valid in the assessment of perceived stress in university students (Roberti, Harrington, \& Storch, 2006). The items are assessed using a 5-point Likert scale with categories from never (0) to very often (5). The total Perceived Stress Scale score is obtained by reversing the scoring for the positive items for example, $0=4,1=3,2=2$, etc. and then summing across all 10 items. The positive items are items 4, 5, 7 and 8. An example question is: "In the last month, how often have you felt nervous and stressed?" Higher scores indicate higher degrees of stress.

2. The Fantastic Lifestyle Assessment questionnaire (Wilson \& Ciliska, 1984). This 25-item questionnaire assesses physical, emotional and social components of health that are considered relevant to quality of life, morbidity and mortality. There are three options for each item, scoring 2, 1 or zero points. This sums to a total score out of 40 . The higher the score, the more positive the lifestyle of the participant. The correlation co-efficient has been found to be 0.88 (Wilson \& Ciliska, 1984).

3. The Australian version of the World Health Organisation Quality of Life Brief (WHOQOL-BREF) tool, is a 26-item assessment of quality of life over four domains (Murphy, Herrman, Hawthorne, Pinzone, \& Evert, 2000). The first two domains, physical and psychological, were of interest. The higher the score, the higher the quality of life. This instrument has been found to be valid for use in the Australian population (Murphy et al., 2000). The original WHOQOL-BREF scores demonstrated good content validity, internal consistency and test-retest reliability (Harper, 1998) For all of the questionnaires an "I do not wish to answer" option was added. When students utilised this item in the Perceived Stress Scale and Fantastic Lifestyle Assessment questionnaires it was determined that a total score could not be calculated and this resulted in missing data for that questionnaire. In alignment with the WHOQOL-BREF protocol (World Health Organization, 1996), a missing item was substituted with the mean of the other items in the domain. Where more than two items were missing from the domain, the domain score was not calculated. When more than $20 \%$ of data were missing from a participant's 
questionnaire, the assessment was discarded. According to protocol, WHOQOL-BREF domain scores were multiplied by four such that the scores could be comparative to the WHOQOL-100 normative values. Students were also asked to complete an evaluation survey regarding the Health Enhancement Programme.

Data process and analysis

We exported the numerical survey data into Microsoft Excel ${ }^{\mathrm{TM}}$ to aggregate scores. We conducted repeated measures t-testing on the pre and post scores on each of the three scales: Perceived Stress Scale, Fantastic Lifestyle Assessment questionnaire and the WHOQOL-BREF (Australian version) for both the 3 and 4-week programmes.

We calculated the power of the sample. The probability was $52 \%$ percent that the study would detect a treatment difference at a two-sided 0.05 significance level, if the true difference between interventions was 2.0 units. This is based on the assumption that the standard deviation of the response variable was 5.92

The qualitative data were analysed using the realist method of qualitative analysis, reporting experiences and meanings from the participants' perspective. These themes were coded rather than thematic analysis (Braun \& Clarke, 2006). There was no minimum number of responses needed to generate a theme as we wished to provide a thematic description of our entire data set to give a sense of the predominant or important themes. We used inductive thematic analysis and themes were applied until data saturation occurred. Themes were identified at a semantic level and we used an essentialist / realist epistemology. First, the two independent researchers familiarised themselves with the data, initial codes were developed. Codes were then collated into themes. These themes were then reviewed by two researchers. When consensus was reached as to the final theme titles, the data were recoded into the final themes. Another period of consensus followed to check that the allocation of themes was consistent. Where possible, qualitative data was used to expand on quantitative findings. Data are reported in alignment with the quality assessment tool for pre-post studies with no control group (National Heart Lung and Blood Institute, 2014).

\section{RESULTS}

Flow of participants through the study There were 362 students enrolled in the first year of the Bachelor of Physiotherapy programme from 2009 to 2013. The 3-week programme had 33 complete datasets for the Perceived

Table 1: Summary of mean and standard deviation data, normative values and follow-up paired samples t-tests for measures across T1 and T2

\begin{tabular}{|c|c|c|c|c|c|c|c|c|c|c|c|c|}
\hline \multirow{2}{*}{ Variable } & \multirow[b]{2}{*}{$\mathrm{n}$} & \multicolumn{2}{|l|}{$\mathrm{T} 1$} & \multicolumn{3}{|l|}{$\mathrm{T} 2$} & \multirow[t]{2}{*}{$\mathrm{T}$} & \multirow[t]{2}{*}{$d f$} & \multirow{2}{*}{$\begin{array}{l}\text { Significance } \\
\text { (two tailed) }\end{array}$} & \multirow[t]{2}{*}{$95 \% \mathrm{Cl}$} & \multicolumn{2}{|c|}{ Normative data } \\
\hline & & Mean & SD & $n$ & Mean & SD & & & & & Mean & SD \\
\hline PSS 3-week & 33 & 18.09 & 6.13 & 33 & 18.21 & 6.55 & 0.17 & 32 & $p=0.860$ & -1.27 to 1.51 & \multirow{3}{*}{$16.78^{*}$} & \multirow{3}{*}{$6.86^{*}$} \\
\hline & & & & & & & & & & & & \\
\hline PSS 4-week & 115 & 16.02 & 5.72 & 115 & 17.60 & 5.74 & 3.01 & 114 & $p=0.003$ & 0.54 to 2.60 & & \\
\hline $\begin{array}{l}\text { Fantastic lifestyle } \\
\text { assessment } \\
\text { 3-week }\end{array}$ & 35 & 27.11 & 3.65 & 35 & 28.20 & 4.79 & 1.11 & 34 & $p=0.274$ & -0.90 to 3.07 & - & - \\
\hline $\begin{array}{l}\text { Fantastic lifestyle } \\
\text { assessment } \\
\text { 4-week }\end{array}$ & 96 & 26.37 & 3.36 & 95 & 28.90 & 4.10 & 4.51 & 95 & $p<0.0001$ & 1.41 to 3.62 & & \\
\hline \multicolumn{13}{|l|}{ WHOQOL-BREF } \\
\hline $\begin{array}{l}\text { Physical domain } \\
\text { 3-week }\end{array}$ & 43 & 92.47 & 12.84 & 43 & 93.42 & 11.84 & 0.39 & 42 & $p=0.70$ & -4.06 to 5.97 & \multirow{2}{*}{85.40} & \multirow{2}{*}{10.90} \\
\hline $\begin{array}{l}\text { Physical domain } \\
\text { 4-week }\end{array}$ & 176 & 90.75 & 12.01 & 176 & 91.03 & 12.67 & 0.21 & 175 & $p=0.836$ & -2.36 to 2.91 & & \\
\hline $\begin{array}{l}\text { Psychological } \\
\text { domain 3-week }\end{array}$ & 43 & 84.74 & 11.05 & 43 & 87.44 & 10.50 & 1.11 & 42 & $p=0.272$ & -2.20 to 7.59 & & \\
\hline $\begin{array}{l}\text { Psychological } \\
\text { domain 4-week }\end{array}$ & 176 & 83.27 & 10.73 & 176 & 83.66 & 12.63 & 0.32 & 175 & $p=0.751$ & -2.04 to 2.82 & 71.40 & 17.5 \\
\hline
\end{tabular}

Notes: SD, standard deviation; $\mathrm{Cl}$, confidence interval

*2009 data for < 25 year old sample from United States (Cohen \& Janicki Deverts, 2012). 
Stress Scale, 34 data sets for the Fantastic Lifestyle Assessment and 42 for the WHOQOL-BREF. The 4-week programme had the following complete datasets: 115 for the Perceived Stress Scale, 96 for the Fantastic Lifestyle Assessment questionnaire and 176 for the WHOQOL-BREF.

Means and standard deviations were calculated for each of the outcome measures at both T1 and T2. Table 1 displays these scores with the associated normative reference scores for adolescents where available. For the WHOQOL-BREF predata, there was one participant whose data were excluded as more than $20 \%$ of the questionnaire data were missing. There was only one instance that the mean domain score needed to be substituted for missing values to enable calculation. For the WHOQOL-BREF post data, data from three participants were excluded as more than $20 \%$ of the questionnaire data were missing. In five cases the mean domain score needed to be substituted for missing values to enable calculation: three in domain 1 (physical) and two in domain 2 (psychological). Increases in the physiotherapy students' mean scores across T1 and $\mathrm{T} 2$ were observed.
Repeated measures t-tests revealed that the Perceived Stress Scale scores increased significantly from $\mathrm{T} 1$ to $\mathrm{T} 2$ for the 4-week programme only, indicating higher levels of stress. The Fantastic Lifestyle Assessment measures increased significantly from T1 to T2 for the 4-week programme only, indicating a more positive lifestyle. The WHOQOL-BREF scores from T1 to T2, across both the physical and psychological domains, increased but not significantly for both the 3 and the 4-week programmes (Table 1).

The results of the survey evaluating the components of the Health Enhancement Programme including overall enjoyment of the programme are given in Figure 1. There were between 203-205 responses for each questionnaire item. Figure 2 shows the topics participants suggested they would like to spend more time exploring. Participants discussed the optimum duration of the Health Enhancement Programme: $2 \%$ no lectures or tutorials, $11.2 \% 1$ hour lecture and no tutorials, 48.8\% 1 hour lecture and 1 hour tutorial, 15.1\% 1 hour lecture and 1.5 hour tutorial, 3.9\% 1 hour lecture and 2 hour tutorials and $18.5 \%$ tutorial only.

\section{0}

I have found the mindfulness strategies useful

\section{8}

I enjoyed the Health Enhancement Program

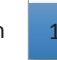

\begin{tabular}{|c|c|c|c|c|c|}
\hline 19 & \multicolumn{2}{|c|}{92} & 72 & 1471 & \\
\hline & 50 & 100 & 150 & 200 & 250 \\
\hline
\end{tabular}

Figure 1: Student experience of the Health Enhancement Programme

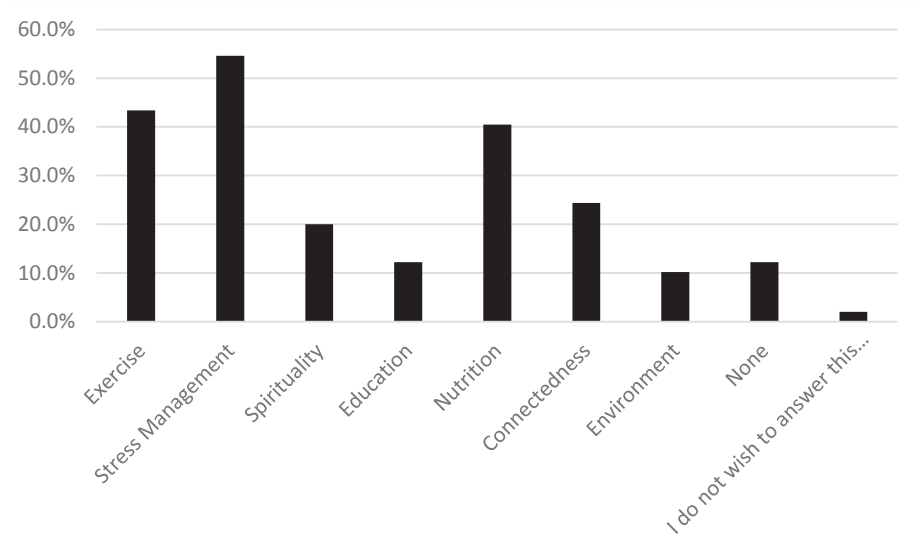

Figure 2: The ESSENCE topics that participants would have liked to spend more time exploring 
When asked what particular things participants enjoyed, there were six themes, seen in Figure 3 with respondent numbers provided in parentheses. Figure 4 indicates the nine themes identified by participants of the particular changes that could be made to improve the programme. Figure 5 summarises the nine themes under "other comments" made by participants.

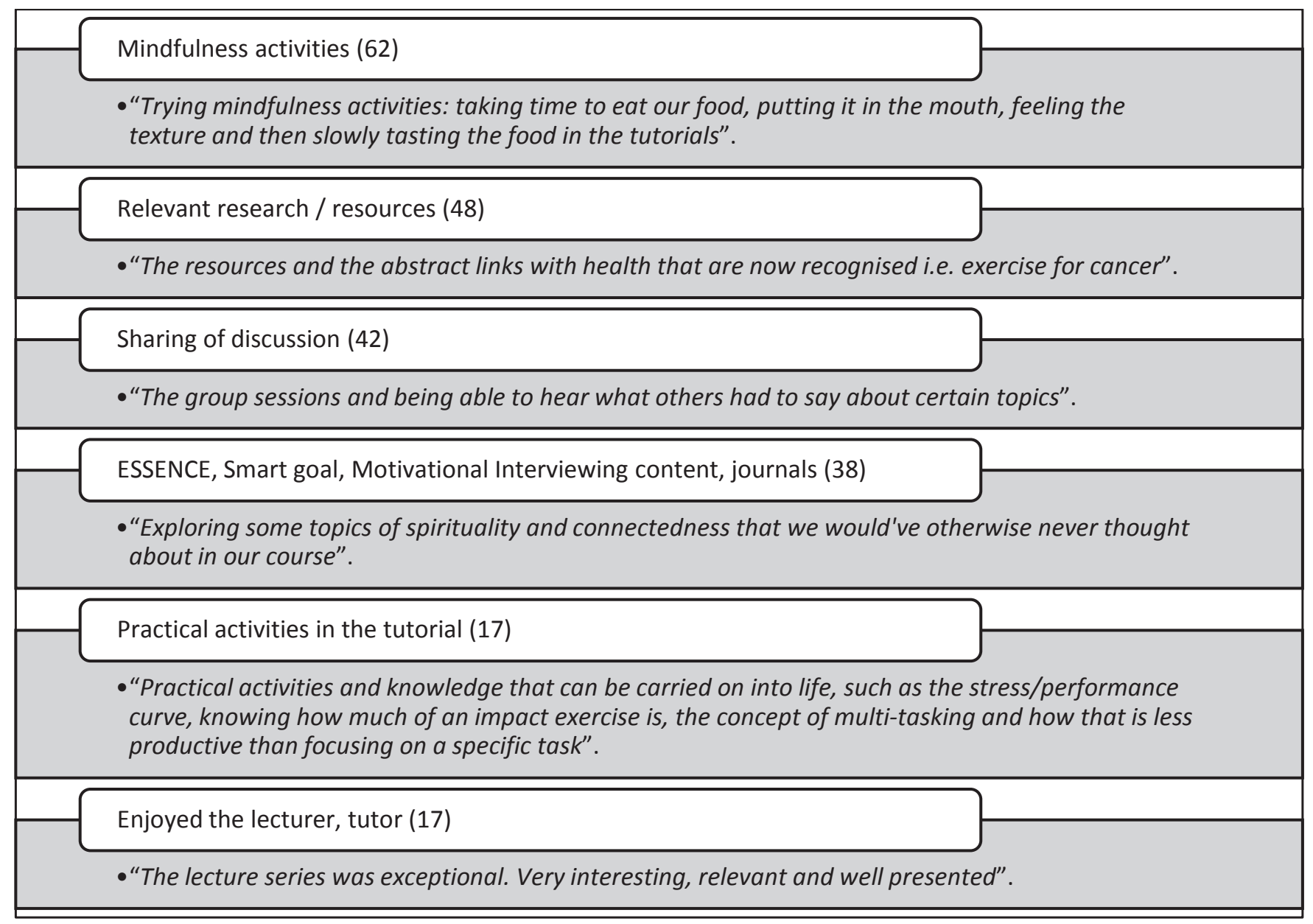

Figure 3: The particular things participants enjoyed (6 themes) 
Reduce lecture or tutorial time (56)

- "Lectures were great, would love to have more lectures and less tutorial time. The lectures themselves were thought provoking however the tutorials were a little bland."

More interactivity of lecture / tutorial (28)

- "More interactive lectures, at times it became hard to focus on what was being said, as we did not interact with the lecturer very much", "Make the tutorial more interactive with more activities rather than sitting and discussing for most of the tutorial".

\section{More content (17)}

- on self-help, stress management, nutrition, mindfulness, games, practice of skills, group discussion, Motivational Interviewing, examples of how ESSENCE relevant "More information on self-help areas to assist us in organisation as well as stress reduction. You are going to be stressed if you are unorganised".

Longer course (14)

- "Allow more weeks to the programme, four weeks felt as if it was all rushed and the programme ended before we actually got into it". "I feel the programme should run for longer as when it finished I was only just reaching the action phase. Not sure how I'll go in the future without someone to give me feedback".

More structured tutorial (5)

- "Shorter, more focused tutorials. I found some parts of the tutorials were just discussion of preexisting knowledge with very little learning of new information. More practise of application of the skills of Motivational Interviewing, establishing SMART goals, SOLVER* and ESSENCE would be good".

Smaller tutorial group (4)

- "Smaller tutorial groups to allow more individuals to contribute".

Change of day (4)

- "Don't have it on a Tuesday, do it on Friday in the break".

Change to the journal (3)

- "The journal questions that we were asked to answer did not seem useful seeing as it was not indicated that we were meant to actually practise the mindfulness exercises at home. If this had been specified at the beginning I feel I might have gotten more out of the program and noticed a change in my health..."

Change of environment (2)

- "Maybe hold the tutorials in a more comfortable room with tea/coffee/hot chocolate and biscuits kind of as a mini stress break throughout the week".

\section{Figure 4: Changes that could be made to improve the programme ( 9 themes)}

Note: *S.O.L.V.E.R is a way of facilitating communication and stands for Sitting squarely, Open posture, Lean into the client, Verbal reinforcements, Eye contact and Relaxed posture. 
Expertise of tutor / lecturer (13)

- "The spirituality component was a good topic and the tutors and lecturers mediated the discussion very well, not favouring a particular side or opinion, not putting down any religion, and having a broad and open view".

Thank you (13)

- "The programme is a welcome change in our timetable and it was incredibly enjoyable and beneficial".

Mindfulness (5)

- "HEP was overall a great unit and I found it very enjoyable. I especially liked the meditation component and learning about how to manage stress during exam times" and "Meditation sessions should be separate from tutorials and optional - it does not suit everyone".

Future value of the course (3)

-I see the value of this topic in a health profession".

Group dynamics (3)

- "It was really hard to be open and honest with such a large group. I felt naturally inclined to reject the help that was being given to me on the basis that I did not want other students to become aware of my personal emotional and physical state".

Duration of course (2)

- There were 2 comments on increasing the duration of the HEP "HEP is a fantastic programme. I strongly support the idea of it and am very impressed that Monash is providing such an initiative. I only wish it could have been run over a longer period".

Tutorial sessions (2)

- "Overall I think the concept of the HEP is a great idea, and something I'd like to continue learning about in future years. However, I would have liked the tutorials to be more practical".

Get to know you (2)

- "This programme is a great idea to promote individual learning and progress as individuals and it could also be a great bonding experience for the students and to get to know each other on a deeper level and bond too".

Good addition (2)

- "I liked how the approach was quite relaxed and therefore facilitated a relaxing environment. I think it is a good addition to the physiotherapy course".

Figure 5: Other comments provided by the participants ( 9 themes)

Note: HEP, Health Enhancement Programme 


\section{DISCUSSION}

Our study data demonstrated that the 3-week programme had an increase in Perceived Stress Score but this was not statistically significant. The 4-week programme had an associated significant increase in Perceived Stress Scale score indicating higher levels of stress. The 4-week programme had a significant increase in Fantastic Lifestyle Assessment score indicating a more positive lifestyle. This is a particularly encouraging finding given the post-test measures were taken towards the middle of semester when the assessment load was higher. We note that while a one point increase is statistically significant, this may not be a clinically significant change. Our findings differ to those of Carmody and Baer (2008) who demonstrated significant reductions in the Perceived Stress Scale scores in an 8-session Mindfulness Based Stress Reduction course for medical students. It is unknown however whether the timing of the post-assessment coincided with increased workload in the medical curriculum. Our findings highlight the importance of the timing of re-assessment with regards to assessment periods. Pre-post studies in an educational context where workload can interact with stress and coping, may be inappropriate and randomised controlled trials that take this into account are thus indicated. Erogul and colleagues (2014) completed a randomised controlled trial of 58 undergraduate medicine students taking an abridged 8-week Mindfulness Based Stress Reduction course versus a no-intervention control and found a significant reduction in Perceived Stress Scale score $(p=0.03)$. This reduction did not persist at six months post study.

Another mitigating factor in our study was the duration of the programme and it may be that a longer intervention is warranted. In the literature, the duration of mindfulness courses varied from 1 to 16 weeks with an average of 6 weeks (Lo et al., 2017). The Fantastic Lifestyle Assessment measures increased across the duration of the Health Enhancement Programme which was statistically significant for the 4-week programme. These data support that a 4-week programme is preferable to a 3-week programme in relation to impact on lifestyle. This finding however would need to be confirmed with a randomised controlled trial. The Fantastic Lifestyle Assessment tool has not been researched extensively and it has not been previously used to assess responses to wellbeing curriculum so we are unable to compare findings to current literature.

The WHOQOL-BREF scores increased across both the 3 and 4-week programmes indicating an increase in quality of life. This increase was however not statistically significant. A six week Health Enhancement Programme by Hassed and colleagues (2009) demonstrated a significant improvement in mean scores on the psychological domain of the WHOQOL-BREF scale and a trend towards improved physical health. These findings were assessed in the week prior to examination which was encouraging, however a randomised controlled trial is required to conclude that this positive change is in response to the programme.

In response to questions on participants' experiences of the Health Enhancement Programme, the majority thought that the tutorials and lectures were useful and interesting. The majority of students found the mindfulness strategies useful and anticipated that the mindfulness strategies would also be useful in the future. Chen (2013) asked participants to rate the effectiveness of the 7-day mindfulness meditation programme after the completion of the intervention. This was measured on a 10-point analogue scale, with " 1 " indicating that the programme provided no help at all and "10" indicating that the programme provided the maximum level of help. The average response was 5.2 with a standard deviation of 1.4. Jain and colleagues (2007) asked participants to evaluate the teacher and the environment in which the mindfulness sessions were conducted, however they found no significant differences between groups in response to these two variables. Other than these two examples, published programme evaluations by participants in response to randomised controlled trials of Mindfulness-Based wellness programmes were not found.

The top three topics that students wished to explore further were stress management, exercise and nutrition. The programme could thus be expanded to include further information on these topics. The majority of students preferred 1 hour lectures and 1 hour tutorials and a 3-week duration course, with 4 weeks as the second most preferred duration. This information can be used to inform the structure of the programme for a planned randomised controlled trial.

Participants provided valuable insights into the Health Enhancement Programme. The positive attributes were the mindfulness activities including relevant research in the lectures, sharing of discussion in the tutorials and the ESSENCE SMART goals. Motivational Interviewing content, journals and the practical activities in the tutorial were also deemed beneficial. Having interesting lecturers and tutors who gave good presentations was also important.

Improvements to the course were suggested which included reductions in the lecture or tutorial time and enhanced interactivity of the lectures and tutorials. Participants wished there to be more structured tutorials with content on self-help, stress management, nutrition, mindfulness including games, practise of skills, group discussion, Motivational Interviewing and relevant examples of ESSENCE. A number of students suggested that the programme duration be extended, and that the programme should be offered on a different day to align with the established lecture programme rather than on a day when no other lectures were scheduled. Suggestions of reduced tutorial group sizes were acknowledged, which may further facilitate discussion. The significance and content of the homework journal may have been more adequately introduced in the tutorial sessions. There were also suggestions of different environments for the tutorials that would support what was trying to be achieved by the programme.

\section{Limitations}

The number of data points for pre-post analysis across the Perceived Stress Scale and the Fantastic Lifestyle Assessment questionnaire was limited by including the item "I do not wish to answer" as one of the options in each questionnaire. This inclusion was to support ethics approval of the study. The WHOQOL-BREF had a protocol to manage missing data so the maximum number of datasets was achieved for this questionnaire. There were limited data on the 3-week 
programme as this was for one cohort of students only and this may have impacted the results. There were also simultaneous assessment tasks occurring during the Health Enhancement Programme which may impact on the results. In addition, this study followed students for a 3 or 4-week period only and thus conclusions regarding long-term benefits should be interpreted with caution. Participants in this study only included an Australian population of physiotherapy students and is limited by being a pre-post study with no control group.

Future research

Given the potential confounding variables such as curriculum assessment load, future recommendations include the need for high quality randomised controlled trials particularly investigating long-term effects of interventions. To optimise the quality of future research it is important to specify the eligibility of participants (for example: all first year students in the Bachelor of Physiotherapy programme). Random allocation to groups must be concealed from the researcher. Blinding of the assessors can be maintained by online completion of the outcome measures. Our calculated sample size was 126 participants. Given the participation rate was $40 \%$ we would need to use 315 participants (three cohorts of participants) for a randomised controlled trial. Given a systematic review found that there was a lack of literature investigating burnout, the Maslach burnout inventory (Maslach, Jackson, \& Leiter, 1986) may be indicated as an additional outcome measure or potential replacement for the Fantastic Lifestyle Assessment. Research may benefit from including records of student attendance and compliance with home practice to establish the potential confounding or influential effects this may have on outcomes. Studies may also benefit from selecting student participants rather than advertising for volunteers as volunteer participants may already be interested in the course content which may be a confounding variable. Agreement on consistent outcome measures including physiological measures of stress would be beneficial to enable pooling of data in meta-analysis. As strategies to support male students are limited (Regehr et al., 2013), gender would be particularly important to record. Application of the Health Enhancement Programme to further health professional student programmes would be a valuable extension of this study.

\section{CONCLUSION}

A 3-week brief wellness programme resulted in non-significant increases in Perceived Stress. A 4-week brief wellness intervention resulted in significant increases in the Perceived Stress Scale, indicating higher levels of stress, and a significant increase in Fantastic Lifestyle Assessment score, indicating a healthier lifestyle. The WHOQOL-BREF scores increased across both the 3 and 4-week programmes indicating increased quality of life, however this increase was not significant. Participants enjoyed the mindfulness (being aware of the present moment) activities, resources, sharing of discussion, content on healthy behaviours and goal setting. They also enjoyed practical activities in tutorials and interaction with the lecturer and tutorial staff. There were a number of suggested changes to the programme including changes to the lecture and tutorial timing and content, changes to the day and size of the tutorial groups, changes to the journal and to the environment in which the tutorials were held. It is suggested that randomised controlled trials be conducted to discern the effect of curriculum assessment load on programme outcome measures.

\section{KEY POINTS}

1. A brief wellness intervention resulted in a non-clinically significant increase in the Perceived Stress Score which coincided with increased assessment load during the semester.

2. Increases in the Fantastic Lifestyle Assessment scores indicate a healthier lifestyle.

3. To our knowledge this is the first documented wellness programme for physiotherapy students.

4. Qualitative data indicate areas for improvement in wellness courses in the health professions.

\section{DISCLOSURES}

No funding was obtained for the study. The authors report no conflicts of interest.

\section{ACKNOWLEDGEMENTS}

The physiotherapy students at Monash University and the tutors involved in the Health Enhancement Programme: Philip Stevens and Tania Dioniso. We acknowledge the traditional owners of the land on which this work occurred and pay our respects to their elders, past and present.

\section{ADDRESS FOR CORRESPONDENCE}

Kristin Lo, Department of Physiotherapy, Monash University Peninsula Campus Building B, McMahons Road Frankston, VIC, Australia 3199. Telephone: +61 39904 4137,

Email: Kristin.lo@monash.edu.

\section{REFERENCES}

Bennett, P., Lowe, R., Matthews, V., Dourali, M., \& Tattersall, A. (2001). Stress in nurses: coping, managerial support and work demand. Stress and Health, 17(1), 55-63. doi:10.1002/1532-2998(200101)17:1.

Braun, V., \& Clarke, V. (2006). Using thematic analysis in psychology. Qualitative Research in Psychology, 3(2), 77-101. doi:10.1191/1478088706qp063oa.

Carmody, J., \& Baer, R. A. (2008). Relationships between mindfulness practice and levels of mindfulness, medical and psychological symptoms and well-being in a mindfulness-based stress reduction program. Journal of Behavioral Medicine, 31(1), 23-33. doi: 10.1007/s10865-007-9130-7.

Chen, Y., Yang, X., Wang, L., \& Zhang, X. (2013). A randomized controlled trial of the effects of brief mindfulness meditation on anxiety symptoms and systolic blood pressure in Chinese nursing students. Nurse Education Today, 33(10), 1166-1172. doi:10.1016/j.nedt.2012.11.014.

Cohen, \& Williamson, G. (1988). Perceived stress in a probability sample of the United States (S. Spacapan \& S. Oskamp Eds. The Social Psychology of Health: The Claremont Symposium on Applied Social Psychology ed.: Newbury Park, California: SAGE Publications, Incorporated.

Cohen, S., \& Janicki-Deverts, D. (2012). Who's stressed? Distributions of psychological stress in the United States in probability samples from 1983, 2006, and 2009. Journal of Applied Social Psychology, 42(6), 1320-1334. doi:10.1111/j.1559-1816.2012.00900.x.

Dallender, J., Nolan, P., Soares, J., Thomsen, S., \& Arnetz, B. (1999). A comparative study of the perceptions of British mental health nurses and psychiatrists of their work environment. Journal of Advanced Nursing, 29(1), 36-43. 
Derogatis, L., Rickels, K., \& Rock, A. (1976). The SCL-90 and the MMPI: A step in the validation of a new self-report scale. The British Journal of Psychiatry, 128(3), 280-289.

DiClemente, C., Prochaska, J., \& Gibertini, M. (1985). Self-efficacy and the stages of self-change of smoking. Journal of Cognitive Therapy and Research, 9(2), 181-200.

Doran, G. (1981). There's a SMART way to write management's goals and objectives. Management Review, 70(11), 35-36.

Erogul, M., Singer, G., Mclntyre, T., \& Stefanov, D. (2014). Abridged mindfulness intervention to support wellness in first-year medical students. Journal of Teaching and Learning in Medicine, 26(4), 350-356.

Feskanich, D., Hastrup, J. L., Marshall, J., Colditz, G., Stampfer, M., Willett, W. C., \& Kawachi, I. (2002). Stress and suicide in the Nurses' Health Study. Journal of Epidemiology and Community Health, 56(2), 95-98.

Fjorback, L., Arendt, M., Ornbol, E., Fink, P., \& Walach, H. (2011). Mindfulness-based stress reduction and mindfulness-based cognitive therapy: a systematic review of randomized controlled trials. Acta Psychiatry Scandinavia, 124(2), 102-119. doi:10.1111/j.16000447.2011.01704.x.

Harper, A. (1998). Development of the World Health Organisation WHOQOLBREF quality of life assessment. Psychological Medicine, 28(3), 551-558.

Hassed, C., De Lisle, S., Sullivan, G., \& Pier, C. (2009). Enhancing the health of medical students: outcomes of an integrated mindfulness and lifestyle program. Advances in Health Sciences Education, 14(3), 387-398.

Hillhouse, J., \& Adler, C. (1997). Investigating stress effect patterns in hospital staff nurses: results of a cluster analysis. Social Science \& Medicine, 45(12) 1781-1788.

IsHak, W., Nikravesh, R., Lederer, S., Perry, R., Ogunyemi, D., \& Bernstein, C. (2013). Burnout in medical students: a systematic review. The Clinical Teacher, 10(4), 242-245. doi:10.1111/tct.12014.

Jain, S., Shapiro, S., Swanick, S., Roesch, S., Mills, P., Bell, I., \& Schwartz, G. (2007). A randomized controlled trial of mindfulness meditation versus relaxation training: effects on distress, positive states of mind, rumination, and distraction. Annals of Behavioral Medicine, 33(1), 11-21.

Kabat-Zinn, J. (2009). Wherever you go, there you are: Mindfulness meditation in everyday life. London, UK: Piatkus.

Lo, K., Waterland, J., Todd, P., Gupta, T., Bearman, M., Hassed, C., \& Keating, J. (2017). Group interventions to promote mental health in health professional education: A systematic review and meta-analysis of randomised controlled trials. Advances in Health Sciences Education, 1-35. doi:10.1007/s10459-017-9770-5.

Maslach, C., \& Jackson, S. E. (1981). The measurement of experienced burnout. Journal of Organizational Behavior, 2(2), 99-113.
Maslach, C., Jackson, S. E., \& Leiter, M. P. (1986). Maslach Burnout Inventory. Palo Alto.

Miller, W. R., \& Rollnick, S. (2012). Motivational Interviewing: Helping people change. New York, America: Guilford press.

Murphy, B., Herrman, H., Hawthorne, G., Pinzone, T., \& Evert, H. (2000). Australian WHOQoL instruments: User's manual and interpretation guide. Melbourne, Australia: Australian WHOQOL Field Study Centre.

National Heart Lung and Blood Institute. (2014). Quality assessment tool for before-after (pre-post) studies with no control group. Retrieved 8/6/17, from https://www.nhlbi.nih.gov/health-pro/guidelines/in-develop/ cardiovascular-risk-reduction/tools/before-after.

Nixon, P., Murray, R., \& Bryant, C. (1979). Stress Response curve. Retrived 8/6/17, from https://explorable.com/how-does-stress-affect-performance.

Regehr, C., Glancy, D., \& Pitts, A. (2013). Interventions to reduce stress in university students: a review and meta-analysis. Journal of Affective Disorders, 148(1), 1-11. doi: 0.1016/j.jad.2012.11.026.

Roberti, J. W., Harrington, L. N., \& Storch, E. A. (2006). Further psychometric support for the 10-item version of the perceived stress scale. Journal of College Counseling, 9(2), 135-147.

Seritan, A., Hunt, J, Shy A, Rea M, Worley, L. (2012). A call for culture change. Academic Psychiatry, 36 (7), 10.1176/appi.ap.10030042.

Stallman, H. M., \& Shochet, I. (2009). Prevalence of mental health problems in Australian university health services. Australian Psychologist, 44(2), 122 127.

Tully, A. (2004). Stress, sources of stress and ways of coping among psychiatric nursing students. Journal of Psychiatric and Mental Health Nursing, 11(1), 43-47.

Tyler, P., \& Cushway, D. (1998). Stress and wellbeing in healthcare staff: The role of negative affectivity, and perceptions of job demand and discretion. Stress and Health, 14(2), 99-107.

Walsh, J. M., Feeney, C., Hussey, J., \& Donnellan, C. (2010). Sources of stress and psychological morbidity among undergraduate physiotherapy students. Physiotherapy, 96(3), 206-212. doi: 10.1016/j. physio.2010.01.005.

Weissman, J., Pratt, L. A., Miller, E. A., \& Parker, J. D. (2015). Serious psychological distress among adults: United States, 2009-2013. NCHS data brief, 203, 1-8.

Wilson, D. M., \& Ciliska, D. (1984). Lifestyle Assessment. Canadian Family Physician, 30, 1527

World Health Organization. (1996). WHOQOL-BREF: introduction, administration, scoring and generic version of the assessment: field trial version, December 1996. Retrieved 8/6/17, from http://www.who.int/ mental_health/media/en/76.pdf. 


\section{Physiotherapy clinical education in Australia: Development and validation of a survey instrument to profile clinical educator characteristics, experience and training requirements.}

Clint Newstead BPhysio (Hons)

PhD candidate, Faculty of Health Science, The University of Sydney, Sydney, Australia.

Lecturer in Physiotherapy, School of Community Health, Charles Sturt University, Orange, Australia.

Catherine Johnston PhD, MAppSc (Cardioresp Physio), BAppSc (Physiotherapy)

Senior Lecturer and Clinical Education Manager, School of Health Sciences, The University of Newcastle, Newcastle, Australia.

Gillian Nisbet PhD, MMEd, DipNutr, BSc(Hons)

Senior Lecturer, Work Integrated Learning, Faculty of Health Science, The University of Sydney, Sydney, Australia.

Lindy McAllister PhD, MA(SpPath), BSpThy

Professor, Work Integrated Learning, Faculty of Health Science, The University of Sydney, Sydney, Australia.

\section{ABSTRACT}

Clinical education (also termed "clinical supervision") is essential for entry-level physiotherapy student training. Physiotherapists providing clinical education have a vital role in facilitating student learning and assessing performance, however research suggests that many assume this role due to willingness, availability or expectation rather than skills or experience. There is a lack of literature internationally describing the involvement of physiotherapists in clinical education, and currently no valid and reliable survey instrument with which to collect this information. The purpose of this study was to develop and validate a survey to explore physiotherapy clinical education in Australia. A draft online survey was developed and reviewed by expert physiotherapists, clinical education managers and clinical educators to ensure face and content validity. Following revision, physiotherapists employed in various healthcare facilities pilot-tested the survey. Survey utility and internal consistency were then evaluated. The final survey has 39 questions in five sections with categorical, Likert and free text response options. Internal consistency of the variables in the two Likert scale questions was acceptable (Cronbach's alpha: 0.98 and 0.97, respectively). A valid and reliable survey has been developed and can be used to profile the professional characteristics of physiotherapy clinical educators, perceived barriers and training requirements related to the provision of clinical education.

\section{Newstead, C., Johnston, C., Nisbet, G., McAllister, L. Physiotherapy clinical education in Australia: Development and validation of a survey instrument to profile clinical educator characteristics, experience and training requirements. New Zealand Journal of Physiotherapy (45(3): 154-169. doi:10.15619/NZJP/45.2.07}

Key words: Physiotherapy, Clinical education, Health educators, Surveys, Questionnaires

\section{INTRODUCTION}

Clinical education is an essential component of all entrylevel physiotherapy training programmes including, bachelor graduate-entry masters and doctoral degrees (World Confederation for Physical Therapy (WCPT), 2011). Physiotherapy clinical education provides an opportunity for entry-level students to apply theoretical concepts and skills acquired at university to 'real-life' situations with patients and team members (Buccieri, Pivko \& Olzenk, 2011; Jette, Nelson \& Wetherbee, 2014; Patton, Higgs \& Smith, 2013; WCPT, 2011; Wetherbee, Buccieri, Fitzpatrick, Timmerberg \& Stolfi, 2014) and is necessary to prepare students to enter the workforce as competent health professionals (Crosbie et al., 2002; Delany \& Bragge, 2009; Ernstzen, Bitzer \& Grimmer-Somers, 2010; Giles, Wetherbee \& Johnson, 2003; WCPT, 2011). In Australia and New Zealand, the structure and duration of clinical education is similar across all entry-level physiotherapy training programmes and students are evaluated using a common assessment tool against the same standards of practice (Australian Physiotherapy
Council (APC), 2016a; Crosbie et al., 2002; Dalton, Davidson, \& Keating, 2011; McAllister \& Nagarajan, 2015). Typically in Australia, physiotherapy students undertake clinical placements in five week blocks in a variety of clinical settings, such as public and private hospitals, private practices and community based facilities. During these clinical education placements, students are responsible for managing people across the lifespan with musculoskeletal, neurological or cardiorespiratory pathology under the supervision and instruction of a qualified physiotherapist, commonly referred to as a clinical educator (Fish, Pickering \& Hagler 2005; WCPT, 2011). In the discipline of physiotherapy, clinical educators (Australian terminology, in this instance, as often termed "clinical supervisors" in New Zealand) play a vital role in facilitating learning of physiotherapy students through the provision of clinical training, supervision and assessment of competence to practise (Ernstzen et al., 2010; Greenfield et al., 2012; Best, 2005).

Over the past decade there has been a large increase in the number of tertiary institutions offering entry-level physiotherapy 
programmes within Australia and internationally (Bennett, 2003; McMeeken, Grant, Webb, Krause \& Garnett, 2008 Rodgers, Dunn \& Lautar, 2008). This has resulted in an overall rise in the total number of physiotherapy students (Crosbie et al., 2002, Dean et al., 2009, Johnston, Newstead, Sanderson, Wakely \& Osmotherly, 2016; McMeeken et al., 2008), with a $34 \%$ increase in the number of students enrolled in approved physiotherapy training programmes in Australia between 2011 and 2013 alone (Health Workforce Australia (HWA), 2014). As a consequence, the demand for physiotherapy clinical placements has also increased (Bennett, 2003; Edgar \& Connaughton, 2014; Johnston et al., 2016; McMeeken et al., 2008) and is recognised by physiotherapy professional organisations as a key challenge facing the workforce (Australian Physiotherapy Association (APA), 2015). It is currently not clear how the increasing demand for clinical placements is being met by physiotherapists employed in clinical settings. In recent years, some changes have occurred with respect to the structure and delivery of clinical education, including changes in the ratio of students allocated to clinical educators and the introduction of simulated learning experiences, which may assist in meeting the rising demand for physiotherapy clinical placements (Blackstock et al, 2013; Currens, 2003; Lekkas et al, 2007; Moore, Morris, Crouch \& Martin, 2003; Watson et al, 2012). In addition to these changes, it is also possible that physiotherapists already involved in clinical education are more frequently providing experiences for physiotherapy students (Bennett, 2003), or that physiotherapists are assuming a clinical educator role earlier in their career (Rogers, Lautar \& Dunn, 2010). Previous research suggests that some physiotherapists are involved in clinical education due to willingness, availability or as a job expectation rather than because of demonstrated skills, experience and confidence in facilitating student learning (McMeeken, 2008; Öhman, Hägg \& Dahlgren, 2005; Rodger et al., 2008; Rodgers et al, 2008; Sevenhuysen \& Haines, 2011). Although not thoroughly investigated, a rising demand for clinical education placements, and increasing reliance on a range of physiotherapists to assume the role of a clinical educator, might impact upon the overall quality of clinical experiences and student learning outcomes. This could be related to inexperience and a lack of confidence in the provision of varying aspects of clinical education, such as clinical instruction, providing feedback and assessment.

To maintain the quality of clinical education experiences, it is imperative that physiotherapists involved in clinical education are adequately prepared for, and supported in, their role (Higgs \& McAllister, 2007; McAllister, Blithell \& Higgs, 2010; ReckerHughes, Mowder-Tinney \& Pivko, 2010). One method of ensuring this is to provide effective training regarding clinical education and supervision, particularly for novice clinical educators (Currens \& Bithell, 2000; Edgar \& Connaughton, 2014; Greenfield et al., 2014; Higgs \& McAllister, 2005; Jarski, Kulig \& Olson, 1990; Öhman et al., 2005; Recker-Hughes et al., 2010). In Australia and New Zealand, clinical education training resources are available through individual workplaces, universities and professional organisations, such as the Australian Health Education Training Institute (HETI). However the content of these materials, and mode of delivery, are often generic and participation is not mandatory for physiotherapists in Australia or New Zealand prior to becoming a clinical educator. Available training programmes and materials related to clinical education may not be targeted to the individual skill levels of physiotherapists with respect to clinical education, or the needs of physiotherapists based on factors such as work type, setting and geographical location. In addition, it is not clear if current methods of training are effective in developing the clinical education skills of physiotherapists, particularly novice clinical educators, or if training methods impact on student learning and assessment outcomes in the clinical setting.

At present, little is known about the characteristics of physiotherapists involved in student clinical education in Australia or New Zealand, including their professional qualifications, clinical and clinical education experience, and perceived training needs regarding entry-level physiotherapy student clinical education. A comprehensive review of published literature identified a limited number of studies exploring the professional characteristics and experience of physiotherapists involved in student clinical education (Buccieri et al., 2006; Giles, Wetherbee \& Johnson, 2003; Morren, Gordon \& Sawyer, 2008). These publications present data obtained from cross-sectional surveys of clinical educators affiliated with physiotherapy training programmes in various locations within the United States of America. Findings from these studies cannot necessarily be extrapolated to physiotherapy clinical educators in Australia or New Zealand due to differences in the structure of entry-level physiotherapy clinical education, the assessment of entry-level students in the clinical setting, and the availability and content of training opportunities relating to physiotherapy clinical education. No similar literature focusing on the professional characteristics, experience and training requirements of physiotherapists involved in clinical education in Australia or New Zealand was identified.

To ensure that physiotherapists are adequately prepared to be clinical educators, and optimise the quality of clinical education experiences, it is necessary to gain an understanding of contemporary clinical education practices. At present, no published validated survey instrument exists to obtain detailed information regarding clinical education from the physiotherapy workforce in Australia or New Zealand. Surveys used to gather similar data in the United States of America (Buccieri et al., 2006; Giles et al., 2003; Morren et al., 2008) have not been validated for use with the Australian or New Zealand physiotherapy workforce, and the content is not relevant to this population due to differences in the structure of clinical education and available training opportunities. Therefore the purpose of this study was to develop and validate a survey instrument to profile physiotherapy clinical education initially in Australia, including: the professional characteristics of physiotherapists; barriers preventing involvement in clinical education and training requirements relating to entry-level student clinical education.

\section{METHODS}

This research project was conducted between October 2015 and June 2016 and occurred in three discrete stages (presented in Figure 1) based on published literature relating to survey development and validation (Keszei, Novak \& Streiner, 2010; 
Liamputtong, 2010; Sarantakos, 2005; Streiner, Norman \& Cairney, 2014): (i) survey item development and expert review; (ii) survey face and content validity testing; (iii) survey utility and internal reliability testing. The proposed methodology was deemed appropriate to ensure the developed survey instrument adequately covered the intended scope of interest, would produce reliable information and would be sufficient to describe the professional characteristics, experience and training requirements of physiotherapists regarding student clinical education (Liamputtong, 2010; Streiner et al., 2014).

\section{STAGE 1: Survey item develpment and expert review}

Draft survey instrument developed by research team Expert review

Expert physiotherapists ( $n=3$ )

Emailed draft survey instrument

Feedback regarding survey content, format, length and topic coverage
Ethics approval was received from the University of Sydney (Reference no. 2015/785) and Northern Sydney Central Coast Local Health District (LNR/16/HAWKE/147) Human Research Ethics Committees.

\section{STAGE 2: Survey face and content validity testing}

Physiotherapy clinical education managers $(n=6)$

Physiotherapy clinical educators $(n=1)$

Emailed invitation with hyperlink to online draft survey

Review of online survey (REDCap' ${ }^{\mathrm{TM}}$ )

Feedback on survey item relevance and topic coverage

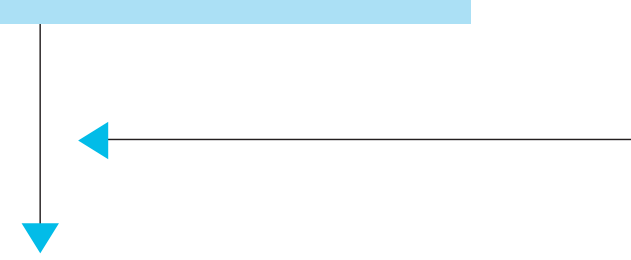

Data analysis and survey revision

\section{STAGE 3: Survey utility and internal reliability testing}

Physiotherapists employed clinically $(n=30)$

Emailed invitation with hyperlink to online survey

Completed online survey (REDCap' ${ }^{\mathrm{TM}}$ ) 
Stage 1: Survey item development and expert review

\section{Participants}

Draft survey items were based on gaps in current literature and developed by a multi-professional research team with professional backgrounds in physiotherapy, speech pathology and nutrition and dietetics. All members of the research team had prior experience in entry-level student clinical education and clinical educator training. Following development of the draft survey items, a convenience sample of three physiotherapists was selected to review these items and overall survey structure. The selected physiotherapists were known to the research team and were chosen due to their past experience of greater than ten years facilitating student learning in clinical and academic settings. In an attempt to minimise bias associated with this convenience sample, the physiotherapists chosen differed with respect to gender, physiotherapy qualifications, workplace and setting and geographical location (public healthcare facilities and a tertiary education institution across metropolitan and regional areas of New South Wales, Australia).

\section{Data collection}

A single email invitation containing a copy of the draft survey items was sent to all three physiotherapists by a member of the research team. These physiotherapists were asked to review the draft survey items and provide feedback via reply email regarding question format, survey content and survey structure, including the overall length of the draft survey instrument.

\section{Data analysis}

Written response data provided by the expert physiotherapists were collated and reviewed by the research team. Based on this feedback a draft survey instrument was created in online format using Research Data Capture (REDCap ${ }^{\mathrm{TM}}$ ), a web-based application hosted at the University of Sydney (Harris et al., 2009). The developed draft survey instrument consisted of 38 questions in five sections: demographic data; work type and location; experience and opinions regarding physiotherapy clinical education; physiotherapy clinical educator training and general comments. Survey item responses included a combination of closed categorical questions (for example, participant demographics), Likert scale items (relating to participant experience and confidence in various aspects of clinical education) and free-text response options. The developed draft survey instrument, in online format, was subject to further review to ensure face and content validity. Establishing face and content validity of the survey instrument was deemed necessary to ensure the survey content adequately covered aspects of clinical education relating to the professional characteristics of physiotherapists, barriers preventing involvement in clinical education and training requirements relating to entry-level student clinical education (Imms \& Greaves, 2010).

Stage 2: Survey face and content validity testing

\section{Participants}

A sample of academic physiotherapy clinical education managers (ACEM) and physiotherapy clinical educators (CE) were selected to participate in face and content validity testing of the draft online survey instrument. Physiotherapy ACEM participants were employees of Australian universities delivering physiotherapy training programmes. The contact details of the ACEM participants $(n=6)$ were obtained from individual university websites. In Australian states or territories with more than one entry-level physiotherapy training programme, one ACEM from one university was randomly selected to participate.

Physiotherapy CE participants were purposefully selected from a university database of physiotherapists regularly involved in clinical education for entry-level physiotherapy students. To ensure a representative sample of physiotherapy participants, the following selection criteria were used: a male and female physiotherapist, working in public and private healthcare facilities across metropolitan and regional areas of Australia $(n=6)$.

\section{Data collection}

An email invitation was sent to selected physiotherapy ACEMs $(n=6)$ and CEs $(n=6)$ inviting them to participate in the face and content validity testing of the survey instrument. This email invitation contained a participant information statement, a brief explanation of the research project including the survey aims, and a link to the online survey instrument. Participants were asked to indicate whether or not they thought each individual survey item was relevant to the topic and if it should be included in the final survey instrument. Participants were asked to provide written feedback on each survey item and explain why they thought any item should be excluded. A free text section was also provided for participants to give general feedback on any aspect of the survey instrument. A single reminder email was sent two weeks following the initial email invitation. All responses were anonymous.

Data analysis

A matrix of participant responses was created and any survey items identified by participants as not being relevant to the overall project aims, along with corresponding written comments, were reviewed by the research team. Consensus of all members of the research team was required prior to excluding or amending any individual survey item. Following data analysis a revised draft survey instrument was created and hosted online using REDCap ${ }^{\mathrm{TM}}$ (Harris et al., 2009).

Stage 3: Survey utility and internal reliability testing

\section{Participants}

The revised draft survey instrument was subject to online testing to evaluate the utility of the instrument and interitem consistency of survey scale items (Streiner et al., 2014; Liamputtong, 2010). A sample of physiotherapists ( $n=97)$ employed in public and private healthcare facilities were invited to participate in pilot testing the online survey instrument. To ensure that physiotherapists were represented from differing workplaces, convenience sampling was used to select healthcare facilities from one Australian state (New South Wales) and included two private physiotherapy practices and two public hospital facilities, including associated community physiotherapy services. Each of these facilities were located in metropolitan and regional areas.

\section{Data collection}

Publicly available sources were used to obtain the contact details of the managers of the physiotherapy private practice 
and hospital facilities. Managers of these facilities distributed an invitation to participate in pilot testing of the anonymous online survey instrument, on behalf of the research team, to all physiotherapists employed at their healthcare facility. Each invitation contained a participant information statement and a link to the survey instrument, hosted on REDCap ${ }^{\mathrm{TM}}$ (Harris et al., 2009) software. Participants were instructed to access and read the information statement and complete the anonymous online survey instrument. A reminder email was sent by the same means to all participants two weeks and four weeks following the initial invite.

\section{Data analysis}

Final pilot survey data were transferred from REDCap ${ }^{\mathrm{TM}}$ (Harris et al., 2009) to SPSS software (Version 20.0. Armonk, NY: IBM Corp) for further analysis. All closed categorical response options were reviewed to determine if any responses were consistently omitted from any individual survey item. Free text responses were reviewed to ensure that written data were relevant to the question in terms of providing an appropriately positively or negatively framed response based on individual attitudes or beliefs. For the survey items consisting of Likert scale items, an inter-item correlation matrix was developed and each subscale analysed to ensure a Cronbach's alpha coefficient of greater than 0.7 (Nunnally \& Bernstein, 1994).

\section{RESULTS}

Stage 1: Survey Item development and expert review All three expert physiotherapists invited to review the original draft survey items provided feedback to the research team. Minor suggestions were made regarding wording for clarity; for example, one physiotherapist suggested the addition of an introductory paragraph at the commencement of sections two and three of the survey instrument to define a 'primary physiotherapy role', an 'entry-level physiotherapy student' and the role of a 'primary physiotherapy clinical educator'. In addition, two physiotherapists suggested incorporating extra response options for categorical questions in section four of the survey relating to physiotherapy clinical education training. For example, one physiotherapist suggested the addition of a single response option to a question asking participants to indicate why they had not participated in any additional training related to clinical education post-graduation. All changes suggested by the expert physiotherapists were made accordingly, none of the physiotherapists suggested the removal of any individual survey item, and only one participant recommended the addition of a question asking participants to provide the postcode of their workplace. This question was incorporated to allow more thorough analysis of participant responses based on geographical location. The experts invited to review the survey instrument indicated that the survey structure was logical and of appropriate length with an estimated a completion time of 15 to 20 minutes.

\section{Stage 2: Survey face and content validity testing} Six physiotherapy ACEMs (100\%) and one physiotherapy CE $(17 \%)$ reviewed the survey to evaluate the face and content validity. Responses consisted primarily of written feedback relating to wording of survey items for clarity and suggestions for expansion of categorical question response options. For example, some physiotherapy ACEM participants suggested the addition of free text response options to allow participants to elaborate on training they had previously received relating to clinical education, barriers to accessing training opportunities and content to be included in the development of future training programmes. These changes were made to the relevant survey item responses as suggested.

A small number of participants questioned the relevance of the survey items relating to participant demographic and workplace information in sections one and two of the draft survey, for example, questions relating to participant post graduate qualifications, current work status, and location of workplace by Australian state or territory. All questions were discussed by the research team and a collective decision made to retain all demographic items in the final survey instrument to allow for thorough exploration of the professional characteristics of physiotherapists involved in physiotherapy student clinical education, consistent with the overall aims of the survey instrument.

Stage 3: Survey utility and internal reliability testing The demographic data relating to participant characteristics for Stage 3: Survey utility and internal reliability testing are presented in Table 1. Thirty physiotherapists participated in pilot testing the survey instrument, with an overall response rate of $32 \%$. The mean age of participants was 33 years (SD 10 years), with a mean of 11 years (SD 8 years) of experience working as a physiotherapist in a clinical setting. The majority of physiotherapists were employed in public hospital facilities in metropolitan and regional areas of New South Wales, Australia.

Review of participant responses indicated that the survey instrument was functioning as intended in its online format with respect to access via the survey hyperlink, data format rules and 'skip logic' functions. Review of written response data indicated that all questions were interpreted appropriately. In total, 29 (94\%) returned surveys were completed in full, suggesting the survey length and content was appropriate. Across all questions requiring a closed categorical response, only seven questions yielded missing data, amounting to a total of 15 (1\%) omitted data points. The highest rate of missing data was observed for question 7 (asking participants to indicate the number of years they had worked as a physiotherapist in a clinical role), with no response from four participants (13\%). Only one response was missing from a single Likert sub-item in one survey question. All data provided in the free text sections were consistently relevant to the corresponding survey item, with no misinterpretation of any individual question based on response. Written responses were provided by more than $63 \%$ of participants $(n=19)$ for each question requiring a free text response.

Item-total correlation for the 16 Likert scale items in questions 25 and 26, relating to participants' 'experience' and 'confidence' with various components of clinical education ranged from 0.79 to 0.96 and 0.73 to 0.92 , respectively. Likewise, the sixteen Likert scale items in questions 25 and 26 demonstrated 'excellent' internal reliability (Nunnally \& Bernstein, 1994) with an overall Cronbach's alpha coefficient of 0.98 and 0.97 , respectively. No individual Likert sub-items were removed from either question 25 or 26 of the survey instrument. 
Table 1: Stage 3: Survey utility and internal reliability testing - Participant characteristics.

\begin{tabular}{|c|c|}
\hline Respondent characteristics & $n(\%)$ \\
\hline \multicolumn{2}{|l|}{ Gender } \\
\hline Female & $17(57)$ \\
\hline Male & $13(43)$ \\
\hline \multicolumn{2}{|l|}{ Entry-level physiotherapy qualification } \\
\hline Bachelor degree & $26(87)$ \\
\hline Graduate-entry Masters & $4(13)$ \\
\hline \multicolumn{2}{|l|}{ Post-graduate qualification } \\
\hline Graduate diploma & $1(3)$ \\
\hline Coursework masters & $3(10)$ \\
\hline None & $24(80)$ \\
\hline Missing & $2(7)$ \\
\hline \multicolumn{2}{|l|}{ Location of entry-level training } \\
\hline Australia & $30(100)$ \\
\hline \multicolumn{2}{|l|}{ Employment status } \\
\hline Full time & $26(87)$ \\
\hline Part time & $4(13)$ \\
\hline \multicolumn{2}{|l|}{ Primary job classification } \\
\hline Clinician & $26(87)$ \\
\hline Administrator & 1 (3) \\
\hline Educator/teacher & $3(10)$ \\
\hline \multicolumn{2}{|l|}{ Primary work setting } \\
\hline Private practice & $8(27)$ \\
\hline Hospital (inpatient service) & $17(57)$ \\
\hline Hospital (outpatient service) & $5(17)$ \\
\hline Rehabilitation service & $1(3)$ \\
\hline Educational facility & $1(3)$ \\
\hline Community health service & $2(7)$ \\
\hline \multicolumn{2}{|l|}{ Population of primary workplace location } \\
\hline Less than 5000 people & 1 (3) \\
\hline Between $5001 \& 10000$ people & 1 (3) \\
\hline Between $10001 \& 25000$ people & $0(0)$ \\
\hline Between $25001 \& 100000$ people & $18(64)$ \\
\hline Greater than 100000 people & $10(30)$ \\
\hline \multicolumn{2}{|c|}{ Classification of workplace location (MMM)* } \\
\hline MMM1 & $18(60)$ \\
\hline MMM3 & $12(40)$ \\
\hline
\end{tabular}

Note: *MMM=Modified Monash Model classification (1 - 7) of geographical location.

\section{DISCUSSION}

The outcome of this study is the development of a valid and reliable survey instrument (Appendix 1). To the authors' knowledge, this is the first published valid and reliable survey instrument which can be used to gather data regarding: the professional profile of physiotherapists in Australia, their experience in entry-level physiotherapy student clinical education, barriers to providing clinical education experiences and perceived training needs relating to clinical education. The survey instrument was developed with input from a multiprofessional research team, based on gaps in current literature and utilising published recommendations for survey item development and evaluation (Liamputtong, 2010; Streiner et al., 2014). The final survey instrument, consisting of 39 questions in five sections, is user-friendly, easily comprehensible and of appropriate length and content for use with Australian physiotherapists.

The methodology used to develop and validate the survey instrument was rigorous and based on a classical test theory process (Liamputtong, 2010) and published literature describing survey instrument validation (Liamputtong, 2010; Streiner et al., 2014). In accordance with author recommendations, the project occurred in several well defined stages including survey item creation, expert review, and pilot testing prior to the formulation of a final survey instrument (Sarantakos, 2005). Individual survey items and corresponding response options were extensively reviewed and revised to minimise measurement error, with careful consideration given to the overall survey length and structure in order to enhance utility (Liamputtong, 2010). Face and content validity of the survey instrument, along with internal consistency of survey items, were evaluated using response data from a cross section of physiotherapists from one Australian state where initial survey dissemination is planned. In addition, comparisons can be made between the participants in the pilot testing stage of the research project and the physiotherapy workforce in Australia in terms of gender, age, years of physiotherapy clinical experience and physiotherapy qualifications attained (Australian Institute of Health and Welfare (AlHW), 2014; Australian Government Department of Health National Health Workforce Dataset (NHWDS), 2015). Although most respondents in the survey pilot testing phase were employed in public hospitals, responses were obtained from physiotherapists in a range of work settings including outpatient, rehabilitation, community, educational and private practice facilities

The development and validation of a survey instrument relating to physiotherapy clinical education is likely to be of interest to physiotherapists, and other allied health professionals, employed in academic and clinical education management roles at tertiary education institutions in Australia and by association, New Zealand. As highlighted in published literature, obtaining information regarding the professional profile of physiotherapists involved in the clinical education of entry-level students is essential in order to provide training and support relevant to the needs of clinical educators (Crosbie et al., 2002), and the survey instrument developed from this study can be used by tertiary institutions for this purpose. Information obtained from completion of this survey instrument will 
provide a greater insight into the professional characteristics of physiotherapists currently involved in student clinical education, along with those who are planning on becoming involved in clinical education in the future. Furthermore, invaluable information regarding the barriers to accessing physiotherapy clinical educator training, such as associated cost, travel, time and knowledge of training opportunities, will be obtained. Collecting this information will assist in improving the quality of physiotherapy clinical education experiences available for entrylevel physiotherapy students through the provision of targeted training and support for physiotherapists involved in clinical education.

Although the survey instrument has been developed and validated for dissemination amongst Australian physiotherapists, globally clinical education is a common element of all health professional education programmes (Patton et al., 2013), and the results of this research may be of interest to physiotherapists internationally, as well as other allied health professionals. The survey instrument could be adapted in the future to explore the professional characteristics, experience and training requirements of clinical educators in different health professions and geographical locations, including New Zealand. Collecting information related to clinical education in different health professions and geographical locations would enable comparison of clinical education practices and training needs. This information could assist in the development of novel support and training models for individual health professions, or the development of multi-professional training resources based on common needs.

\section{Limitations}

The main limitation of this research project was that a small sample of physiotherapists from only one Australian state were invited to pilot test the survey instrument. However, in Australia the standards of physiotherapy practice and entrylevel physiotherapy training are regulated nationally by the Australian Physiotherapy Council (APC) (APC 2016a; APC, 2016b; HWA, 2014). Furthermore the practice thresholds for physiotherapists are the same for Australia and New Zealand ensuring consistency in physiotherapy standards, and entrylevel physiotherapy student training, across Australia and New Zealand (Physiotherapy Board of Australia and Physiotherapy Board of New Zealand, 2015). In addition, physiotherapists involved in pilot testing the survey instrument were employed in public and private healthcare facilities in metropolitan and regional areas and are likely to be representative of the final survey target population.

\section{CONCLUSION}

A valid and reliable survey instrument has been developed with input from a multi-professional research team and following extensive review by a range of physiotherapists. The survey instrument will be used to gather information relating to the professional characteristics, experience and training requirements of Australian physiotherapists regarding entry-level student clinical education. Information obtained from future research projects utilising this survey will assist in addressing gaps in published literature regarding the involvement of physiotherapists in entry-level student clinical education. In addition, the data collected from Australian physiotherapists using this survey could form the foundation of further research into the preparation of physiotherapists for the role of a clinical educator.

\section{KEY POINTS}

1. Clinical education is an essential component of all entrylevel physiotherapy training programmes. During clinical education experiences, students are supervised by qualified physiotherapists commonly referred to as a clinical educators. Clinical educators play a vital role in the provision of student clinical training and assessment of competence.

2. Due to an increasing number of students enrolled in entrylevel training programmes, the demand for physiotherapists to participate in clinical education is also increasing. There is a need to explore the professional profile of physiotherapists in Australia and New Zealand, including: their involvement in entry-level physiotherapy student clinical education, participation in training relating to student clinical education, barriers to accessing available training opportunities and perceived training needs.

3. No published validated survey instrument exists to obtain information from Australian physiotherapists regarding their professional characteristics, experience and training requirements. This study describes the processes of developing a valid survey instrument which can be used to gather this information.

\section{DISCLOSURES}

No funding was received for any part of this research project. The authors declare no conflicts of interest.

\section{ACKNOWLEDGEMENTS}

The authors would like to acknowledge and thank the administration staff in Work integrated Learning, Faculty of Health Sciences, The University of Sydney for assisting with this research project.

\section{ADDRESS FOR CORRESPONDENCE}

Clint Newstead, Faculty of Health Science, The University of Sydney, 75 East Street Lidcombe, Sydney, NSW, 2141, Australia. Telephone: +61 26365 7588. Email: cnew3956@uni.sydney. edu.au.

\section{REFERENCES}

Australian Government Department of Health: Health Workforce Data (2015). National Health Workforce Dataset (NHWDS) Physiotherapy 2015. Retrieved from http://data.hwa.gov.au/webapi/customer/documents/ factsheets/Physiotherapy\%20-\%202015.pdf. [Accessed 19/07/2017].

Australian Institute of Health and Welfare (AIHW). (2014). Physiotherapy Workforce. Retrieved from http://www.aihw.gov.au/workforce/ physiotherapy/. [Accessed 19/07/2017].

Australian Physiotherapy Association (APA). (2015). InPublic 2025: The future of physiotherapy in the health system. Retrieved from http://physiotherapy. asn.au/DocumentsFolder/APAWCM/Resources/PublicPractice/ InPublic_2025_updated\%20150925.pdf. [Accessed 19/07/2017]

Australian Physiotherapy Council (APC). (2016a). Accreditation of entry-Level physiotherapy programs guide for education providers. Retrieved from https://physiocouncil.com.au/media/1192/accreditationguide-2016-08122015.pdf. [Accessed 19/07/2017]. 
Australian Physiotherapy Council (APC). (2016b). Accreditation standard requirements 2016. Retrieved from https://physiocouncil.com.au/ media/1209/accreditation-standard-requirements-20052016.pdf. [Accessed 19/07/2017].

Bennett, R. (2003). Clinical Education: Perceived abilities/qualities of clinical educators and team supervision of students. Physiotherapy, 89(7): 432-40. doi: 10.1016/S0031-9406(05)60077-6

Best D. (2005). Exploring the roles of the clinical educator. In: Rose M., Best D. (Ed). Transforming practice through clinical education, professional supervision and mentoring. (pp 45-48). Edinburgh, United Kingdom: Elsevier Churchill Livingstone.

Blackstock F.C., Watson K.M., Morris N.R., Jones A., Wright A., McMeeken J.M., Rivett D.A., O'Connor V., Peterson R.F., Haines T.P., Watson G., Jull G.A. (2013). Simulation can contribute a part of cardiorespiratory physiotherapy clinical education: two randomized trials. Simulation in Healthcare, 8(1): 32-42.

Buccieri K.M., Schultze K., Dungey J., Kolodziej T., Malta S., Marocco S. Michaels J.A., Stolove R. (2006). Self-reported characteristics of physical therapy clinical instructors: a comparison to the American Physical Therapy Association's guidelines and self-assessments for clinical education. Journal of Physical Therapy Education, 20(1): 47-55

Buccieri K.M., Pivko S.E., Olzenak D.L. (2011). How does a physical therapist acquire the skills of an expert clinical instructor? Journal of Physical Therapy Education, 25(2): 17-25.

Crosbie J., Gass E., Jull G., Morris M., Rivett D., Ruston S., Sheppard L., Sullivan J., Vujnovich A., Webb G., Wright T. (2002). Sustainable undergraduate education and professional competency. Australian Journal of Physiotherapy, 48(1): 5-7. doi: 10.1016/S0004-9514(14)60276-2.

Currens J.B. (2003). The 2:1 clinical placement model: Review. Physiotherapy, 89(9): 540-554

Currens J.A.B., Bithell C.P. (2000). Clinical education: listening to different perspectives. Physiotherapy, 86(12): 645-53. doi: 10.1016/S00319406(05)61302-8.

Dalton, M., Davidson, M., \& Keating, J. (2011). The Assessment of Physiotherapy Practice (APP) is a valid measure of professional competence of physiotherapy students: a cross-sectional study with Rasch analysis. Journal of Physiotherapy, 57(4), 239-246.

Dean C.M., Stark A.M., Gates C.A., Czerniec S.A., Hobbs C., Bullock L.L.D., Kolodziez I. (2009). A profile of physiotherapy clinical education. Australian Health Review, 33(1): 38-46. doi: 10.1071/AH090038.

Delany C., Bragge P. (2009). A study of physiotherapy students' and clinical educators' perceptions of learning and teaching. Medical Teacher, 31(9): e402-e11. doi: 10.1080/01421590902832970.

Edgar S., Connaughton J. (2014). Exploring the role and skill set of physiotherapy clinical educators in work integrated learning. Asia-Pacific Journal of Cooperative Education, 15(1): 29-36.

Ernstzen D.V., Bitzer E., Grimmer-Somers K. (2010). Physiotherapy students' and clinical teachers' perspectives on best clinical teaching and learning practices: A qualitative study. South African Journal of Physiotherapy, 66(3): 25-31. doi: 10.4102/sajp.v66i3.70.

Fish D., Pickering M., Hager P. (2005). Introduction to clinical education, professional supervision and mentoring. In: Rose M., Best D. (Ed). Transforming practice through clinical education, professional supervision and mentoring. (pp 1-26). Edinburgh, United Kingdom: Elsevier Churchill Livingstone.

Giles S., Wetherbee E., Johnson S. (2003). Qualifications and credentials of clinical instructors supervising physical therapist students. Journal of Physical Therapy Education, 17(2): 50-5.

Greenfield B.H., Bridges P.H., Hoy S., Metzger R., Obuaya G., Resutek L. (2012). Exploring experienced clinical instructors' experiences in physical therapist clinical education: a phenomenological study. Journal of Physical Therapy Education, 26(3): 40-47.

Greenfield B., Bridges P., Phillips T., Drill AN., Gaydosik C.D., Krishnan A., Yandziak H.J. (2014). Exploring the experiences of novice clinical instructors in physical therapy clinical education: a phenomenological study. Physiotherapy, 100(4): 349-55. doi: 10.1016/j.physio.2013.10.005

Harris P.A., Taylor R., Thielke R., Payne J., Gonzalez N., Conde J.G.

(2009). Research electronic data capture (REDCap) - a metadata-driven methodology and workflow process for providing translational research informatics support. Journal of Biomedical Informatics, 42:377-381. doi: 10.1016/j.jbi.2008.08.010.

Health Workforce Australia (2014). Clinical training profile: physiotherapy 2014. Retrieved from http://www.qrtn.com.au/images/pdf/Resources/ HWA\%20Clinical\%20Training\%20Profile\%20Physiotherapy-201403.pdf [Accessed 15/12/16].

Higgs J., McAllister L. (2007). Educating clinical educators: using a model of the experience of being a clinical educator. Medical Teacher, 29(2-3): e51-e7. doi: 10.1080/01421590601046088

Higgs J., McAllister L. (2005). The lived experiences of clinical educators with implications for their preparation, support and professional development. Learning in Health and Social Care, 4(3): 156-71. doi: 10.1111/j.1473$6861.2005 .00097 . x$

Imms C., Greaves S. (2010). Measure twice, cut once: Understanding the reliability and validity of the clinical measurement tools used in health. In Liamputtong P. (Ed.) Research methods in health: foundations for evidence-based practice (pp. 173-195). South Melbourne, Australia: Oxford University Press.

Jarski R.W., Kulig K., Olson R.E. (1990). Clinical teaching in physical therapy: student and teacher perceptions. Physical Therapy, 70(3): 173-8.

Jette D.U., Nelson L., Wetherbee E. (2014). How do we improve quality in clinical education? Examination of structures, processes, and outcomes. Journal of Physical Therapy Education, 28: 6-12.

Johnston C., Newstead C., Sanderson M., Wakely L., Osmotherly P. (2016). The changing landscape of physiotherapy student clinical placements: an exploration of geographical distribution and student performance across settings. Australian Journal of Rural Health. doi:10.1111/ajr.12302.

Keszei A.P., Novak M., Streiner D.L. (2010). Introduction to health measurement scales. Journal of Psychosomatic Research, 68(4): 319-23. doi: 10.1016/j.jpsychores.2010.01.006.

Lekkas P., Larsen T., Kumar S., Grimmer K., Nyland L., Chipchase L., Jull G., Buttrum P., Carr L., Finch J. (2007). No model of clinical education for physiotherapy students is superior to another: a systematic review. Australian journal of Physiotherapy, 52: 19-28.

Liamputtong P. (2010). Research methods in health: foundations for evidence-based practice. South Melbourne, Australia: Oxford University Press.

McAllister L., Bithell C., Higgs J. (2010). Innovations in fieldwork education: current trends and future directions. In: McAllister L., Paterson M., Higgs J., Bithell C. (Eds). Innovations in allied health fieldwork education: A critical appraisal (pp. 1-13). Rotterdam, Netherlands: Sense Publishers.

McAllister L., Nagarajan S. (2015). Accreditation requirements in allied health education: Strengths, weaknesses and missed opportunities. Journal of Teaching and Learning for Graduate Employability, 6(1): 2-23. doi: 10.21153/jtlge2015vol6no1art570

McMeeken J. (2008). Physiotherapy education-what are the costs? Australian Journal of Physiotherapy, 54(2): 85-6.

McMeeken J., Grant R., Webb G., Krause K.L., Garnett R. (2008). Australian physiotherapy student intake is increasing and attrition remains lower than the university average: a demographic study. Australian Journal of Physiotherapy, 54: 65-71. doi: 10.1016/S0004-9514(08)70068-0.

Moore A., Morris J., Crouch V., Martin M. (2003). Evaluation of physiotherapy clinical education models: comparing 1:1, 1:2 and 3:1 placements. Physiotherapy, 89(8): 489-501.

Morren K., Gordon S., Sawyer B. (2008). The relationship between clinical instructor characteristics and student perceptions of clinical instructor effectiveness. Journal of Physical Therapy Education, 22(3): 52-63.

Nunnally J.C., \& Bernstein, I.H. (1994). Psychometric theory ( $2^{\text {nd }}$ edn). New York, NY: McGraw-Hill. 
Öhman A., Hägg K., Dahlgren L. (2005). A stimulating, practice-based job facing increased stress - clinical supervisors' perceptions of professional role, physiotherapy education and the status of the profession. Advances in Physiotherapy, 7(3): 114-22. doi: 10.1080/14038190510010359.

Patton N., Higgs J., Smith M. (2013). Using theories of learning in workplaces to enhance physiotherapy clinical education. Physiotherapy Theory and Practice, 29(7): 493-503. doi: 10.3109/09593985.2012.753651.

Physiotherapy Board of Australia and Physiotherapy Board of New Zealand (2015). Physiotherapy Practice Thresholds in Australia and Aotearoa New Zealand. Retrieved from https://physiocouncil.com.au/media/1020/ physiotherapy-board-physiotherapy-practice-thresholds-in-australia-andaotearoa-new-zealand-6.pdf. [Accessed 19/07/2017].

Recker-Hughes C., Mowder-Tinney J., Pivko S. (2010). Clinical instructors' perspectives on professional development opportunities: availability, preferences, barriers, and supports. Journal of Physical Therapy Education, 24(2): 19-25

Rodger S., Webb G., Devitt L., Gilbert J., Wrightson P., McMeeken J. (2008). Clinical education and practice placements in the allied health professions: an international perspective. Journal of Allied Health, 37(1): 53-62.

Rogers J.L., Dunn L.R., Lautar C.J. (2008). Training health care providers to be educators. Health Care Management, 27(1): 40-44. doi: 10.1097/01. HCM.0000285029.79762.e8.

Rogers J.L., Lautar C.J., Dunn L.R. (2010). Allied health students' perceptions of effective clinical instruction. Health Care Management, 29(1): 63-7. doi: 10.1097/HCM.0b013e3181cca311
Sarantakos S. (2005). Social research. (3rd edn). Basingstoke, England: Palgrave Macmillan.

Sevenhuysen S.L., Haines T. (2011). The slave of duty: why clinical educators across the continuum of care provide clinical education in physiotherapy. Hong Kong Physiotherapy Journal, 29(2): 64-70. doi:10.1016/j. hkpj.2011.06.002.

Streiner D.L., Norman G.R., Cairney J. (2014). Health Measurement Scales: a practical guide to their development and use (5th edn) New York, NY: Oxford University Press.

Watson K., Wright A., Morris N., McMeeken J., Rivett D., Blackstock F., Jones A., Haines T., O'Connor V., Watson G., Petersen R., Jull G. (2012). Can simulation replace part of clinical time? Two parallel randomised controlled trials. Medical Education, 46: 657-667.

Wetherbee E., Buccieri K.M., FitzpatrickTimmerberg J., Stolfi A.M. (2014). Essential characteristics of quality clinical education experiences: standards to facilitate student learning. Journal of Physical Therapy Education, 28 48-55.

World Confederation for Physical Therapy (WCPT) (2011). WCPT guideline for the clinical education component of physical therapist professional entry level education. Retrieved from http://www.wcpt.org/sites/wcpt.org/files/ files/Guideline_clinical_education_complete1.pdf. [Accessed 19/07/2017]. 


\section{APPENDIX 1}

Final survey instrument

\section{Physiotherapy Clinical Education in Australia: Educator characteristics, experience and training requirements.}

Section 1: Demographic data - Information about you and your physiotherapy qualification

1. What is your gender?

$\square$ Male

$\square$ Female

2. What is your age in years?

3. Which of the following describes the entry-level physiotherapy training programme you completed? (Select one)
$\square$ Diploma
$\square$ Bachelor degree
$\square$ Masters degree
$\square$ Professional doctorate

4. In what year did you complete your entry-level physiotherapy qualification?

5. Where did you complete your entry level physiotherapy qualification? (Select one)

\section{$\square$ Australia}

$\square$ Overseas, please specify the country below:

6. Since completing your entry-level physiotherapy qualification, have you completed any of the following post graduate qualifications? (Select all that apply)

Graduate certificate (Please specify area of study below)

Graduate diploma (Please specify area of study below)
Masters degree (coursework) (Please specify area of study below)

Masters degree (research)

Doctorate (Professional) (Please specify area of study below)

$\square$ Doctorate (PhD)

Other (Please specify area of study below)

I have not completed any post-graduate qualifications

7. How many years have you worked as a physiotherapist in a clinical role? (Excluding breaks of greater than one year)?

I have never worked as a physiotherapist in a clinical setting

8. Are you a member of any of the following education related professional associations? (Select all that apply)

Australian Physiotherapy Association (APA) Educator's group

$\square$ Australian and New Zealand Association for Health Professional Educators (ANZAHPE)

Australian Collaborative Education Network (ACEN)

Association for Medical Education in Europe (AMEE)

Other, please specify

I am not a member of any education related professional associations 


\section{Section 2: Information about your work type and location}

This section contains questions regarding your work type and location. Some questions in this section ask you to indicate your 'primary' physiotherapy role, workplace and area of expertise. The term 'primary' refers to the physiotherapy role, workplace and area of expertise in which you spend most of your time during a typical working week.

9. Which of the following describes your current work status? (Select one)

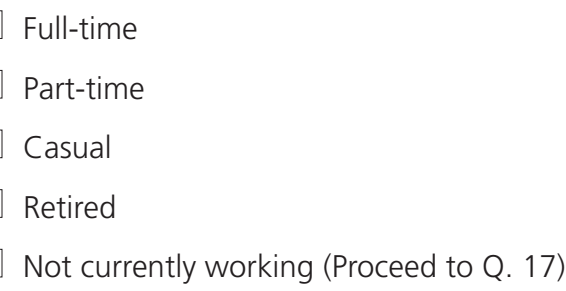

10. Which of the following describes your primary physiotherapy role? (Select one)

$\square$ Clinician (including managers also providing clinical services)

$\square$ Administrator (including managers not providing clinical services)

$\square$ Teacher or educator

\section{Researcher}

Not currently employed in a physiotherapy role

Other, please specify

11. Which of the following describes your current primary place of work? (Select all that apply)

\section{Private practice}

Hospital (excluding outpatient services)

Outpatient service

Rehabilitation service

Educational facility (e.g. University or TAFE)

Community health services

Residential aged care facility

Other residential care facility
Other commercial business/service

Other government department or agency

Other, please specify

Not applicable

12. In which state or territory are you currently working? (Select all that apply)

New South Wales

Victoria

Queensland

Western Australia

South Australia

Tasmania

Northern Territory

Australian Capital Territory

am not currently working in Australia

13. Which of the following best describes the population of the town or city in which your workplace is located? (Select one)

Less than 5000 people

5001 - 10000 people

$10001-25000$ people

$25001-100000$ people

Greater than 100000 people

14. What is the postcode of the town or city in which your workplace is located? 


\section{Section 3: Your experience and opinions regarding physiotherapy clinical education}

This section contains questions regarding your experience with, and opinions towards, supervising entry-level physiotherapy students in a clinical setting. 'Entry-level' physiotherapy students are those who are completing their primary physiotherapy qualification, such as a bachelor, graduate masters or doctorate of physiotherapy. The term 'entry-level' does not include those completing postgraduate physiotherapy qualifications.

Throughout this section, some questions require you to describe your current or previous involvement in entry-level physiotherapy student clinical education. In this section, a 'clinical educator' refers to a therapist who is involved in teaching, supervising and assessing physiotherapy students on clinical placement (including instances where student training and assessment may be shared with one or more physiotherapists). A 'primary clinical educator' refers to a physiotherapist who has the main responsibility for the organisation, teaching and assessment of entry-level physiotherapy students on clinical placement.

15. As a part of your current role, are you ever a clinical educator for entry-level physiotherapy students? (Select one)

Yes (Proceed to Q 20)

No

16. In your current role, if you are not involved in entry-level physiotherapy student clinical education briefly indicate the reason(s) why?

17. Have you ever been a clinical educator for entry-level physiotherapy student(s)? (Select one)

\section{Yes (Proceed to Q. 20) \\ No}

18. If you have never been a clinical educator for entry-level physiotherapy students briefly indicate the reason(s) why:

19. Are you planning on supervising your first entry-level physiotherapy student(s), as a primary clinical educator, during the next year? (Select one)

\section{Yes (Proceed to Q. 25) \\ No (Proceed to Q. 25)}

20. Which of the following best describes your involvement in entry-level physiotherapy student clinical education? (select one)

Physiotherapy clinical educator with no other clinical caseload

Physiotherapist with own clinical caseload, and a primary supervisor of physiotherapy students

Physiotherapist with own clinical caseload, and sometimes involved in supervising physiotherapy students

\section{Other, please specify}

21. When did you last supervise an entry-level physiotherapy student(s)? (Select one)

Within the last year

Approximately two to five years ago
Approximately six to ten years ago

Greater than ten years ago

22. In total, approximately how many entry-level physiotherapy students have you been the primary clinical educator for? (Select one)

Less than 5

5 to 20

20 to 50

50 to 100

Greater than 100

23. On average, when you are/were a primary clinical educator for entry-level physiotherapy students, how many students do/did you supervise at one time? (Select one)

One

Two

Three

Four

Greater than four

24. In which area of physiotherapy practice do/did you supervise entry-level physiotherapy students? (Select all that apply)

Mixed general

Musculoskeletal

Orthopaedics/trauma

Cardiorespiratory

Neurological

General rehabilitation

Paediatrics

Aged care

Women's health

Other (e.g. burns, hand therapy, oncology, palliative care), please specify 
25. In the following table, please indicate your level of EXPERIENCE with each component of entry-level physiotherapy student clinical education:

\begin{tabular}{|c|c|c|c|c|c|}
\hline \multirow[b]{2}{*}{ Component of clinical education } & \multicolumn{5}{|c|}{ LEVEL OF EXPERIENCE } \\
\hline & $\begin{array}{l}\text { Not at all } \\
\text { experienced }\end{array}$ & $\begin{array}{l}\text { Slightly } \\
\text { experienced }\end{array}$ & $\begin{array}{l}\text { Moderately } \\
\text { experienced }\end{array}$ & $\begin{array}{c}\text { Very } \\
\text { experienced }\end{array}$ & $\begin{array}{l}\text { Not } \\
\text { applicable }\end{array}$ \\
\hline Pre-placement preparation & $\square$ & $\square$ & $\square$ & $\square$ & $\square$ \\
\hline $\begin{array}{l}\text { Organising clinical placement } \\
\text { experiences }\end{array}$ & $\square$ & $\square$ & $\square$ & $\square$ & $\square$ \\
\hline Providing student orientation & $\square$ & $\square$ & $\square$ & $\square$ & $\square$ \\
\hline Teaching theoretical concepts & $\square$ & $\square$ & $\square$ & $\square$ & $\square$ \\
\hline Teaching practical skills & $\square$ & $\square$ & $\square$ & $\square$ & $\square$ \\
\hline Teaching clinical reasoning skills & $\square$ & $\square$ & $\square$ & $\square$ & $\square$ \\
\hline $\begin{array}{l}\text { Teaching/modelling professional } \\
\text { behaviours }\end{array}$ & $\square$ & $\square$ & $\square$ & $\square$ & $\square$ \\
\hline $\begin{array}{l}\text { Providing feedback on student } \\
\text { performance }\end{array}$ & $\square$ & $\square$ & $\square$ & $\square$ & $\square$ \\
\hline Identifying a student's strengths & $\square$ & $\square$ & $\square$ & $\square$ & $\square$ \\
\hline $\begin{array}{l}\text { Identifying a student's area(s) for } \\
\text { improvement }\end{array}$ & $\square$ & $\square$ & $\square$ & $\square$ & $\square$ \\
\hline $\begin{array}{l}\text { Providing students with strategies to } \\
\text { improve/addressing learning needs }\end{array}$ & $\square$ & $\square$ & $\square$ & $\square$ & $\square$ \\
\hline $\begin{array}{l}\text { Performing a formative ('mid- } \\
\text { placement') assessment }\end{array}$ & $\square$ & $\square$ & $\square$ & $\square$ & $\square$ \\
\hline $\begin{array}{l}\text { Performing a summative ('end of } \\
\text { placement') assessment }\end{array}$ & $\square$ & $\square$ & $\square$ & $\square$ & $\square$ \\
\hline $\begin{array}{l}\text { Managing multiple students at one } \\
\text { time }\end{array}$ & $\square$ & $\square$ & $\square$ & $\square$ & $\square$ \\
\hline $\begin{array}{l}\text { Balancing other clinical responsibilities } \\
\text { and student supervision }\end{array}$ & $\square$ & $\square$ & $\square$ & $\square$ & $\square$ \\
\hline Managing challenging students & $\square$ & $\square$ & $\square$ & $\square$ & $\square$ \\
\hline
\end{tabular}


26. In the following table, please indicate your level of CONFIDENCE with each component of entry-level physiotherapy student clinical education:

\begin{tabular}{|c|c|c|c|c|c|}
\hline \multirow[b]{2}{*}{ Component of clinical education } & \multicolumn{5}{|c|}{ LEVEL OF CONFIDENCE } \\
\hline & $\begin{array}{l}\text { Not at all } \\
\text { confident }\end{array}$ & $\begin{array}{l}\text { Slightly } \\
\text { confident }\end{array}$ & $\begin{array}{l}\text { Moderately } \\
\text { confident }\end{array}$ & $\begin{array}{c}\text { Very } \\
\text { confident }\end{array}$ & $\begin{array}{c}\text { Not } \\
\text { applicable }\end{array}$ \\
\hline Pre-placement preparation & $\square$ & $\square$ & $\square$ & $\square$ & $\square$ \\
\hline $\begin{array}{l}\text { Organising clinical placement } \\
\text { experiences }\end{array}$ & $\square$ & $\square$ & $\square$ & $\square$ & $\square$ \\
\hline Providing student orientation & $\square$ & $\square$ & $\square$ & $\square$ & $\square$ \\
\hline Teaching theoretical concepts & $\square$ & $\square$ & $\square$ & $\square$ & $\square$ \\
\hline Teaching practical skills & $\square$ & $\square$ & $\square$ & $\square$ & $\square$ \\
\hline Teaching clinical reasoning skills & $\square$ & $\square$ & $\square$ & $\square$ & $\square$ \\
\hline $\begin{array}{l}\text { Teaching/modelling professional } \\
\text { behaviours }\end{array}$ & $\square$ & $\square$ & $\square$ & $\square$ & $\square$ \\
\hline $\begin{array}{l}\text { Providing feedback on student } \\
\text { performance }\end{array}$ & $\square$ & $\square$ & $\square$ & $\square$ & $\square$ \\
\hline Identifying a student's strengths & $\square$ & $\square$ & $\square$ & $\square$ & $\square$ \\
\hline $\begin{array}{l}\text { Identifying a student's area(s) for } \\
\text { improvement }\end{array}$ & $\square$ & $\square$ & $\square$ & $\square$ & $\square$ \\
\hline $\begin{array}{l}\text { Providing students with strategies to } \\
\text { improve/addressing learning needs }\end{array}$ & $\square$ & $\square$ & $\square$ & $\square$ & $\square$ \\
\hline $\begin{array}{l}\text { Performing a formative ('mid- } \\
\text { placement') assessment }\end{array}$ & $\square$ & $\square$ & $\square$ & $\square$ & $\square$ \\
\hline $\begin{array}{l}\text { Performing a summative ('end of } \\
\text { placement') assessment }\end{array}$ & $\square$ & $\square$ & $\square$ & $\square$ & $\square$ \\
\hline $\begin{array}{l}\text { Managing multiple students at one } \\
\text { time }\end{array}$ & $\square$ & $\square$ & $\square$ & $\square$ & $\square$ \\
\hline $\begin{array}{l}\text { Balancing other clinical responsibilities } \\
\text { and student supervision }\end{array}$ & $\square$ & $\square$ & $\square$ & $\square$ & $\square$ \\
\hline Managing challenging students & $\square$ & $\square$ & $\square$ & $\square$ & $\square$ \\
\hline
\end{tabular}

27. In the section below, list the three main factors that you think would motivate you to participate in physiotherapy student clinical education
28. In the section below, list the three main factors that you think could be a barrier to you participating in physiotherapy clinical education 
29. In the section below briefly describe what you feel are the main benefits and challenges of physiotherapy clinical education for you, your workplace/department and your patients/clients:

\begin{tabular}{|l|l|l|}
\hline & \multicolumn{1}{|c|}{ Benefits } & \\
\hline Yourself & & \\
\hline $\begin{array}{l}\text { Your physiotherapy department } \\
\text { (i.e. other physiotherapists and/or } \\
\text { physiotherapy services) }\end{array}$ & & \\
\hline $\begin{array}{l}\text { Your workplace } \\
\text { (i.e. other staff and/or services within } \\
\text { your workplace) }\end{array}$ & & \\
\hline Your clients/patients & & \\
\end{tabular}




\section{Section 4: Physiotherapy clinical educator training}

30. Did you receive any preparation and/or information as a part of your entry-level physiotherapy programme to prepare you to be a clinical educator? (Select one)

Yes, please specify

\section{No}

Unsure

31. Do you think that entry level physiotherapy training programmes should include any training and/or information to prepare graduates to be clinical educators? (Select one)

Yes, please specify

No

Unsure

32. Have you participated in any additional training programmes, related to clinical education, since receiving your entry level qualification? (Select one)

$\square$ Yes

No (Proceed to Q. 34)

33. In what form was your additional training related to student clinical education delivered? (Select all that apply)

Lecture(s) or seminar(s)

Online training programme(s)

Workshop(s) or short course(s)

Higher degree (e.g. PhD, EdD, Masters degree)

Other, please specify

\section{(Proceed to Q.35)}

34. What are the main reason(s) you have not participated in any additional training, related to clinical education, since receiving your entry level qualification? (Select all that apply)

I am not aware of any available clinical education training programmes
I find it difficult to access clinical education training programmes

There are no training opportunities available in my region

$\square$ I find training programmes too expensive

I do not have the time to attend training programmes

My workplace does not enable or encourage me to attend training programmes

$\square$ I do not think I would benefit from available training programmes

$\square$ I am not interested in further training in clinical education

$\square$ I do not believe you need training to be a clinical educator

Other, please specify:

35. Do you think you require more training related to physiotherapy student clinical education? (Select one)

Yes

No

36. Do you think physiotherapists should complete formal training or credentialing prior to becoming a primary clinical educator? (Select one)
Yes
No
Unsure

37. List three aspects of physiotherapy student clinical education that you think training should cover

38. Do you think physiotherapists should have their skills related to entry-level student clinical education (such as teaching, assessment and feedback) evaluated prior to becoming a primary clinical educator? (Select one)

Yes

No

Unsure

\section{Section 5: General comments}

39. Do you have any additional comments relating to any aspect of entry-level physiotherapy student clinical education or physiotherapy clinical educator training? 


\section{Efficacy and safety of non-immersive virtual reality exercising in stroke rehabilitation (EVREST): a randomised, multicenter, single-blind, controlled trial.}

Saposnik, G., Cohen, L.G., Mamdani, M., Pooyania, S., Ploughman, M., Cheung, D., Shaw, J., Hall, J., Nord, P., Dukelow, S., Nilanont, Y., De los Rios, P., Olmos, L., Levin, M., Teasell, R., Cohen, A., Thorpe, K., Laupacis, A., \& Bayley, M; Stroke Outcomes Research Canada (2016). Efficacy and safety of non-immersive virtual reality exercising in stroke rehabilitation (EVREST): a randomised, multicenter, single-blind, controlled trial. The Lancet. Neurology, 15(10), 1019-1027. https://doi.org/10.1016/S1474-4422(16)30121-1.

\section{OBJECTIVE}

The use of non-immersive virtual reality (NIVR) may be an economical solution to promote recovery for upper limb (UL) motor deficits after stroke. The aim of this study was to investigate the effect of NIVR versus recreational activity (RA) for UL motor control therapy in acute stroke.

\section{METHODS}

A single-blind randomised control trial was undertaken throughout 14 rehabilitation centres in four countries. Participants $(n=141)$ aged $18-85$ years, who had suffered a first ischaemic stroke within the last 3 months and had mild to moderate UL impairment (Chedoke McMaster Stroke Assessment $>3$ ), were randomised to NIVR (Nintendo Wii) or RA (card playing, Jenga). Participants underwent two weeks of one-to-one therapist administered intervention ( $10 \times 60$ minute sessions). Upper limb motor control was measured using the Streamlined Wolf Motor Function Scale (SWMFS) at baseline, two weeks (intervention cessation) and four weeks.

\section{RESULTS}

There were no significant differences between groups at two $(p=0.346 ; C l-14.2 s$ to $22.6 s)$ or four ( $p=0.346 ; C l-52.0$ to 23.7s) weeks. At two weeks SWMFS improvements were observed in the NIVR and RA groups, a decrease of $14 \mathrm{sec}$ and $10.9 \mathrm{sec}$ respectively. At four weeks, a decrease of $17.7 \mathrm{sec}$ (NIVR) and $15.2 \mathrm{sec}$ (RA) was observed.

\section{CONCLUSION}

Both NIVR and RA are equally effective therapies for improving motor control in acute stroke. They enhance treatment intensity and this may be more important than the type of intervention for improving motor performance. Recreational activity however may be more cost effective and more easily implemented than NIVR.

\section{COMMENTARY}

Current evidence suggests that stroke rehabilitation requires "repetitive, task-specific, motivating and intensive" therapy (Saposnik \& Levin, 2011). However, many places lack the resources to provide this (Saposnik \& Levin, 2011; Saposnik et al., 2016). Potential solutions include using NIVR in conjunction with conventional treatment. Virtual reality technology, such as Nintendo Wii, provides instant feedback on performance, includes high repetitions, and enables practice of simulated real-life activity unavailable in hospitals (Saposnik \& Levin, 2011; Laver, George, Thomas,
Deutsch, \& Crotty, 2015). Technology may increase patient motivation leading to increased therapy time (Laver, et al., 2015)

Prior to 2013 the quality of research for virtual reality therapy to enhance UL motor recovery post-stroke was relatively low (Laver, et al., 2015). Some promising results had been reported but, as outlined in a metaanalysis (Saposnik \& Levin, 2011), most trials compared conventional therapy plus virtual reality technology to conventional therapy alone. This approach creates bias towards treatment effect because intervention groups have increased treatment duration which is known to enhance neuroplasticity (Saposnik \& Levin, 2011: Saposnik et al., 2016). In this RCT, Saposnik et al. (2016) accounted for treatment duration bias by ensuring that all participants underwent conventional rehabilitation in addition to either NIVR or RA. Recreational activity is not considered standard care and is a common active control. To account for multiple personal and contributing factors, including baseline function and stroke severity, stratified randomisation was undertaken.

Motor recovery was assessed using the SWMFS which is a reliable measure of UL motor function in chronic stroke (Saposnik et al., 2016; Chen et al., 2014). As no data are available for the SWMFS as an outcome measure in acute stroke, there is an element of uncertainty when interpreting the findings of this study. Further, the inter-rater reliability of the SWMFS does not appear to have been assessed, but the reproducibility of the full version is good (Wu et el., 2011). While the SWMFS has better clinical utility than the complete test it does require training before use (Wu et el. 2011) which may impact on its translation into daily clinical practice. Training for use of this measure would be beneficial if research proves it to be as valid and reliable as the full version. This test could be quickly completed in clinical practice and give important information on the effectiveness of treatment with regard to both quality and level of UL motor function

There were no significant differences between groups at two or four weeks, but both groups showed a decrease in the time to complete the SWMFS. This shows that NIVR and RA are equally effective at enhancing motor performance in acute stroke. The results of this study suggest that conventional therapy for acute stroke patients should continue but that either NIVR or RA may be implemented to increase therapy time in an efficient, cost effective manner. This may be particularly useful during transition preparation (typically two to three weeks) for inpatient stroke patients being discharged to community rehabilitation. Many of these individuals would share similar demographics (late stage acute post-stroke and with mild-moderate UL impairment) to Saposnik et al.'s (2016) study population. Time is limited to provide these services, therefore efficient solutions are required. Community rehabilitation services usually have access to both RA resources and Nintendo Wii, and these are simple, effective and safe interventions to implement in this setting. Both therapies appear equally effective, therefore based on patient preference either could be used to increase motivation and compliance (Saposnik et al., 2016). The interventional protocol was thoroughly described making it replicable in clinical practice, and it is plausible that rehabilitation assistants could be trained to provide the additional therapy with individual clients.

Addition of a conventional therapy control group in future studies would be beneficial (Saposnik et al., 2016) to compare to the value of NIVR and RA. Further research should investigate NIVR and RA in post-acute stroke populations, as this would provide evidence for therapy that may be used consistently pre- and post-discharge.

Nina Barker BSC, BPhty

North West Community Rehabilitation programme at Mount Isa Centre for Rural and Remote Health, James Cook University.

\section{REFERENCES}

Chen, H., Wu, C., Lin, K., Jang, Y., Lin, S., Cheng, J., Chung, C., \& Yan, Y. (2014). Measurement properties of streamlined wolf motor function test in patients at subacute to chronic stages after stroke. Neurorehabilitation and Neural Repair, 28(9), 839-846. doi: 10.1177/1545968314526643

Laver, K., George, S., Thomas, S., Deutsch, J., \& Crotty, M. (2015). Virtual reality for stroke rehabilitation. Cochrane Database of Systematic Reviews, 2, doi: 10.1002/14651858.CD008349.pub3.

Saposnik, G., \& Levin, M. (2011). Virtual reality in stroke rehabilitation: A meta-analysis and implications for clinicians. Stroke, 42, 1380-1386. doi: 10.1161/STROKEAHA. 110.605451

Wu, C., Fu, T., Lin, K., Feng, C., Hsieh, K., Yu, H., Lin, C., Hsieh, C., and Ota, H. (2011). Assessing the Streamlined Wolf Motor Function Test as an outcome measure for stroke rehabilitation. Neurorehabilitation and Neural Repair, 25(2), 194-199. doi: 10.1177/1545968310381249 

